\title{
Algorithmic approach to warehouse consolidation and optimization
}

\author{
A Thesis \\ presented to \\ the faculty of \\ California Polytechnic State University, San Luis Obispo
}

In Partial Fulfillment

of the Requirements for the Degree

Master of Science in Engineering

By

Sonny Nguyen

May, 2008 


\section{AUTHORIZATION FOR REPRODUCTION}

\section{OF MASTER'S THESIS}

I grant permission for the reproduction of this thesis in its entirety or any of its parts, without further authorization from me.

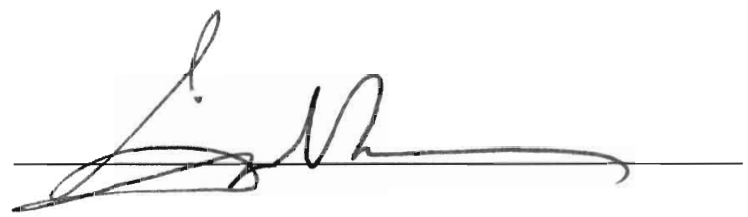

Signature

$8 / 21 / 08$

Date 
APPROVAL PAGE

TITLE: Algorithmic approach to warehouse consolidation and optimization AUTHOR: Sonny Henry Nguyen

DATE SUBMITTED: May 25, 2008

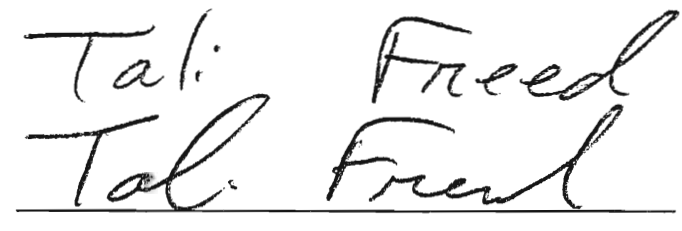

Adviser

LizabetnTSchlemer

Committee Members

Heather S. Smith

Committee Members

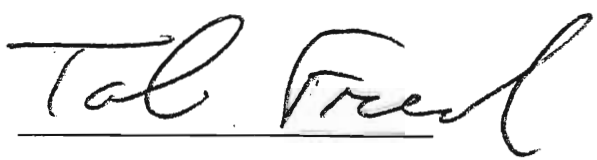

Signature

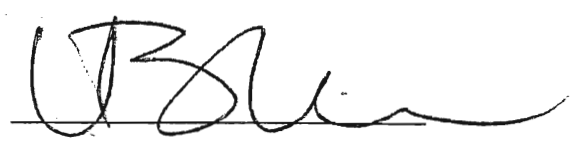

Signature

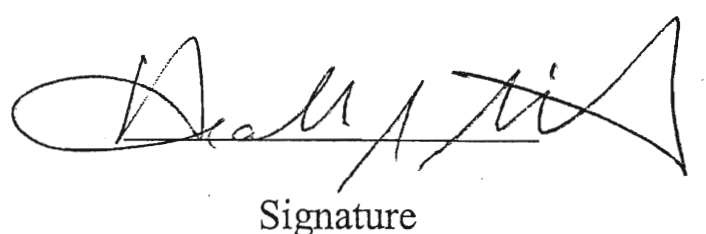

Signature 


\section{ABSTRACT \\ Algorithmic approach to warehouse consolidation and optimization Sonny Henry Nguyen}

This thesis presents a new methodology for warehouse consolidation to optimize the capacity, throughput, and overall efficiency of the warehouse. The application of the methodology allows an organization to become more competitive by reducing real estate and inventory holding costs. The algorithms use various quantitative techniques including statistical inference and integer programming, and apply them to material handling and facilities layout issues. The proposed methodology is independent of the warehouse management system in use. It was implemented by a Fortune 500 company, and resulted in significant cost, capacity and productivity improvements. 


\section{ACKNOWLEDGEMENTS}

I would like to thank my wife, Thu Dang, and parents, John and Jasmine Nguyen, for their wonderful support through my tenure at Cal Poly and my journey completing the thesis. Their support has been invaluable to me for reaching my dreams. I would also like to acknowledge the support, patience, and help of the defense committee, Dr. Tali

Freed, Dr. Lizabeth Schlemer, and Professor Heather Smith for making this thesis possible. 


\section{TABLE OF CONTENTS}

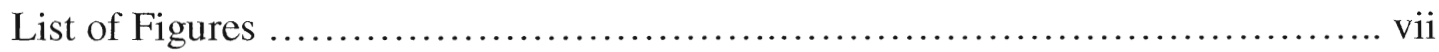

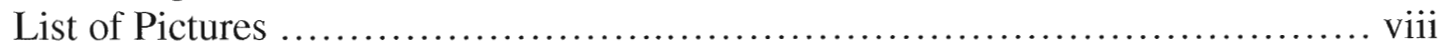

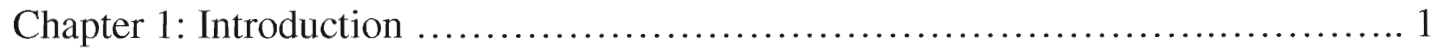

Chapter 2: Objective .......................................................... 3

Chapter 3: Literature Review .............................................. 4

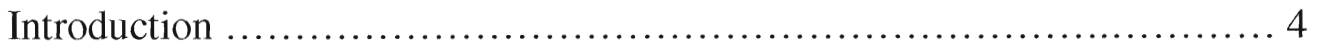

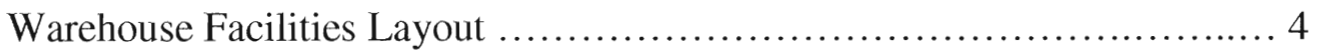

Storage Optimization ................................................. 5

Statistical Sampling Inferences ..................................... 6

Linear Programming ............................................... 6

Conclusion ........................................................... 7

Chapter 4: Design Methodology .......................................... 8

Chapter 5: Test the Algorithm ............................................ 14

Introduction ........................................................ 14

Current State ..................................................... 16

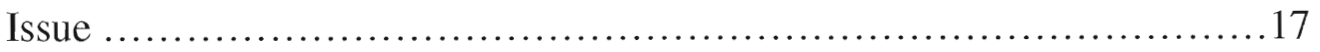

Current Storage Method ...........................................19

Quantitative Analysis I ............................................22

Quantitative Analysis II .............................................26

Quantitative Analysis III .......................................... 32

Quantitative Analysis IV ............................................. 38

Quantitative Analysis V .............................................42

Quantitative Analysis VI ..............................................45

Chapter 6: The Results ................................................ 48

Chapter 7: Conclusion ................................................. 49

Chapter 8: Future Research ................................................. 51

References ............................................................. 53

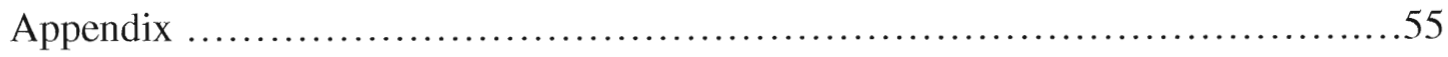




\section{LIST OF FIGURES}

FIGURE 1 .......Warehouse Consolidation Algorithm …...................... 8

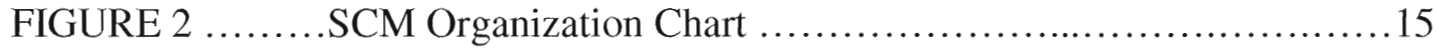

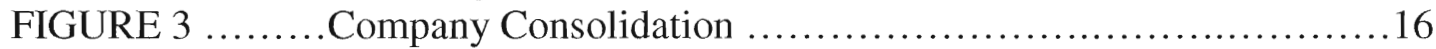

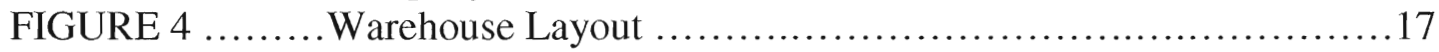

FIGURE 5 .........Conceptual Warehouse Consolidation Vision ....................18

FIGURE 6 .........Consolidation Algorithm Step 1 .............................. 19

FIGURE 7 ........Current Warehouse Storage Process ............................20

FIGURE 8 ........Current Qualitative Capacity ...................................21

FIGURE 9 ........Current Quantitative Capacity Analysis ........................23

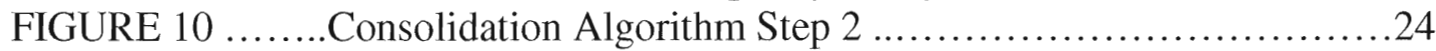

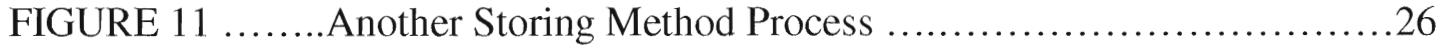

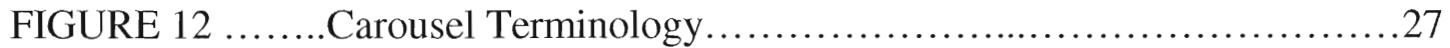

FIGURE 13 .......Carousel Storage Capacity Analysis ..........................28

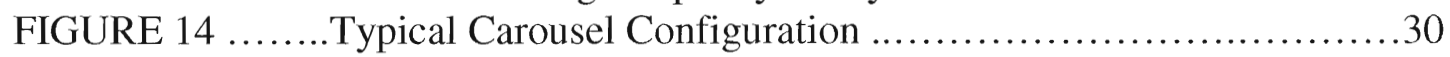

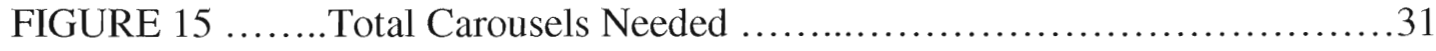

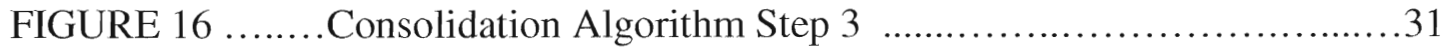

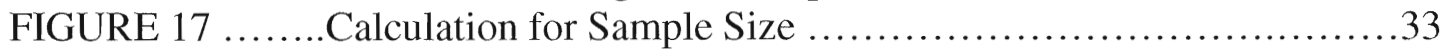

FIGURE 18 .......Percentage Extrapolation for Standard Tote Size ................34

FIGURE 19 .......Random Sampling Data Example ...............................35

FIGURE 20 ........Description of Random Sample Usage ...........................36

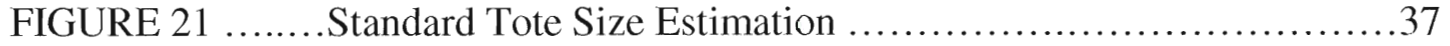

FIGURE 22 ........Different Tote Size Calculation ..................................39

FIGURE 23 .......Extrapolation to Determine Carousels ..........................40

FIGURE 24 .......Total Carousels Needed .....................................4 4

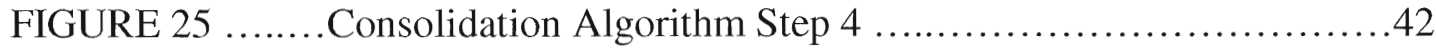

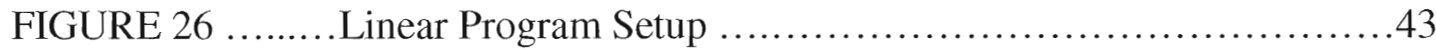

FIGURE 27 ........Linear Program Constraints .................................43

FIGURE 28 ........Linear Program Answer ......................................4 44

FIGURE 29 ........Linear Program Summary ...................................... 44

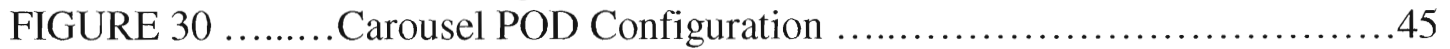

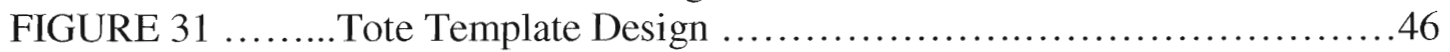

FIGURE $32 \ldots \ldots \ldots$. New Storage Process ..........................................46

FIGURE 33 ........Consolidation Algorithm Step 5 ..........................47

FIGURE 34 .........Matrix of Performance Results from Algorithm ................48 


\section{LIST OF PICTURES}

PICTURE 1 ..........Current Storing Method ................................ 19

PICTURE 2 .......... Inefficient Storing Example .............................. 20

PICTURE 3 ..........Carousel Storage Configuration ..........................27 


\section{CHAPTER 1 \\ INTRODUCTION}

This report describes an algorithm for Optimization Practitioners to consolidate warehouses and improve operation efficiency. Consolidation of several warehouses can occur for a variety of reasons. Through a series of mergers and acquisition a company may be left with several warehouses from different legacy companies. Business leaders may want to consolidate warehouses to reduce redundant labor cost, real estate, and enable better control of requirements and standards. Consolidation of warehouses also provides an opportunity to standardize the processes and optimize operations. In an environment where real estate is becoming increasingly more expensive, optimizing the usage of real estate is necessary for companies to remain competitive. This thesis proposes an algorithm that focuses on the consolidation of warehouses and utilizing the methods to optimize the warehouse production to gain a competitive advantage.

The first step in consolidation is to ask if the business leaders of the company want to consolidate to reduce cost and increase efficiency. Work cannot go further without key management support for such activity because it requires a commitment of expenditures in order to execute. However, the algorithm builds a business case to execute with minimal expenditures while optimizing capacity and production. Once the decision to consolidate is made the next question is to ask if consolidation can occur with the current storage method. Utilizing quantitative analysis to explore alternatives will lead to decisions regarding optimum storage methods. Specifically, carousels will be examined as they can increase capacity and productivity. To fully analyze storage requirements a system to randomly infer the part dimensions needs to be developed. A 
statistical system such as Microsoft Excel or Minitab is used to fit the population of products. After defining the different part dimensions, the number of carousels needed can be extrapolated. After deciding on carousels, the optimum size, shape, and capacity of carousels is determined using Microsoft Excel or any optimization program such as Lindo. Lastly the new configuration is used to develop a process that will improve the production rate of the system.

The algorithm can be presented to business leaders as a proposal to 1) increase real estate utilization, 2) reduce operating cost, and 3) improve production activity by consolidating. This thesis will present the algorithm and how it is used in a Fortune 500 company's decision to consolidate warehouses to stay competitive because of mergers and acquisitions. This algorithm can be used in any business sector that require the storage of products. 


\section{CHAPTER 2}

OBJECTIVE

The objective of this project is to propose an algorithm to consolidate warehouses that optimize storage capacity, reduce operating costs, and improve production activity. This new approach is relevant to any companies that store products for production usage. This thesis validates the algorithm by applying to an aerospace and defense company. The following are the objectives of this Master's thesis:

1) Develop an algorithm - Algorithmic approach to warehouse consolidation and optimization - which:

1. Provides a business proposal for consolidation

2. Employs statistical analysis and optimization tools to execute the vision of consolidation while providing optimal storage capacity and production with minimal cost

3. Increases the awareness of quantitative analysis to make decisions

2) Test the algorithm

3) Report Results

4) Recommend additional research 


\section{CHAPTER 3 \\ LITERATURE REVIEW}

\section{Introduction}

As industries mature and grow, the most efficient and profitable companies begin to purchase, combine, and merge with other companies. The main reason for the activities is to become competitive and be the premier provider of their respective industry. However, not many companies can become the premier provider for their respective industry because mergers and acquisitions cause process and infrastructure inefficiencies. These inefficiencies are caused by poor communication, duplicate processes and work, duplicate systems, different culture and visions to name a few. Companies should actively exercise mergers and acquisitions despite the inefficiencies because the company can grow and by doing so can develop better technology, ideas, and services. This can provide a competitive advantage, but in order to gain this competitive advantage it must quickly make the inefficiencies efficient.

In order to make this happen a company needs to consolidate work, process, and warehouses. The literature review will look at different improvement and optimization methods in order to help make the consolidation of warehouses happen. This literature review consists of four major research areas; Warehouse Facilities Layout, Storage Optimization, Statistical Sampling Inferences, and Linear Programming Optimization

\section{Warehouse Facilities Layout}

Research has been conducted to optimize a facility layout within the warehouse to improve the capacity and efficiency of the operations. Several of these studies used Linear Programming methodology and facilities layout to make this happen. The 
research ranges from an 1870's puzzling technique (Gue and Kim, 2007) to a heuristic model for layout (Larson, and Kusiak March, 1997).

The primer for the research is to utilize floor space more efficiently. A comprehensive study shows that an effective warehouse layout can be just as beneficial and efficient as spending money on automations and an elaborate Warehouse Management System (WMS) (Napolitano, 2003). Another study discovered multiple factors affect the layout and throughput such as quantity, layout type, storage assignment, picking route, etc. (Roodbergen and Vis, 2006). The warehouse layout is just the beginning as others have studied the impact of warehouse layout to transportation efficiencies. The interdependencies between the two are apparent and both need to be optimized in order to improve overall performance (Bartholdi and Gue, 2004).

Effective warehouse layout is apparent to improve warehouse process efficiency and is evident from extensive academic research.

\section{Storage Optimization}

Storage optimization is utilizing real estate as efficient as possible. There are several different techniques to make this happen. Faculties Planning $2^{\text {nd }}$ Edition discussed a myriad of different techniques to store different products in different environment. Most of the discussions surround using Linear Programming techniques (Tompkins et al., 1996). There is even a study developing an algorithm to house multiitem inventory using mixed integers with non linear programming to efficiently store products on aisle (Hariga and Jackson, 1996). 
Effective use of storage is possible through the use of different extensive academic research. The information is available and one can find this in any academic arena.

\section{Sampling Statistical Inference}

The science of statistical sampling is widely used to infer characteristics of a mathematically derived sample of a population. Companies do this to minimize cost and in turn provide a best "guessimate" of the outcome. Doing this can provide a good guess without conducting a study of the entire population. Conducting a study of the entire population can be infeasible to measure in a timely manner (Devore and Nicholas, 1999). This is essential when one needs to consolidate warehouses and decides to use carousels or to buy different size totes to get the most optimal amount of each size. In order to capture the size characteristics of a part one needs to use a set of random samples and make sure the information is unbiased to the results.

A method to find the number of samples if the population is known and determine part size to infer the characteristics of a population is found using an equation called the Normal Approximation to the Binomial. This equation uses the Binomial distribution methodology in order to mirror the behavior of a Normal distribution (Scheaffer et al.,

2006). Other random sampling techniques can be used but this equation will give you the best estimate of a number to randomly sample.

\section{Linear Programming Optimization}

Linear Programming (LP) is a technique from a scientific field called Operations Research. Linear Programming is used to optimize a particular objective, either minimization or maximization. It uses linear algebra to make this happen by developing 
an objective equation and setting it to one or more constraint equations. The constraint equations will bind the objective equation to optimally provide a result (Winston, 1994).

The LP technique is used in the industry in several different applications ranging from automotive and services to aerospace and defense. The usage of LP in warehouse applications has been popular to improve the pick throughput and optimization of product class storage (Hsieh and Tsai, 2006). There has been a study to store products in very high density areas to improve the pick efficiency (Gue et al., 2006). There are also methods using LP to minimize products shipped for combat to efficiently ship for missions (Gue, 2001). Linear Programming techniques are used to not only improve capacity usage but also for process efficiencies for the layout of cross dock and warehouse activities (Bartholdi and Gue, 2000). In fact, LP techniques are even used to determine warehouse order scheduling and traffic flow (Gademann and Van de Velde, 2005).

It is apparent that Optimization Practitioners use Linear Programming extensively in different applications for different purposes. The power of LP is evident. LP usage in warehouse optimization is overwhelming throughout the research.

\section{Conclusion}

Extensive research of warehouse process and capacity optimization has been conducted. However, a study to develop an algorithm to consolidate warehouses has yet to be developed. By combining different types of optimization and improvement ideas, one can develop an algorithm to consolidate warehouses; not only consolidate warehouses but improve the process productivity as well. 


\section{CHAPTER 4 \\ DESIGN METHODOLOGY}

The methodology of this research consists of the following steps:

1) Work with company's leaders to define the potential and issues to consolidating warehouses. This will be the start the algorithm.

Perform a literature review to determine common methods of consolidation and research the topics of 1) Warehouse Facilities Layout 2) Storage Optimization

3) Statistical Sampling Inference 4) Linear Programming Optimization.

2) Develop an algorithm to consolidate warehouses.

3) Test the algorithm at a company.

4) Analyze consolidation results to show improvements.

5) Define areas for future research, and algorithm improvement.

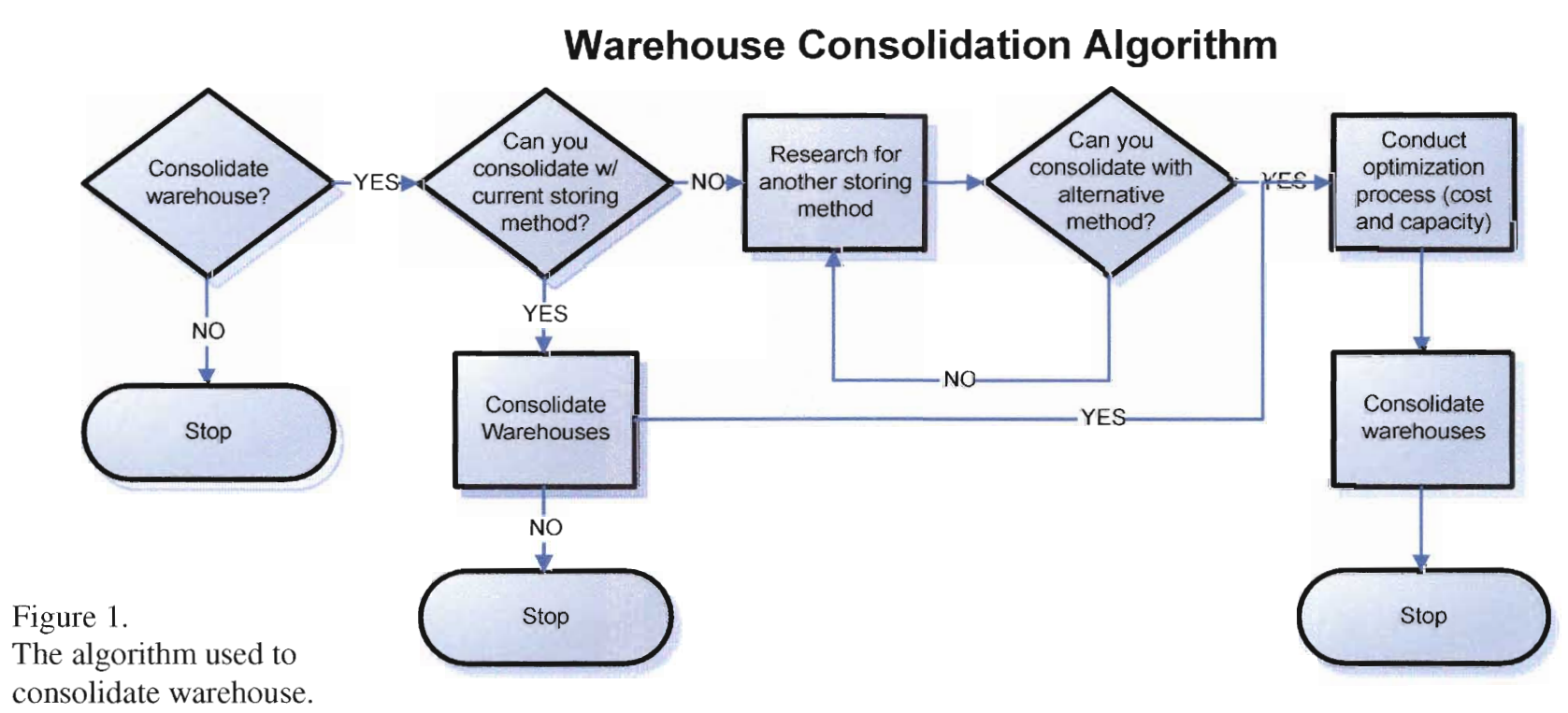




\section{$\underline{\text { ALGORITHM STEPS }}$}

1. The first step of the algorithm is to work with the company's leaders to determine if consolidation of warehouses is a strategic project. Without leadership support to expend resources the algorithm ends.

2. The next step in the algorithm is to analyze the current state to understand if consolidation can happen with the current warehouse storage method. If the analysis suggests that consolidation can happen, then skip Step 3 and conduct optimization process in Step 4. The following equation is used to conduct this analysis:

\section{Equation 1.}

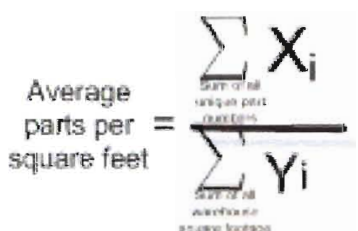

P/SF (Average parts per square feet) = this equation determines how many parts are stored on average per square foot.

Where,

$P / S F=$ Average parts per square feet

$X_{i}=$ Unique part numbers

$Y_{i}=$ Square footage

$i=$ The number of different warehouses in the area

3. If analysis from Step 2 suggests that consolidation can not happen then move to the next step in the algorithm and search for other alternative methods for storage to enable consolidation. The process is iterative until an alternative storage method to enable consolidation is discovered. If an alternative method is not found the algorithm ends and consolidation cannot happen. The following equations are used to conduct this analysis: 


\section{Equation 2.}

Lf $($ Location per part $)=$ this equation determines through time due to parts separation; how many different locations are used per part.

$L f=\frac{L t}{U t}$

Where,

$L f=$ Locations per part

$L t=$ Total number of possible locations

$U t=$ Total unique parts in the system

\section{Equation 3.}

Ln (Locations needed for a carousel $)=$ this equation determines the number of locations needed per carousels dependent of the Population (Nt).

$L n=N t *(1-P b) *(1-P s) *(1+P g) *(L f) *(1+P e)$

Where,

Ln $=$ Total number of carousels bin needed

$N t=$ Number of part numbers

$\mathrm{Pb}=$ Percentage of bulk item

Ps $=$ Percentage of special storage

$\mathrm{Pg}=$ Percentage growth factor

$L f=$ Average number of locations/ part number

$\mathrm{Pe}=$ Average percentage buffer capacity on carousels

\section{Equation 4.}

$C n_{i}($ Total carousels needed $)=$ this equation determines the total number of carousels needed to house the parts expected to be consolidate.

$$
\sum C n_{\mathrm{i}}=\sum\left(\frac{L n_{\mathrm{i}}}{C a}\right)
$$

Where,

Cni $=$ Total carousels needed

Lni $=$ Locations needed

$C a=$ Standard number of locations per carousel

$i=$ The index of different warehouses 


\section{Equation 5.}

$n$ (the sample size $)=$ this equation determines the sample size needed to infer the characteristic part sizes of a population. It is also known as The Normal Approximation to the Binomial (Scheaffer et al., 2006):

$$
n=\frac{N p q}{(N-1) *\left(\frac{B^{2}}{4}\right)+p q}
$$

Where,

$n=$ number of parts needed in the sample

$N=$ number of parts in the population

$p=$ proportion of parts having a particular size characteristic

$q=$ proportion of parts not having that particular size characteristic

$B=$ bound on the error of estimation (i.e., the margin of error)

\section{Equation 6.}

$P i($ percentage for a certain standard tote size $)=$ this equation determines the percentage of a standard tote size in a sample population (Scheaffer et al., 2006):

$$
P i=\frac{C i}{n}
$$

Where,

$P=$ percentage for $i$

$C=$ the count of the parts for $i$

$n=$ the sample size

$i=$ the different type of standard tote size

\section{Equation 7.}

$M E(P i)$ (margin of error for a percentage of a certain standard tote size) $=$ this equation determines the margin of error for a percentage of a standard tote size in a sample population (Scheaffer et al., 2006):

$\operatorname{ME}(P i)=1.96 * \sqrt{\frac{P i * q i}{n}}$

Where,

$M E(P i)=$ the margin of error for the percentage of type $i$

$P i=$ proportion of parts having a particular size characteristic $i$

$q i=$ proportion of parts not having that particular size characteristic $i$ 
$n=$ the sample size

$i=$ the different type of standard tote size

\section{Equation 8.}

Lnj $($ Number of tote type locations needed $)=$ this equation determines the number of different tote types needed per carousel

$\mathrm{Lnj}$ (round down to the nearest integer) $=\mathrm{SCj} * \mathrm{LSj} * \mathrm{PPj}$

Where,

Lnj $=$ Number of carousel locations required for tote type $j$

$S C j=$ Shelves/ Carriers

$L S j=$ Locations/ Shelf

$P P j=$ Percentage of he parts population

$j \quad$ index of tote size

4. Once an alternative method is found to consolidate the warehouses, the next step is to develop an optimization solution in respect to cost, capacity, and process.

The optimization of the process can be determined through Value Stream mapping (Rother and Shook, 1999) and a simulation of the future warehouse as well as visual controls to streamline the put away and picking process using a warehouse management system. A Linear Programming method is used to minimize cost while maximizing capacity (Winston, 1994). The following equation is used:

\section{Equation 9.}

Minimize $Z=($ Cost of Carousel 1) $* X 1+($ Cost of Carousel 2$) * X 2$

Where the cost of $x 1$ is $\$ 42,000$ for a 40 carriers carousel and $x 2$ is $\$ 63,000$ for 50 carriers carousel for the case study.

Constrain by:

1) Capacity (Number of Carriers 1$) * X 1+($ Number of Carriers 2$) * X 2=$ Minimum number of carriers needed

2) $\underline{\operatorname{Cost}}$

$($ Cost Carousel 1$) * X 1+($ Cost Carousel 2$) * X 2 \leq$ Budget amount in $\$$ 
Where the number of carriers is constrained to equal 284 carriers and the budget amount is equal to or less than $\$ 363,000$ in the case study.

5. The final step in the algorithm is to consolidate the warehouse using the findings from the equations. 


\section{CHAPTER 5}

\section{TEST THE ALGORITHM}

\section{INTRODUCTION}

Raytheon is among the leaders in electronics, radars, sensing, and space systems of the aerospace and defense industry. Raytheon has six major business units throughout the country; Space and Airborne System (SAS), Integrated Defense Systems (IDS), Raytheon Missile Systems (RMS), Network Centric Systems (NCS), Information \& Intelligence Systems (IIS) and Raytheon Technical Service Consolidate (RTSC). Raytheon Space and Airborne Systems (SAS) is a \$4 billion business unit within Raytheon, and has launched programs like APG-79 Radars for F/18A Super Hornets, classified sensors and systems for space and reconnaissance. SAS has realized the advantage that comes from effective supply chain management, and has recently reorganized to better align its organization structure with customer expectations. An organization chart shown in Figure $\mathbf{2}$ describes a small portion of the reporting structure for SAS Supply Chain Management based in EI Segundo, California. 


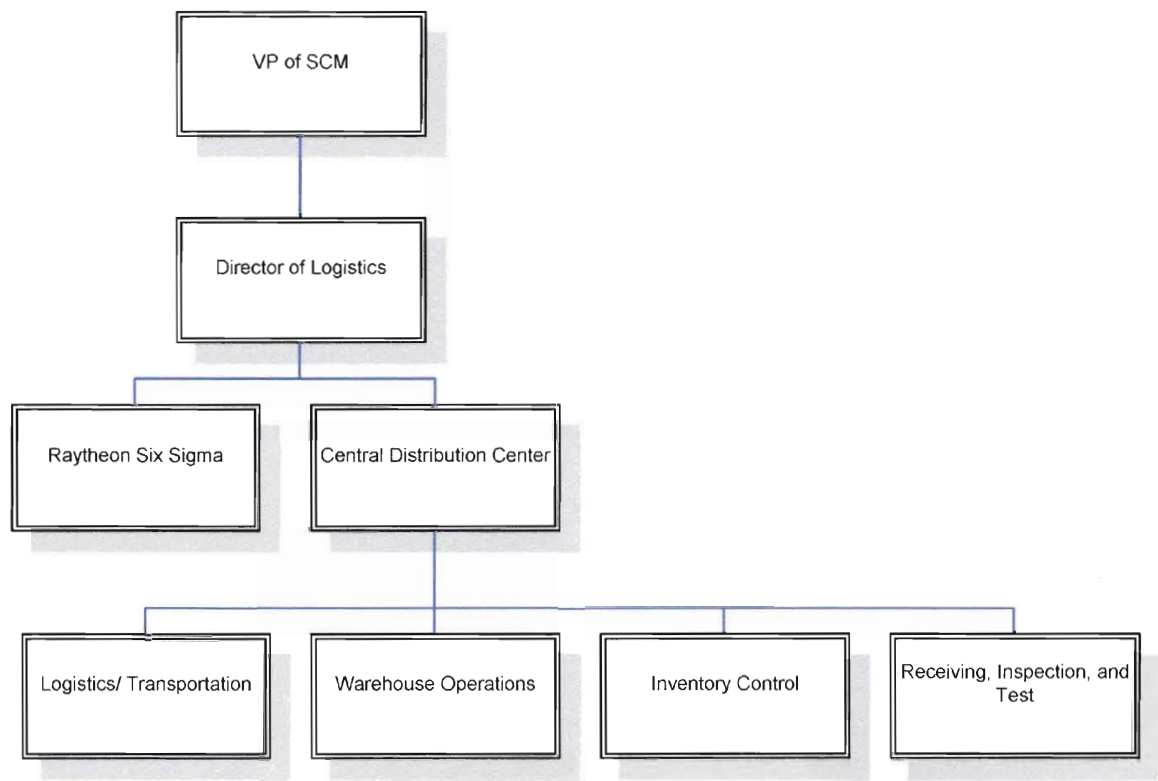

Figure 2. An organization chart of the company's Supply Chain Management business.

Dealing with recent mergers and acquisitions, SAS has to overcome several inefficiencies in order to meet Raytheon's vision. A new process, system, and culture needs to be developed in order to become competitive. Within the last decade the warehouse facility has gone through three name changes, several layoffs, and a myriad of processes and systems mandation. Lack of identity and multiple layoffs caused a decrease in morale and empathy for improvements and growth. The facility was originally Hughes Aircraft and Systems, it then merged with General Motor (GM), and was finally purchased by Raytheon. Raytheon also bought E-System and Texas Instruments (TI) during this time. All four companies were combined to create a business unit within Raytheon call Space and Airborne System (SAS) illustrated in Figure 3. Combining different cultures, processes, and systems that are accomplishing the same tasks is challenging. It leads to confusion, redundancy, layoffs, and ultimately frustration and anxiety. A great case example is the warehouse locations in El Segundo. 


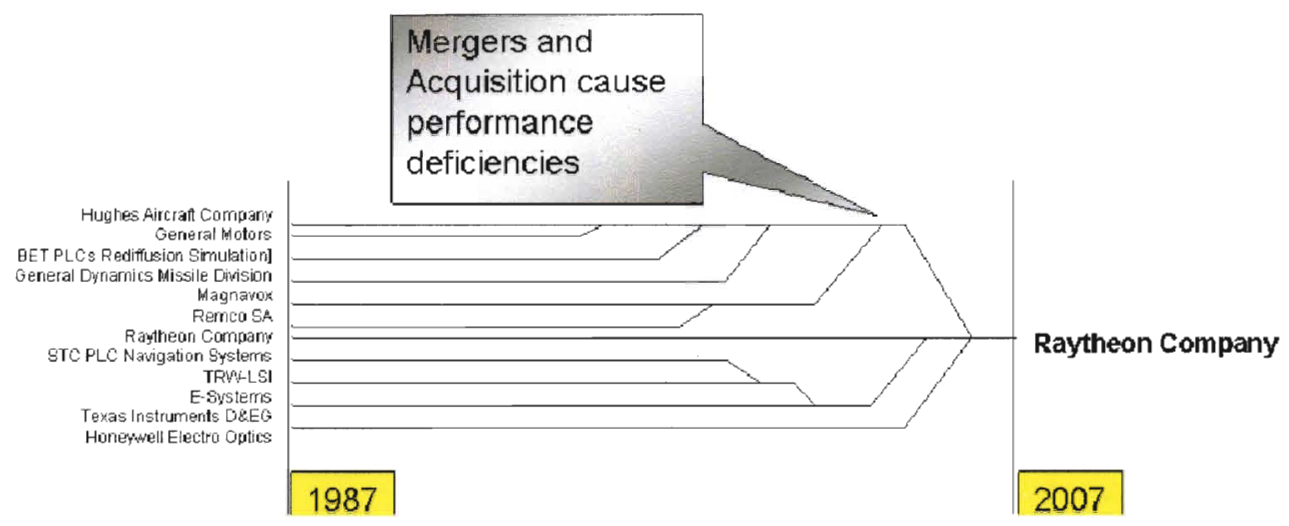

Figure 3.

Modified chart of Raytheon's mergers and acquisitions within the last 20 years from Aerospace and Defense Magazine (October 2007)

\section{THE CURRENT STATE}

The warehouse is not optimally organized due to the mergers and legacy systems shown in Figure 4. It consists of four main areas. The first area is utilized to stage Research and Development or Engineering products. These products are highly unpredictable in customer demand because engineers and scientists do not know what they need until they experiment with them. This area provides challenges for the warehouse process to support these activities. The second area is used to stage Production or Operations related products. These are products that should provide a daily or weekly demand. Unfortunately, due to the challenges of producing products from Development to Production, the demand varies as well. The next area is known as the Frozen Zone. The reason for the title is because products in this area have no demand, old technology, or are staged in case a need arrives. Some of these products date back to when Hughes Systems owned the products in the 80 's. The reason for keeping these parts is because they are expensive to procure and the possibilities of using the products still exist. The fourth area is known as the Bulk/ Government Furnish Products (GFP). 
This area is allocated for bulk items, products that require pallets or folk lift to manage. Similar to the two areas separated for Engineering and Operations usage, the bulk area products are segregated. It also has a portion where products are returned and stored from the government, hence the term GFP. The other warehouses located in several different areas of El Segundo configure storage in a similar manner.

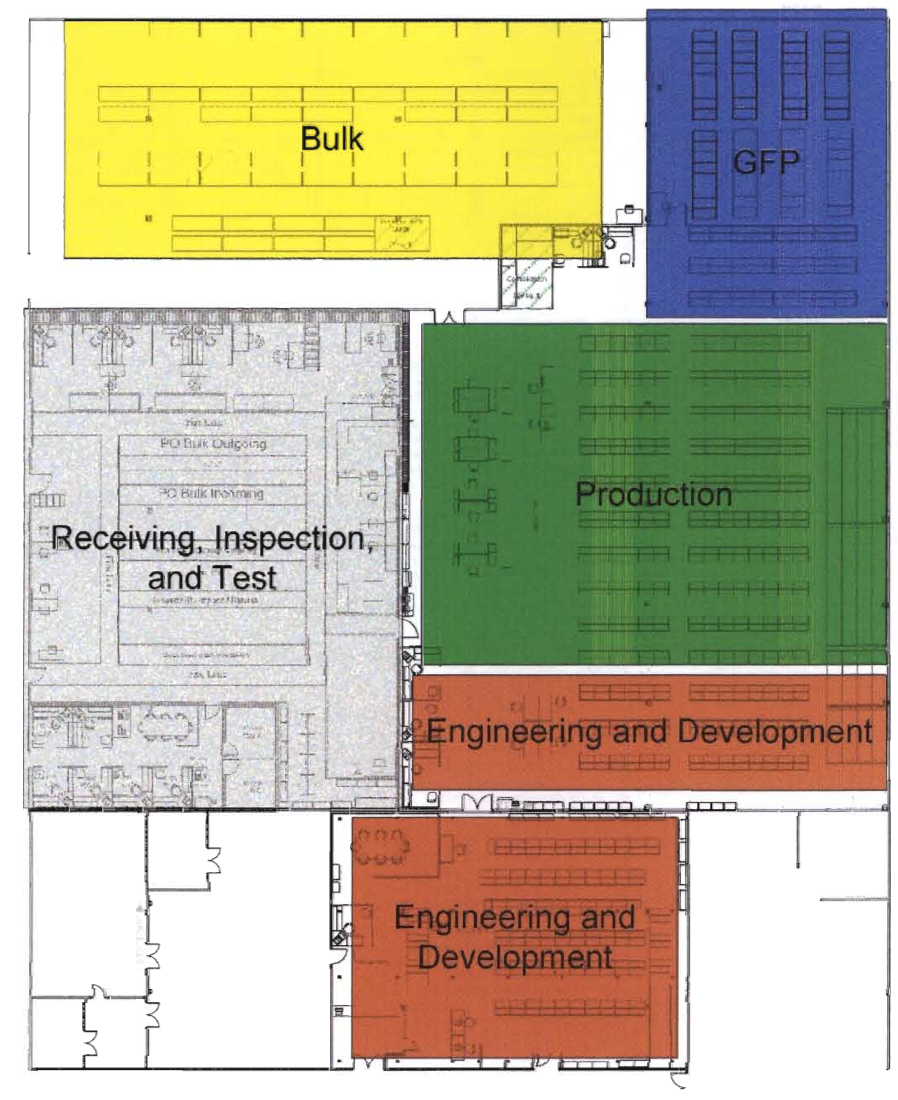

Figure 4.

The main warehouse layout is allocated to the following four areas (Engineering, Production, GFP, and Bulk)

\section{The Issue}

Although the main warehouse that was toured houses most of the products for the company, it only holds approximately $37 \%$ of the total products. The rest are scattered throughout the El Segundo corridor and even in other local cities. Since the warehouse process is highly unpredictable, the programs that purchased the products decide to build and facilitate the products next to the end users. Through time, these "point of use" areas 
grew into a "mini-warehouse," producing the same services and output as the central warehouse. The redundancy of efforts for eight mini-warehouses increase cost of capital for equipments, square area, and labor. It also does not position the company for growth due to limited real estate. These mini-warehouses utilize real estate that could be utilized for production or engineering development. In order to stay competitive and reach Raytheon's vision, all warehouses needed to be consolidated into one single location to optimally improve usage of capital equipments, square footage, and eliminate redundant labor. Figure 5 illustrates the vision.

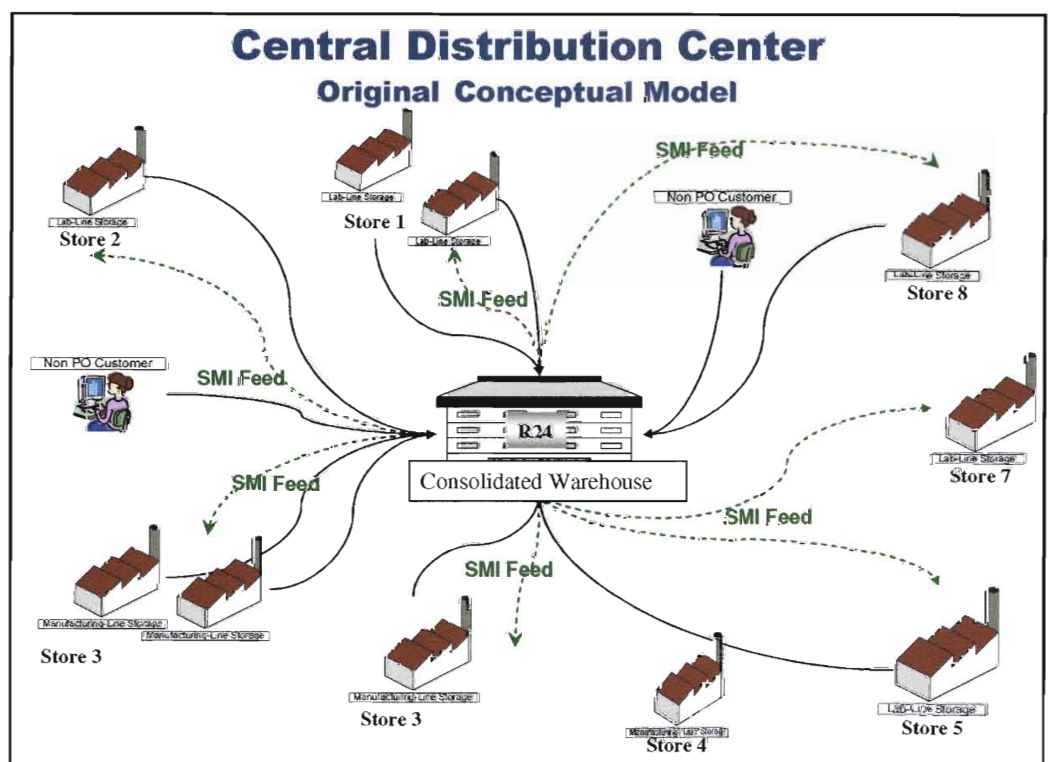

Figure 5.

Conceptual idea of warehouse consolidation and routing services using SMI (supplier manage inventory)

This is the first step in the algorithm: determining strategically to consolidate

warehouses. One cannot move on to the next step if the company's leaders are not willing to spend the resources and the algorithm end shown in Figure 6. The first step to accomplish the vision is to understand the current state of how the products are stored, how much, and where. 


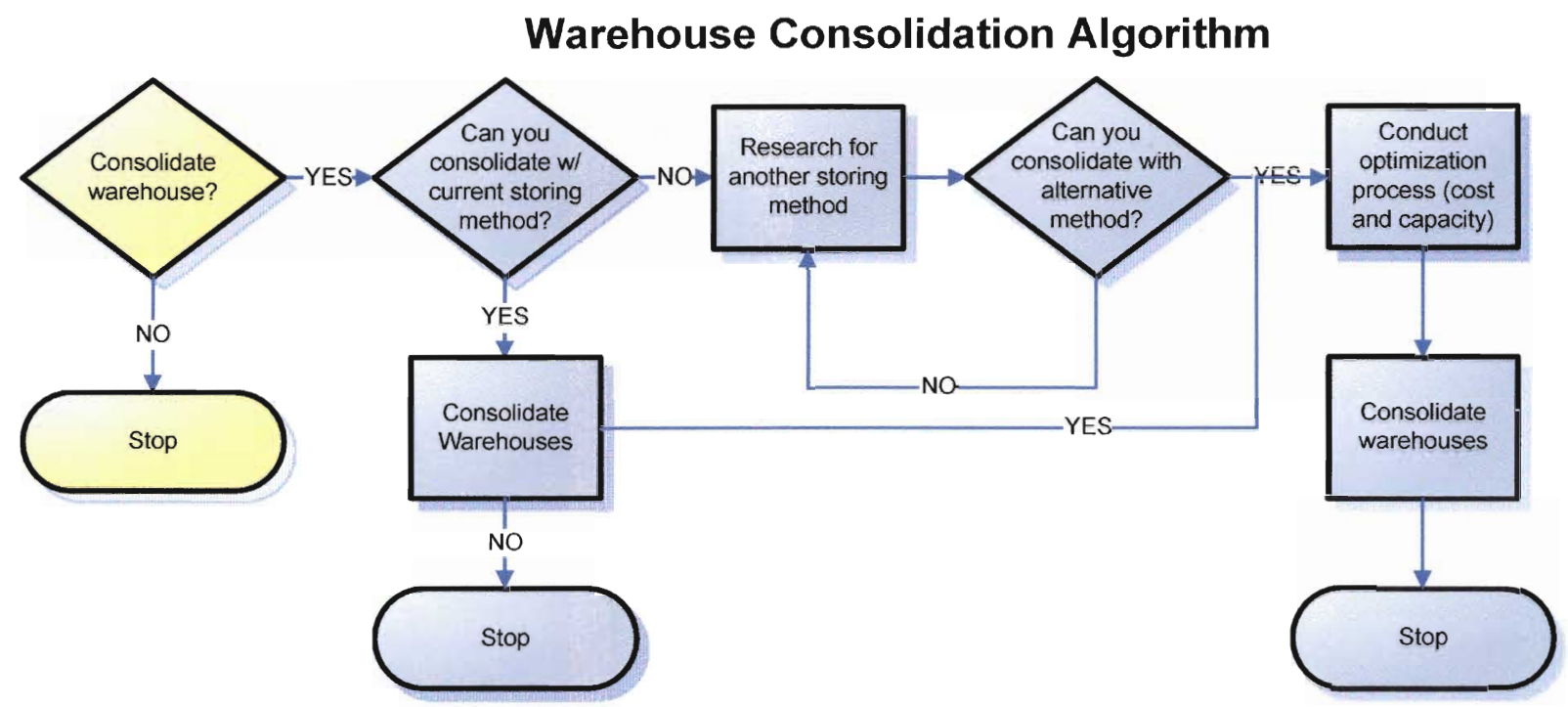

Figure 6.

Figure 6 shows the first step in the algorithm.

\section{Current warehouse storage method}

Since the warehouse is stored by categories the products are segregated. R24 is the name of the location of the main warehouse in California. The products are stored by Programs and the part numbers are stored alpha-numeric from left to right and top to bottom on book shelves configured within totes similar to Picture 1.

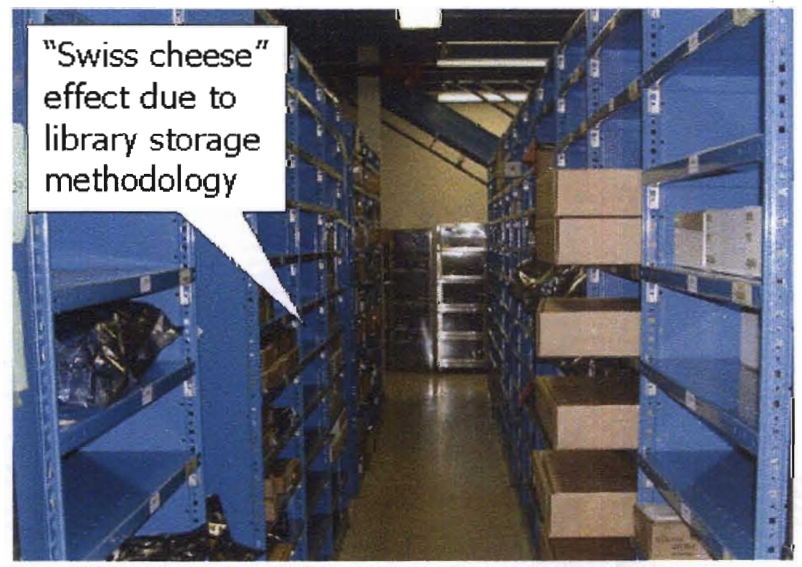

Picture 1.

Current storing method causes inefficient utilization of space.

The storage concept is similar to a conventional library book storage system. In order to put away the products a store clerk would go down the aisle and look for the Program and part number to find its location and store the products. Unfortunately, if the product is 
new the clerk will have to create a new tote bin with its Program and part number and shift the rest of the totes toward the right and down the shelves to make room for the new item (Figure 7). This can be very time consuming if several new products arrive at the same time as anticipated for growth in Raytheon SAS business.

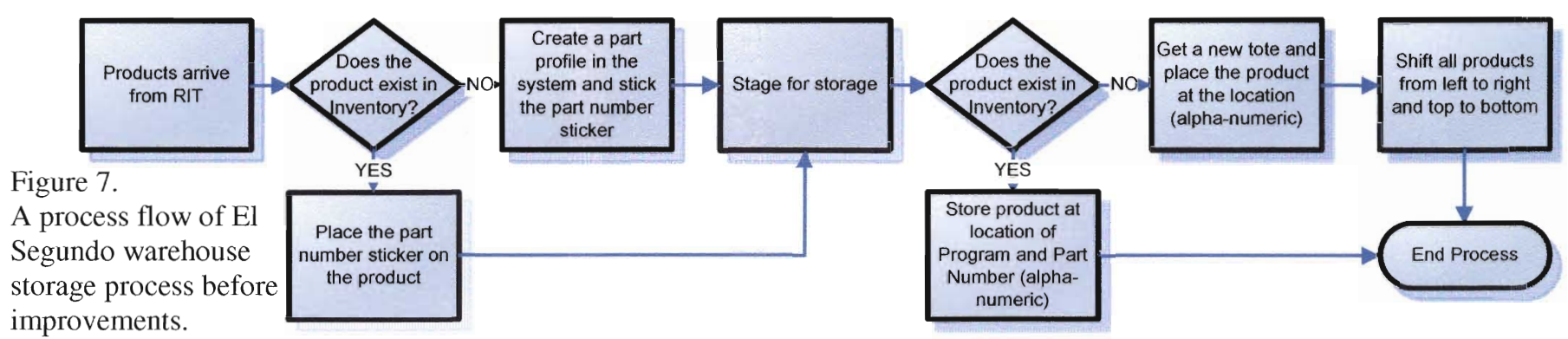

Not only is the put away process cumbersome but the storage of the products is not

optimal. Most products are stored within a tote or left in original packaging on the shelf.

In a typical aisle there are several different size totes housing products and products that do not fit in a tote lying on the side shown in Picture 2.

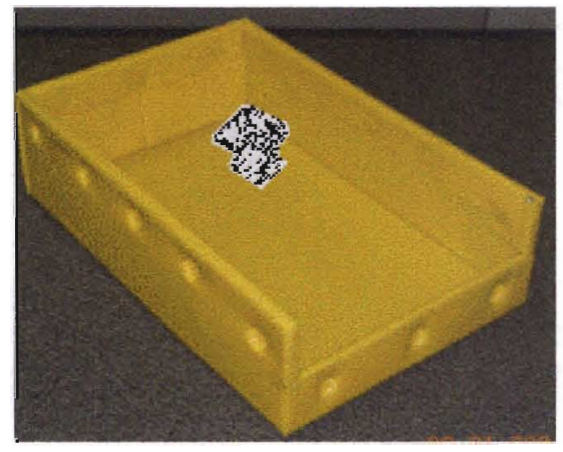

Picture 2.

Picture 2 shows a picture

of a current tote

inefficiently storing a

product.

For instance, if a product is a resistor with a dimension of 1 " $\mathrm{x} 1$ " $\mathrm{x} 1$ " it can be in ate that is much bigger than its actual size which uses valuable storage capacity. This is a likely scenario throughout the warehouse because the first time a package arrives; it can be configured to optimally fit the size of a tote. However, over time the consumption of the products will shrink the dimension into a scenario where the product's size does not justify the storage capacity. 
Another disadvantage of storing products in this fashion is the inability to store the product randomly. Since the products are stored alpha-numerically and segregated by Programs, the flexibility of storing products randomly is not possible. If a solution could be found to store parts randomly it will eliminate the cumbersome process of adding extra products and will utilize the space more efficiently. Also storing products randomly improves the efficiency of the warehouse throughput (Manzini et al., 2006). Visual data were collected to understand how much of the warehouse is occupied with parts shown in Figure 8. Qualitative estimation shows approximately $80 \%$ of the available shelves are occupied. Due to the current storage conditions, the shelves are occupied by products from designated Programs and part numbers but can have empty "air space." Similar to swiss cheese, there are holes in the shelving compartment.

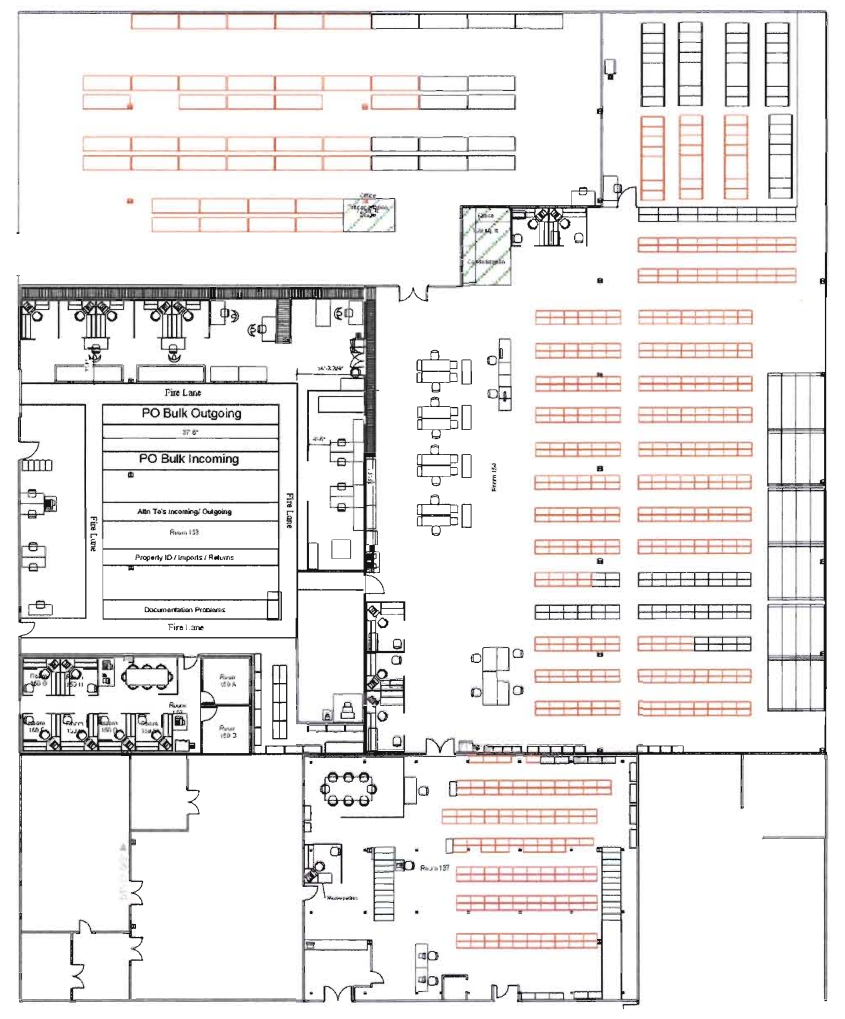

Figure 8.

Warehouse layout with qualitative data of storage consumed in red. 


\section{Quantitative Analysis I}

\section{Analysis of total space required with current storage method}

The next step in the algorithm is to understand if consolidation can happen with the current storing method and condition. Figure 9 shows the preliminary area for the R24 Central Warehouse where the mini-warehouses will be consolidated has a total of 22,750 square feet with 38,717 part numbers already stored in this footage. This compares to the current area data of the eight mini-warehouses cumulating 20,751 square feet with 65,750 part numbers. Taking the summation of unique part numbers divided by the summation of the square footage in the warehouse provides the number of unique part numbers per square foot which is also shown in Figure 9. Currently, the capacity usage of square footage is 2.40 unique part numbers for every square foot by calculating the summation of all unique part numbers divided by the summation of total square footage consume as shown in Equation 1:

$$
\underset{\substack{\text { Average } \\ \text { parts per } \\ \text { square feet }}}{\sum_{\substack{\text { sutd } \\ \text { suted }}} \mathrm{Y}_{\mathrm{i}}}=2.40
$$

Equation 1.

Where,

$\mathrm{X}_{\mathrm{i}}=$ Unique part numbers

$\mathrm{Y}_{\mathrm{i}}=$ Square footage

$\mathrm{i}=$ The number of different warehouses in the area 


\begin{tabular}{|c|c|c|c|}
\hline Warehouse name & Square Footage & Line Items & $\begin{array}{c}\text { Line item per } \\
\text { square footage }\end{array}$ \\
\hline Main Central $^{*}$ & 22,750 & 38,717 & 1.70 \\
\hline Warehouse 1 & 2,651 & 7,372 & 2.78 \\
\hline Warehouse 2 & 3,200 & 13,213 & 4.13 \\
\hline Warehouse 3 & 575 & 147 & 0.26 \\
\hline Warehouse 4 & 1,200 & 5,776 & 4.81 \\
\hline Warehouse 5 & 2,623 & 6,389 & 2.44 \\
\hline Warehouse 6 & 1,625 & 6,440 & 3.96 \\
\hline Warehouse 7 & 3,777 & 12,998 & 3.44 \\
\hline Warehouse 8 & 5,100 & 13,415 & 2.63 \\
\hline Grand Total & 43,501 & 104,467 & 2.40 \\
\hline $\begin{array}{c}\text { Total warehouses to } \\
\text { consolidate }\end{array}$ & 20,751 & 65,750 & \\
\hline $\begin{array}{l}\text { Consolidation Occurs w/ } \\
\text { 20\% growth }\end{array}$ & 22,750 & 125,361 & 5.51 \\
\hline
\end{tabular}

Figure 9.

The figure shows the impact of capacity if consolidation of warehouses occurs. In red are the line items per square footage in the current condition and in green if consolidation occurs. This is a factor of more than $2 \mathrm{X}$ the storage efficiency.

However, if one consolidates the mini-warehouses one would get 4.59 unique part

numbers per square foot using the same equation. Therefore, the goal is to double the current capacity of the central warehouse in order to house all the products. One has to find enough space for an extra 20,751 square feet and more than double the number of line items. In addition, the company is growing rapidly and needs to account for $20 \%$ growth in the next 5 years. This accounts for a total of 125,360 line items in the current square footage of 22,750. That is more than 3 times the current line items in R24 Central Warehouse! This answers the decision block on the algorithm if we can consolidate with current storing method. If yes, then consolidation can be conducted. In this case study we cannot due to the findings and will move to the next step of the algorithm: research for another storing method shown in Figure 10. 


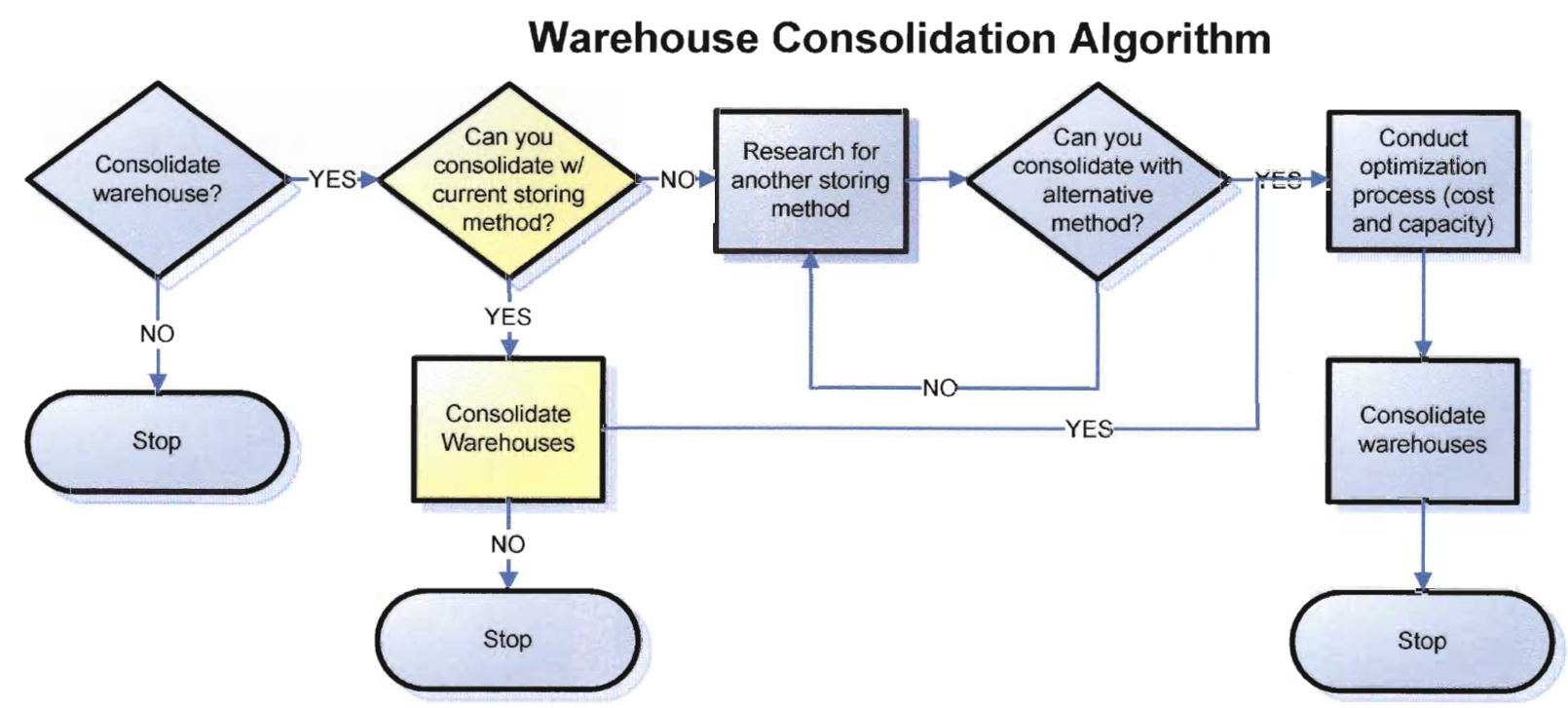

Figure 10.

Figure 10 shows the next step in the algorithm.

\section{Researching for another storage method}

After deciding that the current storage method cannot enable warehouse consolidation the next step in the algorithm is to search for an alternative storing method. It was discovered that the typical industry's solution to capacity constraints for storage is to implement carousels. Carousels can be horizontal or vertical in design and are typically the most flexible storage device to configure into a warehouse. Horizontal carousels are a system of horizontally rotating shelves whereas vertical carousels rotate vertically, move on command, and are driven by a Warehouse Management System (WMS). A carousel brings the product to the store clerk, instead of the clerk searching for the products, reducing the travel time throughout the warehouse. The paradigm shift of the concept of the products coming to you instead of you coming to the product was a refreshing idea to a culture that has worked in the latter process for 30 years. Most WMS are designed with a barcode system providing accuracy and traceability of the products, 
reducing the possibility of human error when reading alpha-numeric part numbers. The new system coupled with carousel and barcoding technology provides shorter cycle time to locate a product and an increase in accuracy of the products thus increasing order picking throughput significantly over traditional methods. Most importantly it was the answer to the issue of providing three times more capacity in the R24 Central Warehouse due to vertical usage, part sizing, and partition capability.

A Raytheon site in Texas which was purchased from Texas Instruments has an active carousels system. Unfortunately, during the tour the author realized that the storage capability is not optimal because it did not have the partition schemes typical in the industry. Barcode technology, the concept of bringing the products to the store clerk, and random storage exist but due to inadequate funds a study was never conducted to design the most optimal partition scheme to house the products at the Texas site.

\section{Evaluating another storage method}

The Texas put away process starts with the products coming from Receiving Inspection and Test (RIT) similar to El Segundo's process, but once it completes the RIT process each product is assigned a barcode from the WMS known as Warehouse Automation Control (WAC) system. The product with the barcode is assigned to a recycle tote from the carousels that best fit the product. If the product is too big for any of the totes it is assigned to the bulk process for storage. Once the barcode is assigned to the product and the tote separately it is transported to the carousels with several other totes at the end of the first shift. Each carousel workstation consists of two carousels called a Pod. The products are randomly assigned to a carousel Pod to be put away. The 
store clerk rotates the carousel until one sees an empty location or an upside down tote.

The upside down tote signifies an empty location. The upside down tote's barcode is

discarded and transported to the RIT area for reuse. The process is described in a process

flow format in Figure 11.

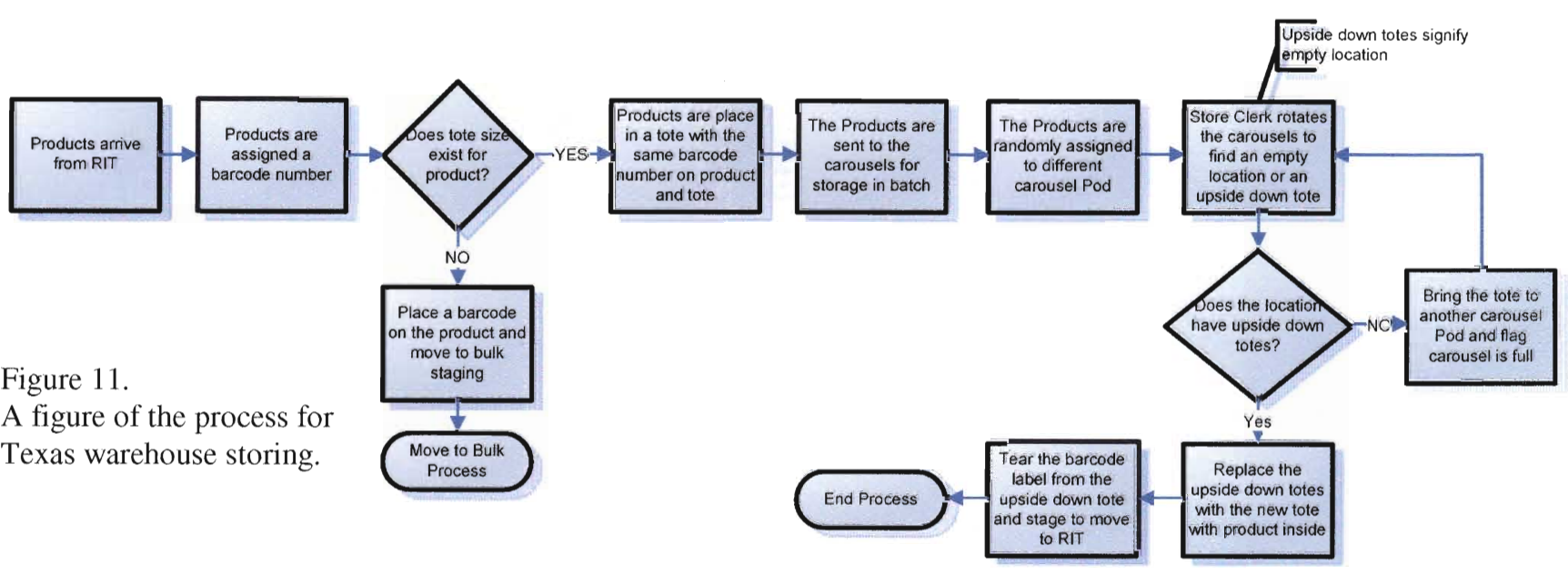

\section{Quantitative Analysis II}

\section{Data analysis of another storing method}

The next step is to analyze the current carousel capacity data to understand how many horizontal carousels were needed to house all products in El Segundo. Before describing the data, some carousels terminology needs to be define shown on Figure 12 and a pictorial schematic with the terminology shown in Picture 3.

\begin{tabular}{|l|l|}
\hline Terminology & Definition \\
\hline Carousel & The entire mechanism housing the product \\
\hline Carrier & A rack that travels around the carousel \\
\hline Shelf & A single shelf on the carrier \\
\hline Totes & A box that houses the products \\
\hline Partition & One or more dividers inside a tote \\
\hline Pods & A set of 2 carousels \\
\hline
\end{tabular}

Figure 12.

A table for carousel's terminologies used in this report. 


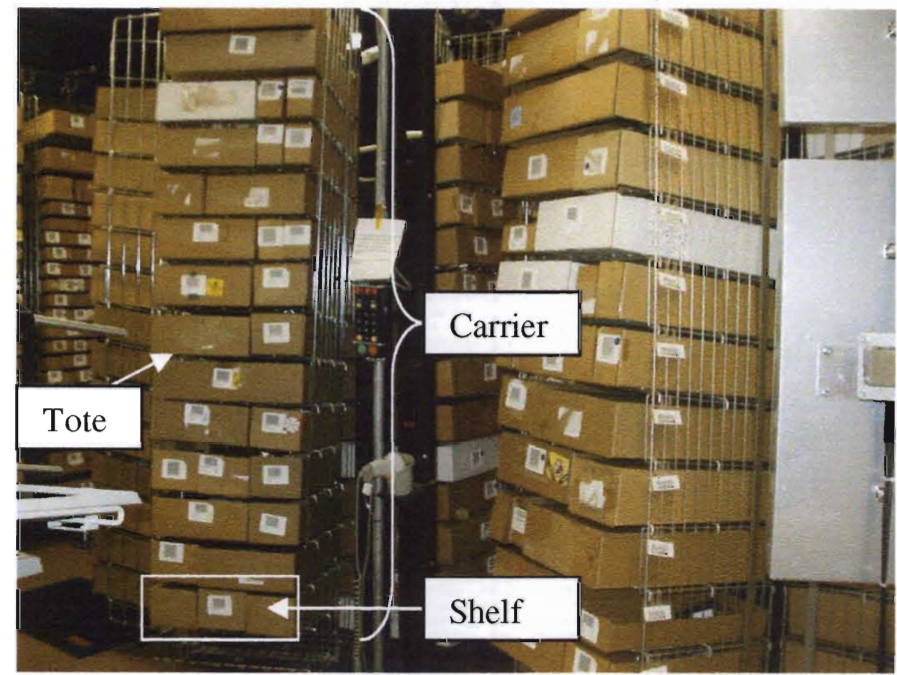

Picture 3.

A picture of a typical carousel configuration at Texas Raytheon.

Data was gathered regarding the carousels such as height, number of carriers, number of totes configuration. Referring back to the total of line items in El Segundo of 104,467 and coupled with the carousel configurations and dimensions, a spreadsheet can be used to determine the amount of carousels needed. First, one needs to understand how many parts can actually be in the carousel because some products have environmental needs and others are just too large to be housed in a carousel. Estimation is used for products that are too large for the carousels and environmental needs by using a percentage factor of $3 \%$ for bulk and $20 \%$ for nitrogen induced products. Estimation is necessary because there is no part profile data for the parts. This estimation was generated by subject matter experts within the warehouse. SAS within Raytheon is growing at a rapid pace of $20 \%$ per year. This growth must be planned into the space and part requirements. Not storing products randomly through time creates inefficiency in capacity; counting the total locations possible and dividing that by the number of unique parts on record provides a factor of inefficiency. For a sample warehouse in El Segundo the total possible locations 
is 3,408 with a total of 2,403 unique parts which equates to a ratio of 1.4 locations per part. This can be determined in Equation 2:

Equation 2. $\quad L f=\frac{L t}{U t}$

Where,

Lf $=$ Locations per part

$\mathrm{Lt}=$ Total number of possible locations

$\mathrm{Ut}=$ Total unique parts in the system

This factor is used to quantify the number of parts in a system divided by the potential location a carousel will have because over time the same part number can be stored in another location and will occupy more than one carousel location. Another factor is an industry standard for carousels; to be most efficient the carrying capacity is at $90 \%$.

Therefore, a factor of $90 \%$ is used to provide the needed required space for the optimal throughput rate. Figure $\mathbf{1 3}$ shows the analysis from the excel spreadsheet for the

Production Inventory products. Similar calculation is needed for Engineering and other warehouses to find the total carousels.

\begin{tabular}{|l|c|}
\hline Horizontal Carousel storage locations (also called bin boxes or line items) re quired: \\
\hline Unique part numbers & 34,503 \\
\hline Percentage that is bulk & $3 \%$ \\
\hline Unique carousel part numbers without bulk & 33468 \\
\hline Percentage that requires special sto rage (environ mental, sensitive, etc.) & $20 \%$ \\
\hline Unique carousel part numbers w/o bulk and environmental need & 26774 \\
\hline Potential growth factor & $20 \%$ \\
\hline Horizontal carousel part numbers with growth & 32129 \\
\hline Storage locations per part number through time factor & 1.4 \\
\hline Horizontal carousel storage unique locations needed & 44981 \\
\hline Utilization factor (for efficient location of empty bin boxes when stocking) & $90 \%$ \\
\hline Total horizontal carousel storage locations needed & 49,479 \\
\hline
\end{tabular}

Figure 13.

Calculation process to determine the number of storage locations needed. 
Equation 3 is used to find the number of locations needed for each warehouse to understand how many carousels are needed in total to consolidate:

$\mathrm{Ln}=\mathrm{Nt} *(1-\mathrm{Pb}) *(1-\mathrm{Ps}) *(1+\mathrm{Pg}) *(\mathrm{Lf}) *(1+\mathrm{Pe})$

Where,

$\mathrm{Ln}=$ Total number of carousel bins needed

$\mathrm{Nt}=$ Number of part numbers

$\mathrm{Pb}=$ Percentage of bulk items

Ps $=$ Percentage of special storage

$\mathrm{Pg}=$ Percentage growth factor

$\mathrm{Lf}=$ Average number of locations/ part number

$\mathrm{Pe}=$ Average percentage buffer capacity on carousels

The total number of storage locations necessary for Production Inventory is 49,479. Using the configuration of the carousels in Texas, the necessary carousels can be determined by calculating the number of storage locations on each shelf, carrier, and finally each carousel. Figure 14 shows Texas totes configuration for a carrier which equates to 78 total possible locations per carrier. Extrapolating the number of totes to the number of carriers will give the total number of totes or locations a single carousel would provide. The calculation consists of 78 totes per carrier multiplied by 58 carriers equating to 4524 total possible locations for a carousel. Knowing the amount of possible locations, one can determine the number of carousels by simply dividing the number of parts locations needed by the number of locations available in a carousel shown below for one sample of Equation 4:

$$
\begin{aligned}
& \mathrm{Cn}=\mathrm{Ln} / \mathrm{Ca} \\
& \mathrm{Ln}=\text { Locations needed for a carousel } \\
& \mathrm{Ca}=\text { Available locations per carousel } \\
& \mathrm{Cn}=\text { Carousels needed for Production Inventory }
\end{aligned}
$$

For the example of Production Inventory numbers equated to:

49,479 needed locations / 4524 available locations $=11$ carousels needed 


\section{Horizontal Carousel capacity information:}

\begin{tabular}{|c|c|c|c|c|c|c|c|c|c|}
\hline tote height: & $2.75^{\prime \prime}$ & $2.75^{\prime \prime}$ & $2.75^{\prime \prime}$ & $2.75^{\prime \prime}$ & $5^{\prime \prime}$ & $5 "$ & $5 "$ & $5 "$ & Total \\
\hline "tote width: & $3.25^{\prime \prime}$ & $6.5^{\prime \prime}$ & $9.75^{\prime \prime}$ & $13^{\prime \prime}$ & $3.25^{\prime \prime}$ & $6.5^{\prime \prime}$ & $9.75^{\prime \prime}$ & $13^{\prime \prime}$ & per carrier \\
\hline \# totes / ca rrier: & 52 & 8 & 4 & 2 & 6 & 3 & 2 & 1 & $7 \varepsilon$ \\
\hline \multicolumn{10}{|c|}{${ }^{\star}$ Note - each shelf is $20^{\prime \prime}$ wide - therefore, as an example, 6 of the bin boxes that are $3.25^{\prime \prime}$ wide could fit on one shelf. } \\
\hline \multicolumn{5}{|l|}{ \# Carriers } & 58 & \multicolumn{4}{|c|}{ (based on Texas actuals) } \\
\hline \multicolumn{5}{|c|}{ Total horizontal carousel storage locations available } & 4524 & \multicolumn{4}{|c|}{ (\# totes/ carrier * \# of carriers on a carousel) } \\
\hline
\end{tabular}

Figure 14.

A typical storage configuration for one carrier at Texas to determine total locations available with one carousel.

This calculation is only for products used for Production or in the Inventory

Control System (ICS). The ICS system consists of products in the R24 Central

Warehouse and other mini-warehouses. Similar calculations need to be developed for

Engineering products in the Engineering Control System (ECS) and other mini-

warehouse from another system for classified products. Summing the total for all four

systems provides a total of 24 carousels shown in Figure 15. The 24 carousels were

found by Equation 4:

Equation 4.

$$
\sum C n_{\mathrm{i}}=\sum\left(\frac{L n_{\mathrm{i}}}{C a}\right)
$$

Where,

Cni $=$ Total carousels needed

Lni $=$ Locations needed

$\mathrm{Ca}=$ Standard number of locations per carousel

$i=$ The index of different warehouses 
This is the number of carousels needed in El Segundo in order to consolidate all the miniwarehouses into one central location.

\begin{tabular}{|l|c|c|c|c|c|}
\hline \multicolumn{7}{|c|}{ Total Carousels needed using Texas configuration } \\
\hline $\begin{array}{l}\text { Warehouse } \\
\text { Total horizontal } \\
\begin{array}{l}\text { carousel storage } \\
\text { locations needed }\end{array}\end{array}$ & 49,479 & 22,071 & 17,000 & 14,309 & 102,858 \\
\hline $\begin{array}{l}\text { Total horizontal } \\
\text { carousel storage } \\
\text { locations available }\end{array}$ & 4524 & 4524 & 4524 & 4524 & 4524 \\
\hline Carousels needed & 11 & 5 & 4 & 4 & 24 \\
\hline
\end{tabular}

Figure 15.

Total carousels needed from Texas carousel configuration for all products in El Segundo.

Unfortunately, the current layout of R24 Central Warehouse containing 22,750

square feet is too small to fit 24 horizontal carousels. Also, the cost of 24 carousels does not justify the return in investment for consolidating the warehouses. Another solution needs to be provided in order to execute. The alternative storage method does not enable warehouse consolidation either. Therefore, the next step on the algorithm is to find another storage method shown on Figure 16.

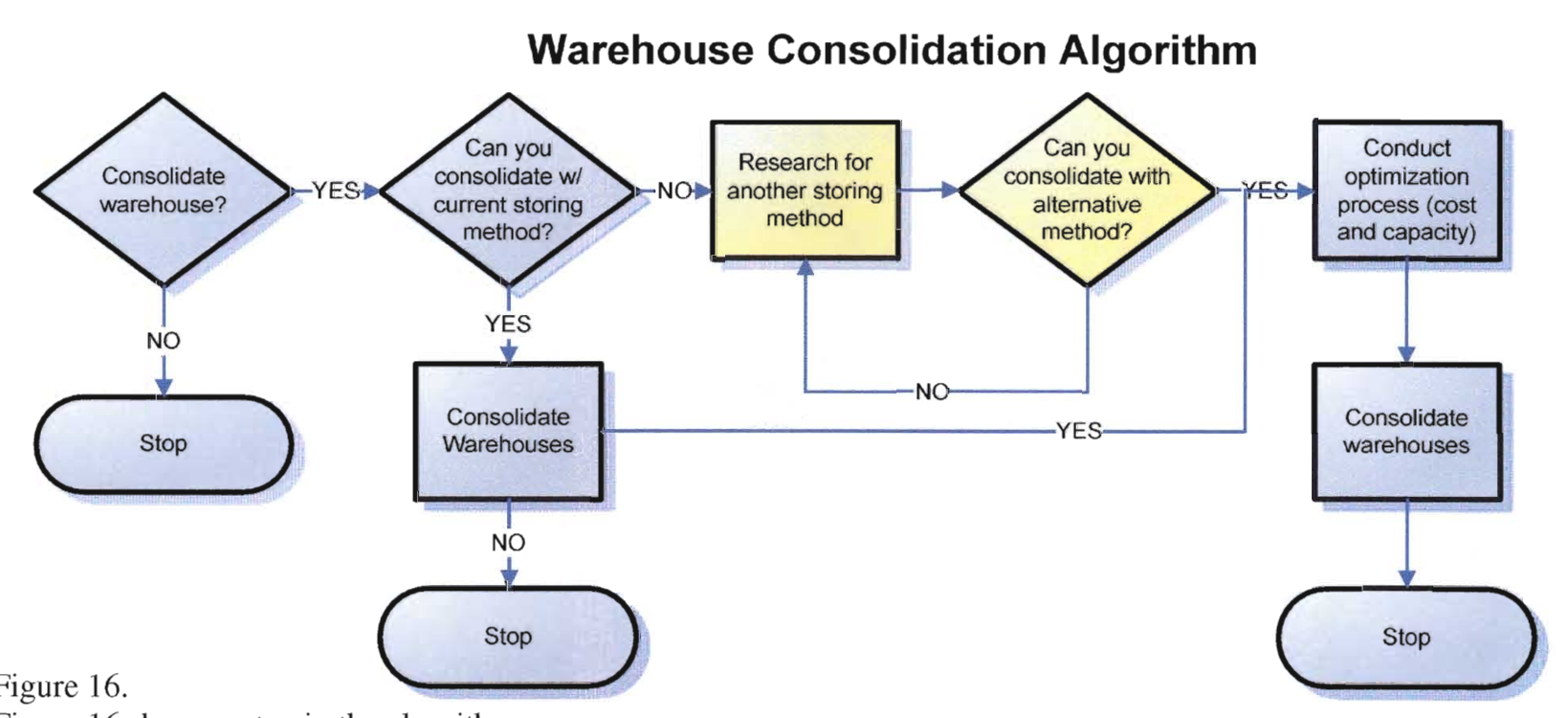

Figure 16 shows a step in the algorithm where the alternative storage method does not enable warehouse consolidation. 
Fortunately, during the author's research outside the company, other companies have developed partitioning schemes to optimize the capacity per tote, shelf, and carrier. By adding one partition to the totes it will provide two locations for one tote, this will double the capacity. Likewise, the more partitions placed in the tote the more capacity one will get from the carousel. However, one cannot add too many partitions unless a good study is used as to the size of the products. Conducting a study to measure all 104,467 products is unreasonable, time consuming, and costly. Therefore, a Random Sampling to infer the product's size from the population is used. This is an analysis to understand if another storage method will enable warehouse consolidation on the algorithm.

\section{Quantitative Analysis III}

\section{Random sampling to infer partition size}

By random sampling the population of the products one can estimate the size and characteristics of the products with a degree of confidence with unbiased data. "The advantages of using random sampling are: 1) it helps to reduce or eliminate bias in the manner in which the sampled items are chosen and 2) it enables us to make precise statements about the extent to which conclusions drawn from a sample can be applied to the entire population" (Devore and Nicholas, 1999). An approach to random sampling to infer the population by using the Normal Approximation to the Binomial taken from the following reference Elementary Survey Sampling (Scheaffer et al, 2006):

Equation 5.

$$
n=\frac{N p q}{(N-1) *\left(\frac{B^{2}}{4}\right)+p q}
$$


Where,

$\mathrm{n}=$ number of parts needed in the sample

$\mathrm{N}=$ number of parts in the population

$\mathrm{p}=$ proportion of parts having a particular size characteristic

$\mathrm{q}=$ proportion of parts not having that particular size characteristic

$\mathrm{B}=$ bound on the error of estimation (i.e., the margin of error)

The first step is to estimate the proportion of the parts in the population having a particular size characteristic. Since this quantity is unknown, the standard process is to start with the assumption that $\mathrm{p}=0.50$. This means that half of the parts in the population will have a particular size characteristic and the rest of the parts will have some other size characteristics. Setting the margin of error, B, to be $.05(5 \%)$ and q to be 0.50 will provide a first cut at the estimation. Conducting this method will yield the following results for the case study with the population size N=83,053 shown in Figure 17.

\begin{tabular}{|c|c|c|c|}
\hline \multicolumn{4}{|c|}{ CONFIDENCE INTERVALS FOR SAMPLES } \\
\hline $\mathrm{n}=$ & 398.09 & $\mathrm{n}$ category $=$ & 199.04 \\
\hline$p=$ & 0.5 & & \\
\hline$q=$ & 0.5 & & \\
\hline$N=$ & 83,053 & & \\
\hline$B=$ & 0.05 & & \\
\hline
\end{tabular}

Figure 17.

An equation to understand the number of sample parts needed using the Normal Approximation to Binomial equation.

This means that one needs to select 399 samples to have a good confidence that the study will yield an estimated proportion having a margin of error of 5\%. In order to make sure this equation is accurate for the population, each part category needs to have at least 5 sampled parts in the final sample. 


\begin{tabular}{|l|c|c|c|c|c|c|c|}
\hline Tote Size Name & A & B & C & D & E & F & G \\
\hline $\begin{array}{l}\text { Tote size dimensions } \\
\text { (L, W, H) inches }\end{array}$ & $4 \times 4 \times 4$ & $4 \times 6 \times 4$ & $6 \times 8 \times 4$ & $8 \times 12 \times 4$ & $12 \times 12 \times 4$ & $12 \times 24 \times 4$ & $24 \times 24 \times 4$ \\
\hline $\begin{array}{l}\text { Number of locations } \\
\text { per shelf }\end{array}$ & $36 \mathrm{loc}$ & $24 \mathrm{loc}$ & $12 \mathrm{loc}$ & $6 \mathrm{loc}$ & $4 \mathrm{loc}$ & $2 \mathrm{loc}$ & $1 \mathrm{loc}$ \\
\hline $\begin{array}{l}\text { Count of parts that fit } \\
\text { in tote size }\end{array}$ & 214 & 264 & 136 & 204 & 146 & 105 & 18 \\
\hline $\begin{array}{l}\text { Percentage of parts } \\
\text { that fit in tote size }\end{array}$ & $19.2 \%$ & $23.7 \%$ & $12.2 \%$ & $18.3 \%$ & $13.1 \%$ & $9.4 \%$ & $1.6 \%$ \\
\hline Margin of error & $+/-2.4 \%$ & $+/-2.6 \%$ & $+/-2.0 \%$ & $+/-2.3 \%$ & $+/-2.0 \%$ & $+/-1.7 \%$ & $+/-0.76 \%$ \\
\hline
\end{tabular}

Figure 18.

Total of 1,087 parts categorized into lot size locations from A to G.

Figure 18 shows the final results and size characteristics for a 1,113 part sample. Only 1,087 of the parts sampled were used because the rest did not fit a standard lot size tote. The smallest parts count from this sample is 18 , which is well over 5 . If there is a sample size of less than 5 than the inference of a binomial distribution does not follow a normal distribution and the equation is inaccurate for this study. For example, tote A is calculated by taking the count of parts that fit in tote A dimensions and dividing by the sample population (n) like Equation 6:

Equation 6. $P i=\frac{C i}{n}$

Where,

$\mathrm{P}=$ percentage for $i$

$\mathrm{C}=$ the count of the parts for $i$

$\mathrm{n}=$ the sample size

$i=$ the different type of standard tote size 
The margin of error can also be calculated by using Equation 7:

Equation 7. $M E(P i)=1.96 * \sqrt{\frac{P i * q i}{n}}$

Where,

$\mathrm{ME}(P i)=$ the margin of error for the percentage of type $i$

$\mathrm{P} i=$ proportion of parts having a particular size characteristic $i$

$\mathrm{q} i=$ proportion of parts not having that particular size characteristic $i$

$n=$ the sample size

$i=$ the different type of standard tote size

In the case study another random sampling equation was used to infer the

population that yielded the sampling of 1087 parts. The Normal Approximation to the

Binomial equation yielded 399 part numbers to sample. Therefore, the study provided a

sound result.

Once the sample size is found and the confidence interval is acceptable, a random sampling plan must be developed. In order to randomly measure the products to reduce bias a random number generator from Minitab is used. This gives a set of randomly generated numbers for the sample size with four digits for each warehouse. This is shown in Figure 19 on column label Location (RN).

\begin{tabular}{|c|l|c|c|c|}
\hline Location (RN) & \multicolumn{1}{|c|}{ Part \# } & Length & Width & Depth \\
\hline 2469 & 655655 & 14.00 & 12.00 & 2.50 \\
\hline 1794 & 3267279 & 25.00 & 23.00 & 1.00 \\
\hline 0306 & 5182932 & 8.00 & 7.00 & 2.00 \\
\hline 0792 & 5200977 & 9.00 & 6.00 & 3.00 \\
\hline 2585 & 6385875 & 6.75 & 6.50 & 3.25 \\
\hline 2312 & 6477158.00 & 9.50 & 8.50 & 0.50 \\
\hline 1311 & 8655385 & 11.00 & 9.50 & 2.00 \\
\hline 0059 & JCA812-100 & 12.00 & 4.50 & 1.25 \\
\hline 2097 & $119552-200$ & 23.00 & 9.00 & 3.50 \\
\hline 2612 & 12103 C334KAT2A & 11.00 & 8.50 & 1.00 \\
\hline 0816 & $226 K 010$ CRSB0000 & 10.50 & 9.00 & 0.75 \\
\hline 1248 & $5002636-001 C$ & 9.00 & 6.50 & 0.50 \\
\hline 1915 & $5137502-005$ & 10.50 & 8.50 & 0.50 \\
\hline 2358 & $6380234-002$ & 15.50 & 14.00 & 1.00 \\
\hline
\end{tabular}

Figure 19.

An excerpt of random sampling data with length, width, and depth in inches. 
The four digits are used to systematically identify the storage location of the shelving to randomly measure the products:

- The first 2 digits are the aisle going from the front of the warehouse to the back (from 00 to 43 )

- The next 2 digits are for the number of racks going from the front to back (00 to 14 )

- The next single digit is from the front of the four digits number and is use for the number of shelves from top to bottom (0 to 8)

- The next 2 digits are the second and third digit of the four digits number and is use for the number of totes going from left to right $(00-15)$

For example, random number 1276 will be configured as so:

- The first 2 digits are 12 , therefore it is the thirteenth aisle from the front to back of the warehouse (1276)

- The next 2 digits are 76, therefore you must travel the rack 5 times to surpass 15 sets of rack $(00-14)$ then travel 1 more racks to get to $76(1276)$

- The next digit is the rotating number to the first digit which is 1 . Therefore, the shelf is the second from the top. (1276)

- The next digit is 2 (the second digit). Therefore, the products to measure is in the second tote or if the product is not in the tote then the second product from left to right (1276)

Figure 20 illustrate the location of the part to measure with the random number 1276.

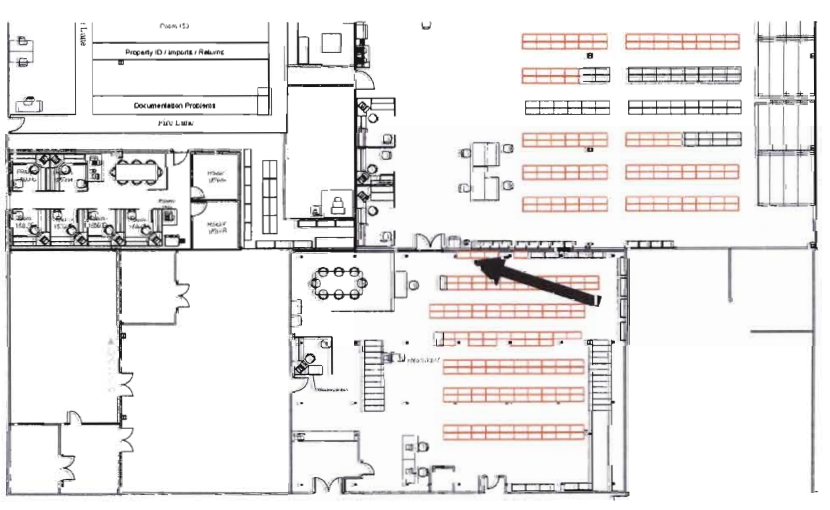

Figure 20.

The location of the part to measure using random sample 1276 in the warehouse.

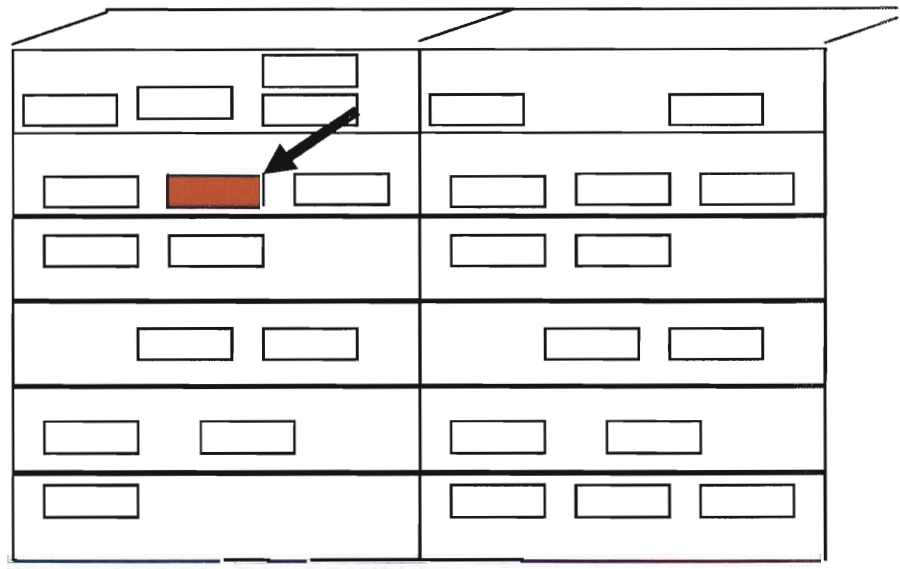


The author used this approach to systematically select random parts to measure. The round table approach to correlate the random numbers to the warehouse configuration is not the correct method because this may cause statistical errors. The correct method is to determine the warehouse configuration first in order to correlate it to the random numbers. In this example four digits were used but the number should be seven total digits. Therefore, each warehouse layout is different and determining the number of digits will be different.

\section{Data inference to determine partition population size}

After measuring and grouping all sample parts in all the stores to different group sizes, the next step is to infer it into different tote sizes. Before analyzing the part's characteristics a carousel vendor provided some standard tote sizes from the vendor's 20 years of experience in carousel installation. The vendor estimated that $70 \%$ of the parts will be in a tote size of 4" X 4" X 4" shown in Figure 21. The vendor also provided the carriers specifics such as the depth and width of the shelf at $24 "$. The height can be adjusted between a minimum of 4" to the entire height of the carrier. The author decided to hold the constraint of the height to be 4 " due to the fact that approximately $96 \%$ of the parts have either a Length, Width, or Height that is 4".

Average bin box configuration per rack/carrier:

\begin{tabular}{|l|c|c|c|c|}
\hline \multicolumn{1}{|c|}{ Tote Type } & A & B & C & D \\
\hline bin box height: & $4^{\prime \prime}$ & $4^{\prime \prime}$ & $4^{\prime \prime}$ & $4^{\prime \prime}$ \\
\hline bin box depth: & $24^{\prime \prime}$ & $24^{\prime \prime}$ & $24^{\prime \prime}$ & $24^{\prime \prime}$ \\
\hline "bin box width: & $4^{\prime \prime}$ & $4^{\prime \prime}$ & $4^{\prime \prime}$ & $8^{\prime \prime}$ \\
\hline \# bin box sub slots & 6 & 4 & 2 & 3 \\
\hline Total Cubic Inches & 64 & 96 & 192 & 256 \\
\hline$\%$ Mix of Totes* & $70 \%$ & $10 \%$ & $10 \%$ & $10 \%$ \\
\hline
\end{tabular}

\section{*Based on observations made in R24 by a carousel vendor}

Figure 21.

A Pareto Chart showing where the majority of the part sizes are grouped. 
Constraining the height to 4" allowed the author to calculate the percentage of each part size by counting the Length and Width that fit in a 4", 6", 8", 12" and 24" configuration.

The number of carousels can now be determined by the percentages of part sizes through extrapolation of the data.

\section{Quantitative Analysis IV}

\section{Data extrapolation to determine number of carousels}

Once the percentage of sample size is characterized into standard tote sizes, the next process is to extrapolate the data to fit in a standard shelf on a standard carrier. The standard carousel has a width and depth of 24" with the height constraint to 4" and provides 16 shelves on one carrier. Calculating using the equation below and rounding down will provide the number of locations per carrier needed to house the products with that size configuration. For example, tote type A is calculated by using Equation 8:

Equation 8.

$\mathrm{Lnj}$ (round down to the nearest integer) $=\mathrm{SCj} * \mathrm{LSj} * \mathrm{PPj}$

Where,

$\mathrm{Lnj}=$ Number of carousel locations required for tote type $\mathrm{j}$

$\mathrm{SCj}=$ Shelves $/$ Carriers

$\mathrm{LSj}=$ Locations/ Shelf

$\mathrm{PPj}=$ Percentage of he parts population

$\mathrm{j}=$ index of tote size

For tote type A you get:

$(16$ shelves/ carriers $) *(36$ locations/ shelf $) *(19.2 \%$ of the parts population $)=$ 110 tote type A needed per carousel (round down to nearest integer)

The total number of locations per carrier can be calculated by summing the total locations per carrier for each tote type and then multiplying by the number of carriers on a carousel. This will provide the total locations available on a carousel as shown in Figure 
22. There are two types of carousels available. One carousel has 50 carriers with a total length of 60 feet while another carousel has only 40 carriers but is only 48 feet long. The calculations shown in Figure $\mathbf{2 2}$ are for 50 carriers. Forty carriers will lead to 10,178 total locations compared to 12,724 with 50 carriers.

\begin{tabular}{|c|c|c|c|c|c|c|c|}
\hline Tote Type & $\bar{A}$ & B & $\mathrm{C}$ & $\mathrm{D}$ & $\mathbf{E}$ & $\mathbf{F}$ & $\mathrm{G}$ \\
\hline Tote Size $(\mathrm{W} \times \mathbf{D} \times \mathbf{H})$ & $4 \times 4 \times 4$ & $4 \times 6 \times 4$ & $6 \times 8 \times 4$ & $8 \times 12 \times 4$ & $12 \times 12 \times 4$ & $12 \times 24 \times 4$ & $24 \times 24 \times 4$ \\
\hline Count & 214 & 264 & 136 & 204 & 146 & 105 & 18 \\
\hline Percent Mix of Totes & $19.2 \%$ & $23.7 \%$ & $12.2 \%$ & $18.3 \%$ & $13.1 \%$ & $9.4 \%$ & $1.6 \%$ \\
\hline Locations/Tote & 6 & 4 & 3 & 2 & 2 & 1 & 1 \\
\hline Locations/Shelf & 36 & 24 & 12 & 6 & 4 & 2 & 1 \\
\hline Locations/Carrier & 110 & 91 & 23 & 17 & 8 & 3 & 0.26 \\
\hline Total Storage Locations/Carrier & \multicolumn{7}{|c|}{252} \\
\hline Locations/Carousel & 5537 & 4554 & 1173 & 879 & 419 & 150 & 12 \\
\hline Total Storage Locations/Carousel & \multicolumn{7}{|c|}{12724} \\
\hline
\end{tabular}

Figure 22.

Calculations of each tote types to determine the number of storage locations per carousel.

The sampling suggested that we will obtain 12,724 locations per carousels compared to the Texas calculations of 4,524 total locations per carousel without partitioning. That's a total of more than 8,000 extra locations per carousel!

The next step after determining the number of locations per carousel is refer to an earlier calculation the total unique locations needed for current capacity and growth (See Figure 15). Taking the data for all products in the R24 Central Warehouse and all other mini-warehouses gives a total of 71,550 locations needed not including products from the secret area to be taken later. To find the total number of carousels needed to house all production and engineering products one simply divides the number of unique locations needed by the number of storage locations per carousel using Equation $\mathbf{4}$ from earlier. This example will yield:

71,550 locations needed/ 12,724 locations per carousel $=5.6$ carousels 
Therefore, one would need 5.6 or 6 carousels to consolidate all production and engineering products into one area using a 50 carriers carousel shown in Figure 23.

Similar calculations are conducted to determine the number of carousels needed for a 40 $\mathrm{ft}$ carousel which is 7 carousels. Doing similar calculations for $\mathbf{J}$ and $\mathbf{F}$ Stores products yield 1 and 2 carousels needed respectively for a total of 9 carousels needed if we mix all products or 10 carousels if one round up and leave all products segregated summarized in Figure 24. Ten carousels is a more economic and feasible solution than 24 carousels calculated earlier using the Texas carousel storage method without partition configuration.

\begin{tabular}{lr|}
\hline 50-Carrier Carousel & \\
\hline Total Carrier/Carousel & 50 \\
Carrier Height & 97 \\
Carrier Width & 24.5 \\
Carrier Depth & 24 \\
Shelf Height & 4 \\
Shelf Height w/Clearance & 6.0625 \\
Total Shelf/Carrier & 16
\end{tabular}

\begin{tabular}{|c|c|c|c|c|c|c|c|}
\hline Tote Type & A & B & C & D & E & $\mathrm{F}$ & G \\
\hline Tote Size $(\mathrm{W} \times \mathrm{D} \times \mathrm{H})$ & $4 \times 4 \times 4$ & $4 \times 6 \times 4$ & $6 \times 8 \times 4$ & $8 \times 12 \times 4$ & $12 \times 12 \times 4$ & $12 \times 24 \times 4$ & $24 \times 24 \times 4$ \\
\hline Count & 214 & 264 & 136 & 204 & 146 & 105 & 18 \\
\hline Percent Mix of Totes & $19.2 \%$ & $23.7 \%$ & $12.2 \%$ & $18.3 \%$ & $13.1 \%$ & $9.4 \%$ & $1.6 \%$ \\
\hline Locations/Tote & 6 & 4 & 3 & 2 & 2 & 1 & 1 \\
\hline Locations/Shelf & 36 & 24 & 12 & 6 & 4 & 2 & 1 \\
\hline Locations/Carrier & 110 & 91 & 23 & 17 & 8 & 3 & 0.26 \\
\hline Total Storage Locations/Carrier & \multicolumn{7}{|c|}{252} \\
\hline Locations/Carousel & 5537 & 4554 & 1173 & 879 & 419 & 150 & 12 \\
\hline Total Storage Locations/Carousel & \multicolumn{7}{|c|}{12724} \\
\hline
\end{tabular}

\# of Carriers Needed:

\begin{tabular}{|l|c|}
\hline **Total carrier storage locations needed & 71,550 \\
\hline Total carrier storage locations available & 252 \\
\hline Total carriers needed & 283.6 \\
\hline
\end{tabular}

\# of Carousels Needed:

\begin{tabular}{|l|c|}
\hline$* *$ Total horizontal carousel storage locations needed & 71,550 \\
\hline Total horizontal carousel storage locations available & 12,724 \\
\hline Total carousels needed & $\mathbf{5 . 6}$ \\
\hline
\end{tabular}

Figure 23.

Calculations method to determine number of carousels needed using partition and random sampling. 


\begin{tabular}{|c|c|c|c|}
\hline & Carriers Needed & $\begin{array}{l}\text { Carousels Needed } \\
\text { from calculations }\end{array}$ & $\begin{array}{c}\text { Carousels Needed to } \\
\text { procure }\end{array}$ \\
\hline F Stores & 74.9 & 1.5 & 2.0 \\
\hline J Stores & 99.1 & 1.9 & 2.0 \\
\hline${ }^{* *}$ Rest of Stores & 283.6 & 5.6 & 6.0 \\
\hline Total & 457.6 & 9.0 & 10.0 \\
\hline
\end{tabular}

NOTE: Results calculated from using ICS Inventory data with stock on hand and orders already given

Figure 24.

Total number of carousels needed to consolidate.

Now the total number of carousels needed to consolidate is known for all the parts, the next question is which exact carousels should be used? There are two types of horizontal carousels. A 40 carriers carousel with 48 foot in length and a 50 carriers carousel with a 60 feet in length are available. To complicate the decision a 48 feet carousel costs $\$ 42,000$ and a 60 foot carousel costs $\$ 63,000$. How would one determine the mix of carousels to determine the optimal mix of carousels to provide the least amount of cost while ensuring enough locations to consolidate? The next step is to develop a Linear Programming equation from the scientific field of Operations Research to determine the right mix of carousels. One also needs to develop a process that will optimize the process for parts storage and distribution. This is the next step in the algorithm once the number of carousels needed is determined shown on Figure 25. 


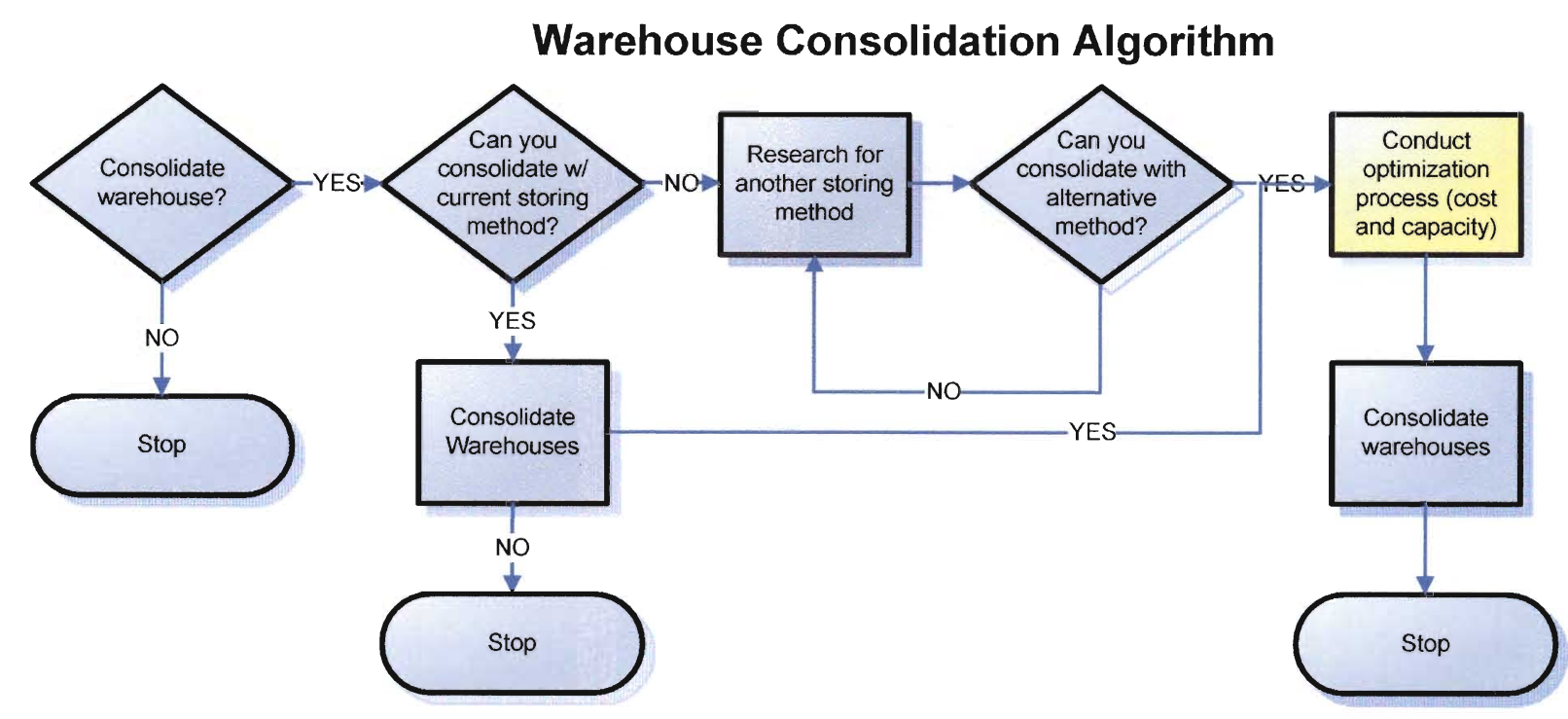

Figure 25.

The alternative method enables consolidation and the next step in the algorithm is to conduct an optimization process to optimize capacity and process.

\section{Quantitative Analysis V}

\section{Optimal carousels equation}

The Linear Program solution technique will be used to determine the mix of carousels needed to meet the budget of $\$ 363,000$. There need to be enough carousels to consolidate all Production and Engineering products. J and F Stores products will be consolidated later due to cost constraint for the fiscal year and the time table of systems migration of these stores into a single Warehouse Management System (WMS). The first step in a Linear Program problem is to determine the Objective Function ( $\mathrm{Z}$ ). In this case one wants to minimize the cost of purchasing two different types of carousels. The two different type of carousels are defined to be the Decision Variables where $\mathrm{X} 1$ is the number of 48 foot carousels and $\mathrm{X} 2$ is the number of 60 foot carousels. This will derive the Objective Function to be and shown in Figure 26 by using Equation 9: 
Equation 9. Minimize $\mathrm{Z}=42,000 * \mathrm{X} 1+63,000 * \mathrm{X} 2$

Where the cost of $x 1$ is $\$ 42,000$ with 40 carriers and $x 2$ is $\$ 63,000$ with 50 carriers

\begin{tabular}{|c|c|}
\hline \multirow[t]{2}{*}{ Objective Function: } & Minimize cost of purchasing carousels \\
\hline & Minimize $\quad Z=42000 \times 1+63000 \times 2$ \\
\hline Decision Variables: & Amount of $48 \mathrm{ft}$. \& $60 \mathrm{ft}$. carousels \\
\hline & $\begin{array}{lll}\mathrm{x} 1 & =\quad \# \text { of } 48 \mathrm{ft} . \text { carousels } \\
\mathrm{x} 2 & =\quad \text { \# of } 60 \mathrm{ft} \text {. carousels }\end{array}$ \\
\hline
\end{tabular}

Figure 26.

The Objective Function and Decision Variables.

The next step is to determine the constraints. The constraints are as follows and shown in

\section{Figure 27:}

- The number of carriers needs to be no less than 284 from the calculation from Figure 24 for Production and Engineering products

- The cost shall not exceed $\$ 363,000$

- The number of carousels is 6 from Figure 24

\begin{tabular}{|c|c|c|c|}
\hline Constraints: & \multirow{2}{*}{$\begin{array}{r}\text { Carriers Needed } \\
40 \times 1+50 \times 2\end{array}$} & \multirow{2}{*}{$\begin{array}{l}= \\
=\end{array}$} & \multirow{2}{*}{$\begin{array}{l}284 \\
284\end{array}$} \\
\hline & & & \\
\hline & \multirow[t]{2}{*}{ Carousels } & $=$ & \\
\hline & & $=$ & 6 \\
\hline & \multirow{2}{*}{$\begin{array}{l}\text { Maximum Spending } \\
42000 \times 1+63000 \times 2\end{array}$} & $=$ & $\$ 363,000$ \\
\hline & & $\leq$ & $\$ 363,000$ \\
\hline
\end{tabular}

Figure 27.

The constraints for the Objective Function.

The Linear Program Equation is developed using a Microsoft add on called Excel Solver to determine the optimal mix of carousels. The output is shown in Figure 28. The Linear Program Equation derives that the optimal mix of carousels to obtain at least 284 carriers while keeping the cost under $\$ 363,000$ is five 60 feet carousels and one 48 feet carousel. The entire spreadsheet is shown in Figure 29. 


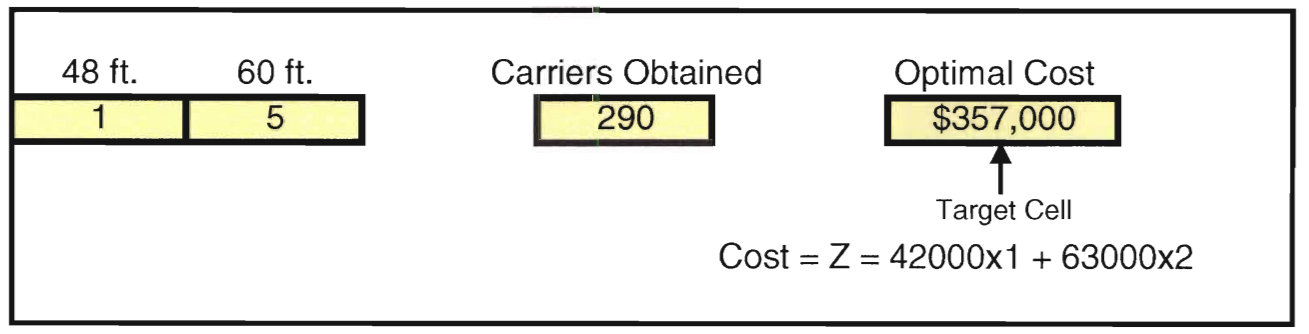

Figure 28.

The Linear Program Equation with Microsoft Solver derived numbers.

Although the equation states that the optimal mix of carousels are five 60 foot and one 48 foot, due to aesthetic and expected growth the author decided to procure six 60 feet carousels for Production and Engineering products in El Segundo. The author convinced the team to procure six 60 foot horizontal carousels, but another concern arrives: How will a store clerk know which standard tote type is needed for which parts as it arrives from Receiving? The author decided to develop a tote template to create an efficient flow of products to store in the carousels.

OPTIMAL CAROUSELS OPERATIONS RESEARCH PROBLEM

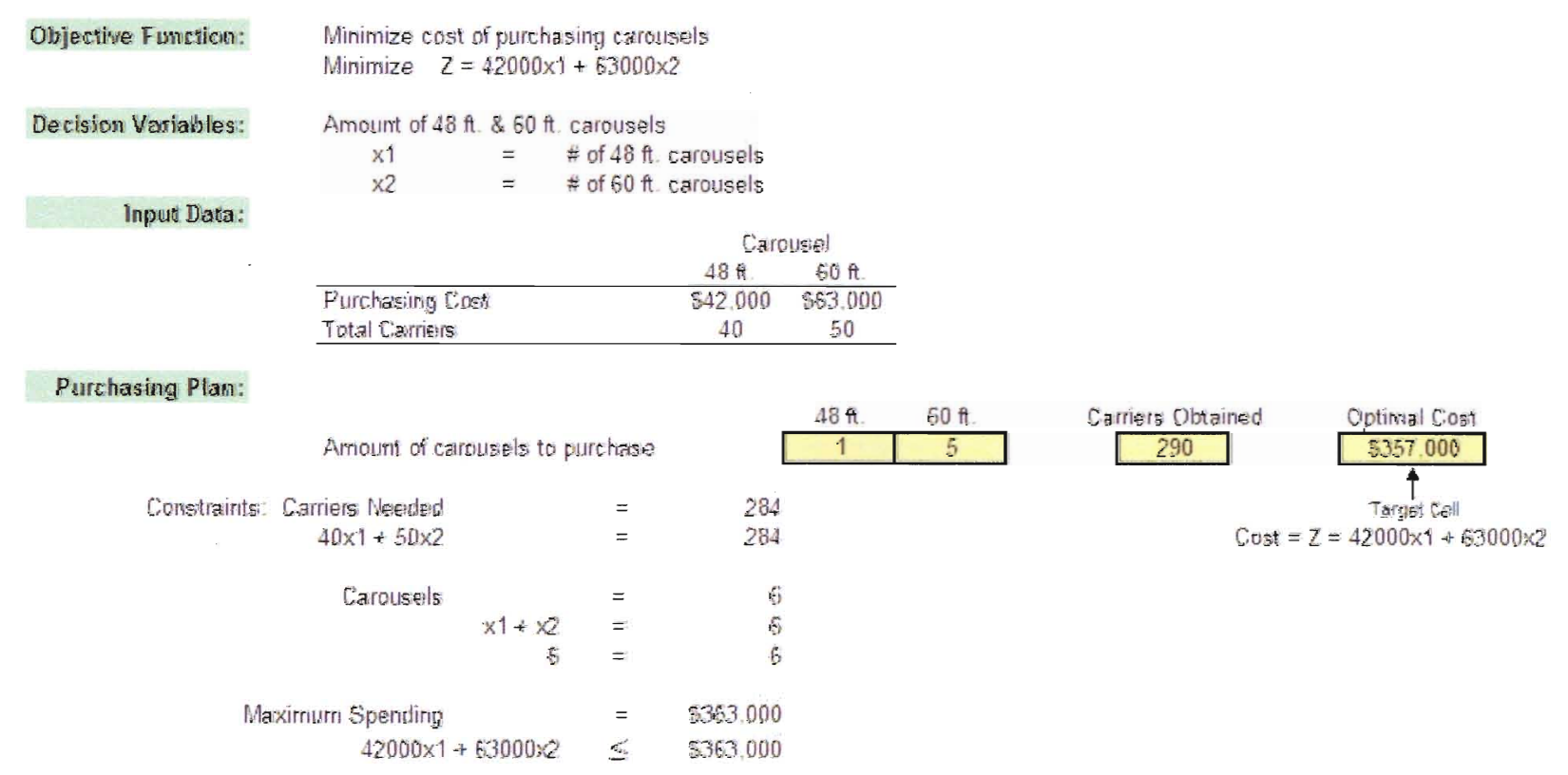

Figure 29.

The Operations Research spreadsheet. 


\section{Quantitative Analysis VI}

\section{Improving Storage Process Flow}

Referring back to the current warehouse storage configuration, the process was cumbersome and time consuming due to lengthy operator travel time in order to store the products. Also, due to the "library" storage concept of the parts, new products are painfully stored by shifting all the parts from top to down and left to right shown in Figure 7. A new storing concept is needed to be efficient. First, the carousels are layout into configuration known as a Pod, which consists of 2 carousels per store clerk as shown in Figure 30. Instead of the store clerk walking to the storage location, the storage location will automatically rotate to the clerk. The clerk worked on one carousel while the other one rotated to the next part to be pulled or put away. This concept was studied and documented in an academic journal to prove efficiency (Meller and Klote, 2004). The store clerk used barcode technology to make sure the correct products are pulled instead of reading the alpha numeric part number preventing transcription errors. With the new storing process the cycle time and part number error improve tremendously.

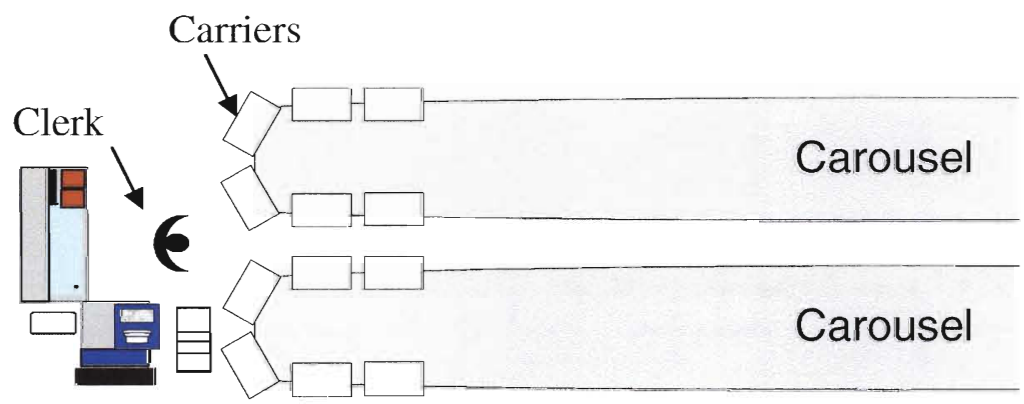

Figure 30.

A schematic of a Carousel POD.

First the clerk will take the products from RIT and place them on a tote type template shown in Figure $\mathbf{3 1}$ with standard sizes derived from the random sampling 
study. The clerk will place the part on the template to determine the tote size that will be entering into the Warehouse Management System (WMS). Once the tote size is entered, the carousel will automatically rotate to the closest open location with the specified tote size. The clerk will then store the parts in the location and scan the location barcode with the part's barcode. The new put away process is shown on Figure 32.

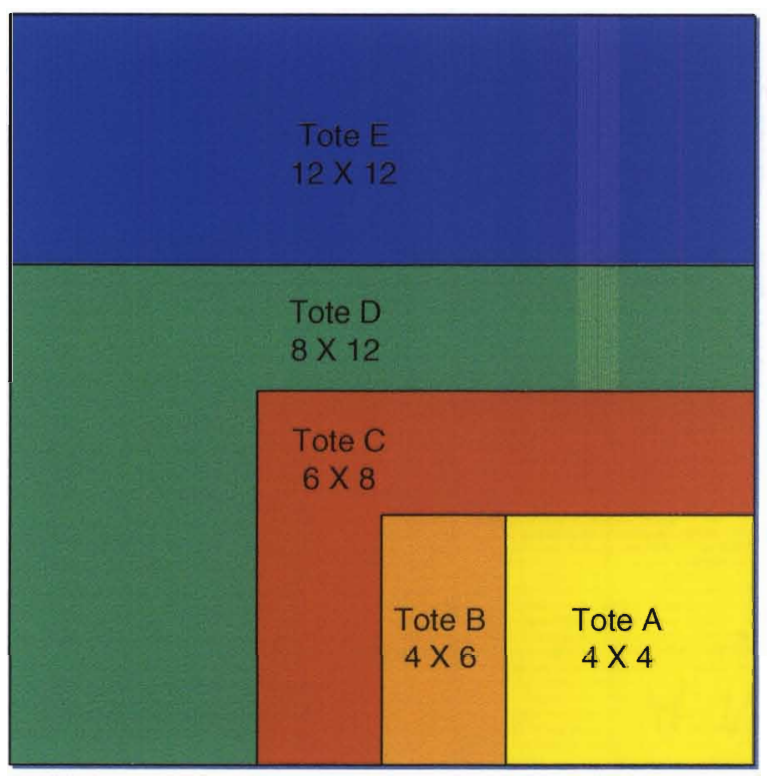

Figure 31.

An example of a standardize tote template place on the store clerk's workstation.

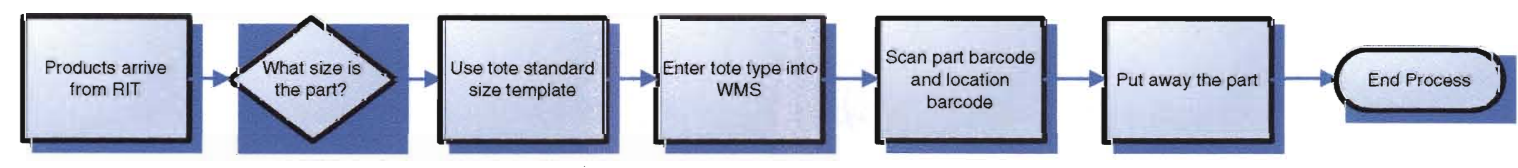

Figure 32.

A process flow of the new storage with carousel and partition.

Developing this new process dramatically improves the productivity of the warehouse.

Total cycle time to retrieve a part and assemble into a kit has improved from $50 \mathrm{hrs}$ to $0.25 \mathrm{hr}$. The total throughput for a product transacted more than quadrupled. Conducting the study and using the algorithm provided a systematic approach to reduce valuable real estate and eliminate redundant work. Most importantly, the customers are now receiving all required parts within a kit due to the new process, whereas; previously they were 
executing the work hoping the parts would come in time for the next assembly. This improves the overall productivity of the company. The final step in the algorithm is to execute the consolidation of warehouses once a practitioner completes the steps in the algorithm shown on Figure 33. The actual execution of consolidation is not within scope of this thesis and will not be discussed.

Figure 33.

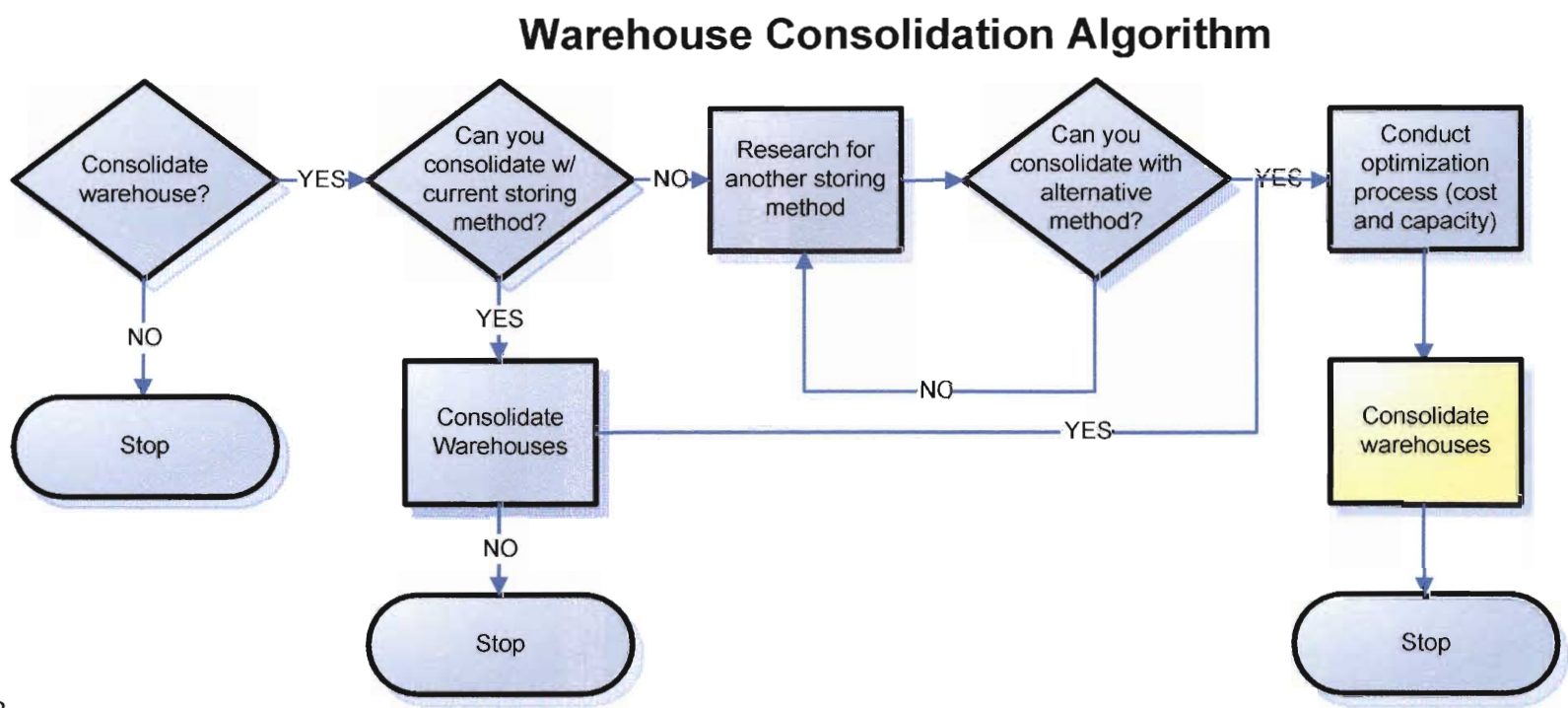

The final step in the algorithm is to consolidate the warehouses. 


\section{$\underline{\text { CHAPTER } 6}$}

\section{THE RESULTS}

At the beginning of the thesis case study the objective was to consolidate all warehouses to a single location to reduce cost and improve efficiency. Originally, the data shows the current capacity is 2.40 unique part numbers for every square foot of available space. The warehouse now can hold 5.51 available locations for every square foot after the consolidation and the process are improved dramatically. This is more than twice the capacity that was consumed before the effort. Not only is the warehouse storing parts more efficiently as shown by the data from the WMS on Figure 29, the process has improved dramatically as well. One can see that the average parts pick and issue from the warehouse has improved dramatically since the consolidation with the new WMS in place. The company realized a savings of over $\$ 1.4$ million in real estate and labor savings through this effort. Most importantly, the company can position itself for future growth while controlling cost.

\begin{tabular}{|l|l|l|l|}
\hline & Dec 03 & Dec 05 & Impact \\
\hline Parts per square foot & 2.4 & 5.51 & $\begin{array}{l}56.54 \% \\
\text { reduction }\end{array}$ \\
\hline \# of picks/ day & 78 picks & 335 picks & $+4 \mathrm{X}$ \\
\hline $\begin{array}{l}\text { Real estate savings } \\
\text { (square footage) }\end{array}$ & 43,501 & 22,750 & $\begin{array}{l}20,751 \text { extra } \\
\text { square foot }\end{array}$ \\
\hline Cycle time per kit & $50 \mathrm{hr}$ & $.25 \mathrm{hr}$ & $99 \%$ reduction \\
\hline $\begin{array}{l}\text { Capacity consume } \\
\text { ( } 80 \% \\
\text { observation }\end{array}$ & $\begin{array}{l}65 \% \\
\text { WMS data }\end{array}$ & $\begin{array}{l}23 \% \text { capacity } \\
\text { improvements }\end{array}$ \\
\hline $\begin{array}{l}\text { Savings impact: } \\
\$ 1.4 \mathrm{M} \text { in real estate and labor savings } \\
\$ 756 \mathrm{~K} \text { in mitigated cost of incur capital (12 carousels) }\end{array}$ \\
\hline
\end{tabular}

Figure 29.

A matrix of performance results from the algorithm. 


\section{$\underline{\text { CHAPTER } 7}$ \\ CONCLUSION}

Real estate is at a premium and optimal usage of the available area is a competitive advantage to a company. Due to mergers and acquisitions a company can allocate and use real estate poorly. The purpose of this thesis was to examine traditional storage methods, identify opportunity areas and document the process to optimally use real estate in order to gain a competitive advantage. An algorithm is developed in this thesis utilizing several quantitative analyses to efficiently and optimally consolidate warehouses.

Raytheon Space and Airborne Systems division headquarter in El Segundo, CA was used as a test bed for the algorithm. The facilities to warehouse products are across the corridor due to recent mergers and acquisition and poor warehouse performance. The solution was to consolidate the warehouses in order to reduce real estate and redundant work cost. It also would provide better control of resources and service requests. The algorithm developed in the thesis consists of a series of quantitative analyses in order to optimize the execution of consolidation. The literature review does not provide any evidence of this type of algorithm for this application. Different concepts and research are put together to develop the algorithm.

The proposed algorithm consists of five steps asking distinct questions in order to move forward. The main questions from the algorithm are:

1. Do you want to consolidate?

2. Can you consolidate with the current storage method?

3. Can you consolidate with an alternative method?

4. Conduct an optimization process for cost and capacity.

5. Consolidate warehouses. 
Within these questions are several quantitative analyses to determine the next step. The analyses consist of statistical inferences from basic arithmetic to linear programming. It will enable a practitioner to decide if one can consolidate. Consolidating warehouses take a lot of resources and investments. The proposed algorithm will help provide a detailed study for managers and leaders to make a sound decision.

The algorithm was tested and found extraordinary results. The algorithm provided the reduction of material handling costs and enabled denser storage of material. It also provided better throughput and visibility by identifying parts and their corresponding locations quickly, reducing search time. Consolidating warehouses enabled the company to utilize real estate more efficiently. The case study from Raytheon showed that the warehouse more than doubles its capacity while improving productivity. Most importantly, this positions the company for growth and provided a competitive advantage.

In conclusion, the algorithm was successfully implemented in a Fortune 500 company to demonstrate the analytical applications. The case study provided improving metrics which are a result of the detailed study from the algorithm. The proposed algorithm can be applied to any company where warehouse consolidation is needed and the parts are not on pallets. The storage optimization for bulk, environmental need, and sensitive handling parts are not within scope of this thesis. The focus of the thesis is about parts utilized in a horizontal carousel environment. By incorporating and combining different improvement and optimization techniques, a proposed algorithm is developed. The algorithm provides a study for decision makers to optimize capacity, cost, and process in order to consolidate warehouses. 


\section{CHAPTER 8}

FUTURE RESEARCH

There are three keys area that need further research for the purpose of warehouse consolidation and optimization. The first is to develop an algorithm to consolidate warehouses that use bulk items on pallets, sensitive handling, and environment needed products. The second is to develop an efficient method to store products in a "library" shelf principle. The third is to develop a better method to quantify the efficient usage of storage in any given warehouse. These are areas that are not discussed in the thesis but should be considered for further research.

Future research can be conducted in developing an algorithm to consolidate warehouses with products that are bulk on pallets, sensitive handling, and environment needed products. The thesis focused on small electronic components that can be stored on shelves or carousels. The study took in account that bulk items and items that need to be stored in environmental control area would not be pursued. Several researches have shown bulk items can be optimized by efficient facility layouts using Linear Programming to prove the theory. Simulations are widely used to mimic the theorized layouts and the material handling flow to show improvements in throughput and reduction in traffic congestion. For the purpose of the thesis an algorithm to consolidate bulk and sensitive items are not analyzed. Better usage of bulk items can be a greater benefit because handling bulk items can be cumbersome and it takes up more space than other types of products. Consolidation of special handling and sensitive products can be a more difficult task because one has to devise a plan to ensure the safety of the products 
during transit. Also, it will need to require special handling equipment that may not be cost effective to relocate due to facility infrastructure. Further research is needed for these types of products.

During the development of the algorithm, the process to find another efficient storage method can cycle. However, if a storage method such as using partitions or carousels is not cost effective, one needs to find a better method to store products in a "library" shelving convention. The "library" shelving convention is used because it is the easiest way to store and locate a products alpha numeric. Through time this process can cause inefficiency due to new products and the travelling time to retrieve and store the products. A study is needed to understand if there is a better method to store products on shelves and retrieve the products quicker.

The third topic of future research can be in developing a mechanism to quantify the density in the warehouse using shelving mechanism. In the case study, the density in the warehouse is determined by two methods 1) determining the numbers of parts per square foot and 2) qualitative analysis of which shelves are open for storage. These two methods have flaws. The first method provides number of parts per square foot but does not tell the volume of space the products consume. The second method provides a good gauge of which shelves on a layout are consumed and which are free. However, this method does not allow accurate quantification of the available space. Determining the density of a warehouse can be tedious if one measures and analyzes each shelf. Therefore, more research is needed in this field to efficiently and accurately determine the density of a warehouse. 


\section{REFERENCES}

Bartholdi, John J. and Gue, Kevin R. 2000 "Reducing Labor Costs in an LTL Cross docking Terminal." Operations Research v48, n 6, Nov-Dec 2000 pp 823-832.

Bartholdi, John J. and Gue, Kevin R. 2004 "The best shape for a crossdock." Transportation Science. V38, n 2, May 2004 pp 235-245.

Bartlett, James E. Kotrlik, Joe W. and Higgins, Chadwick C. 2001 "Organizational Research: Determining Appropriate Sample Size in Survey Research." Information Technology, Learning, and Perfromance. V19, n 1, Spring 2001 pp $43-50$.

Brockmann, Thompson. and Godin, Patty. 1997 "Flexibility for the future in warehouse design.” IIE Solutions. V29, n 7, July 1997 pp 22-26.

Choi, Joongkyu. Cao, J. James. Romejin, H. Edwin. Geunes, Joseph. and Bai, Sherman X. 2005 "A stochastic multi-item inventory model with unequal replenishment intervals and limited warehouse capacity." IIE Transactions. V37, n 12, Dec 2005 pp 1129-1142.

Devore, Jay and Nicholas Farnum. 1999. Applied Statistics for Engineers and Scientists. Pacific Grove, CA: Brooks/ Cole Publishing Company.

Gademann, Noud. and Van de Velde, Steef. 2005 "Order batching to minimize total travel time in a parallel-aisle warehouse." IIE Transactions. V37, n 1, Jan 2005 pp 63-76.

Gue, Kevin R. 2006 "Very high density storage systems." IIE Transactions v38 n 10. June 2006 pp 93-104.

Gue, Kevin R. 2001 “A dynamic distribution model for combat logistics." Graduate $\underline{\text { School of Business \& Public Policy, Naval Postgraduate School. }}$

Gue, Kevin and Kim, Byung Soo. 2007 "Puzzle-Based Storage Systems." Wiley InterScience DOI 10.1002/nav.20230. Jan 2007.

Gue, Kevin. R. Meller, Russell D. and Skufca, Joseph D. 2006 "The effects of pick density on order picking areas with narrow aisles." IIE Transactions v38 n 10. Oct 2006 pp 859-869.

Hsieh, Ling-feng. and Tsai, Lihui. 2006 "The optimum design of a warehouse system on order picking efficiency." International Journal Advance Manufacturing Technology. V28, May 2006 pp 626-637. 
Hariga, Moncer A. and Jackson, Peter L. 1996 "The warehouse scheduling problem: formulation and algorithms." IIE Transactions. V28, n 2, Feb 1996 pp 115-128.

Kiemele, Mark J. Schmidt, Stephen R. and Berdine, Ronald J. 2000. Basics Statistics: Tools for Continuous Improvement. Colorado Springs, CO: Air Academy Press \& Associates, LLC.

Larson, T. Nick. and March, Heather and Kusiak, Andrew. 1997 "A heuristic approach to warehouse layout with class-based storage." IIE Transactions. V29, n 4, April 1997 pp 337-349.

Manzini, Riccardo. Gameri, Mauro. and Regattieri, Alberto. 2006 "Design and control of an AS/RS.” International Journal Advance Manufacturing Technology. V28, 2006 pp 766-774.

Meller, Russell D. and Klote, John F. 2004 "A throughput model for carousel/ VLM pods." IIE Transactions. V36, n 8, August 2004 pp 725-747.

Napolitano, Maida. 2003 "Better layout = Higher Throughput: to squeeze more throughput out of your warehouse, consider these factors when designing or reconfiguring a facility." Logistics Management. V42, n 5, May 2003 pp 57-61.

Niebel, Benjamin. and Freivalds, Andris. 1999. Methods Standards and Work Design $10^{\text {th }}$ Edition: The McGraw-Hills company.

Roodbergen, Kees Jan. and Vis, Iris F.A. 2006 "A model for warehouse layout." IIE Solutions. V29, n 7, July 1997 pp 22-26.

Rother, Michael and Shook, John. 1999 Learning to See: Value Stream Mapping to add value and eliminate muda: Boston, MA. USA. Lean Enterprise Institute, Inc

Scheaffer, Richard. Mendenhall III, Richard L. and Ott, R. Lyman. 2006. Elementary

Survey Sampling $6^{\text {th }}$ Edition. Belmont, CA: Thomson Higher Education Publishing Company.

Sargent, Tiffany A. and Kay, Michael G. 1995 "Implementation and utilization of a decentralized storage system: costing model.” International Journal of Operations \& Production Management. V15, n 9, Sep 1995 pp 210-220.

Tompkins, James A. White, John A. Bozer, Yavuz A. Frazelle, Edward H. Tanchoco, J. M. A. and Trevino, Jaime. 1996. Facilities Planning $2^{\text {nd }}$ Edition. United States: John Wiley \& Sons, Inc.

Winston, Wayne L. 1994. Operations Research Applications and Algorithms $3^{\text {rd }}$ Edition: Belmont, CA: Duxbury Press. 


\section{APPENDIX}

\section{SCENARIO \#1 (WITH STOCK AND ORDERS)}

\begin{tabular}{lr|}
\hline 50-Carrier Carousel & \\
\hline Total Carrier/Carousel & 50 \\
Carrier Height & 97 \\
Carrier Width & 24.5 \\
Carner Depth & 24 \\
Shelf Height & 4 \\
Shelf Height w/Clearance & 6.0625 \\
Total Shelf/Carrier & 16
\end{tabular}

\begin{tabular}{|c|c|c|c|c|c|c|c|}
\hline Tote Type & $\mathbf{A}$ & B & $\mathrm{C}$ & $\mathrm{D}$ & $\mathbf{E}$ & $\mathbf{F}$ & G \\
\hline Tote Size $(W \times D \times H)$ & $4 \times 4 \times 4$ & $4 \times 6 \times 4$ & $6 \times 8 \times 4$ & $8 \times 12 \times 4$ & $12 \times 12 \times 4$ & $12 \times 24 \times 4$ & $24 \times 24 \times 4$ \\
\hline Count & 214 & 264 & 136 & 204 & 146 & 105 & 18 \\
\hline Percent Mix of Totes & $19.2 \%$ & $23.7 \%$ & $12.2 \%$ & $18.3 \%$ & $13.1 \%$ & $9.4 \%$ & $1.6 \%$ \\
\hline Locations/Tote & 6 & 4 & 3 & 2 & 2 & 1 & 1 \\
\hline Locations/Shelf & 36 & 24 & 12 & 6 & 4 & 2 & 1 \\
\hline Locations/Carrier & 110 & 91 & 23 & 17 & 8 & 3 & 0.26 \\
\hline Total Storage Locations/Carrier & \multicolumn{7}{|c|}{252} \\
\hline Locations/Carousel & 5537 & 4554 & 1173 & 879 & 419 & 150 & 12 \\
\hline Total Storage Locations/Carousel & \multicolumn{7}{|c|}{12724} \\
\hline
\end{tabular}

\# of Carriers Needed:

\begin{tabular}{|l|l}
\hline$*$ Total carnier storage locations needed & 71,550
\end{tabular}

\begin{tabular}{|l|r}
\hline Total carrier storage locations available & 252 \\
\hline
\end{tabular}

\begin{tabular}{|l|l}
\hline Total carriers needed & 283.6 \\
\hline
\end{tabular}

\# of Carousels Needed:

\begin{tabular}{|r|r|}
\hline$* *$ Total horizontal carousel storage locations needed & 71,550 \\
\hline
\end{tabular}

\begin{tabular}{|l|c|}
\hline Total horizontal carousel storage locations available & 12,724 \\
\hline
\end{tabular}

\begin{tabular}{|l|c}
\hline Total carousels needed & 5.6 \\
\hline
\end{tabular}

** Total of ICS $(50,171)$ and ECS $(12,898)$ inventory 


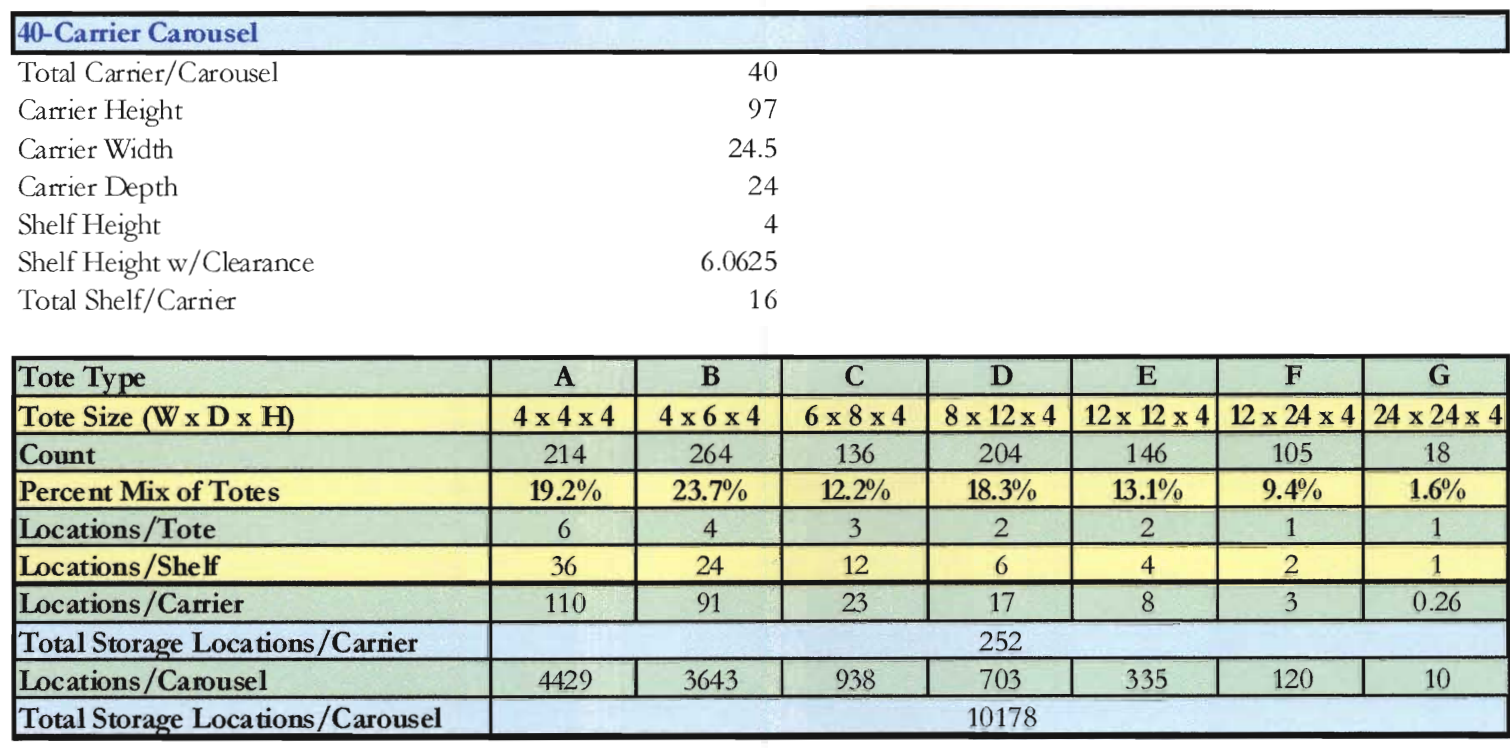

\# of Carousels Needed:

\begin{tabular}{|l|l|}
\hline *Total horizontal carousel storage locations needed & 71,550 \\
\hline
\end{tabular}

\begin{tabular}{|l|c}
\hline Total horizontal carousel storage locations available & 10,178
\end{tabular}

\begin{tabular}{|l|c}
\hline Total carousels needed & 7.0
\end{tabular}

\begin{tabular}{|l|c|c|}
\hline & 50-Carrier Carousel & 40-Carrier Carousel \\
\hline Total Carrier/Carousel & 50 & 40 \\
\hline Carrier Height & 97 & 97 \\
\hline Carrier Width & 24.5 & 24.5 \\
\hline Carrier Depth & 24 & 24 \\
\hline Shelf Height & 4 & 4 \\
\hline Shelf Height w/Clearance & 6.0625 & 6.0625 \\
\hline Total Shelf/Carrier & 16 & 16 \\
\hline
\end{tabular}




\begin{tabular}{|c|c|c|c|}
\hline & Carriers Needed & $\begin{array}{l}\text { Carousels Needed } \\
\text { from calculations }\end{array}$ & $\begin{array}{c}\text { Carousels Needed to } \\
\text { procure } \\
\end{array}$ \\
\hline F Stores & 74.9 & 1.5 & 2.0 \\
\hline J Stores & 99.1 & 1.9 & 2.0 \\
\hline **Rest of Stores & 283.6 & 5.6 & 6.0 \\
\hline Total & 457.6 & 9.0 & 10.0 \\
\hline
\end{tabular}

NO'TE: Results calculated from using ICS Inventory data with stock on hand and orders already given

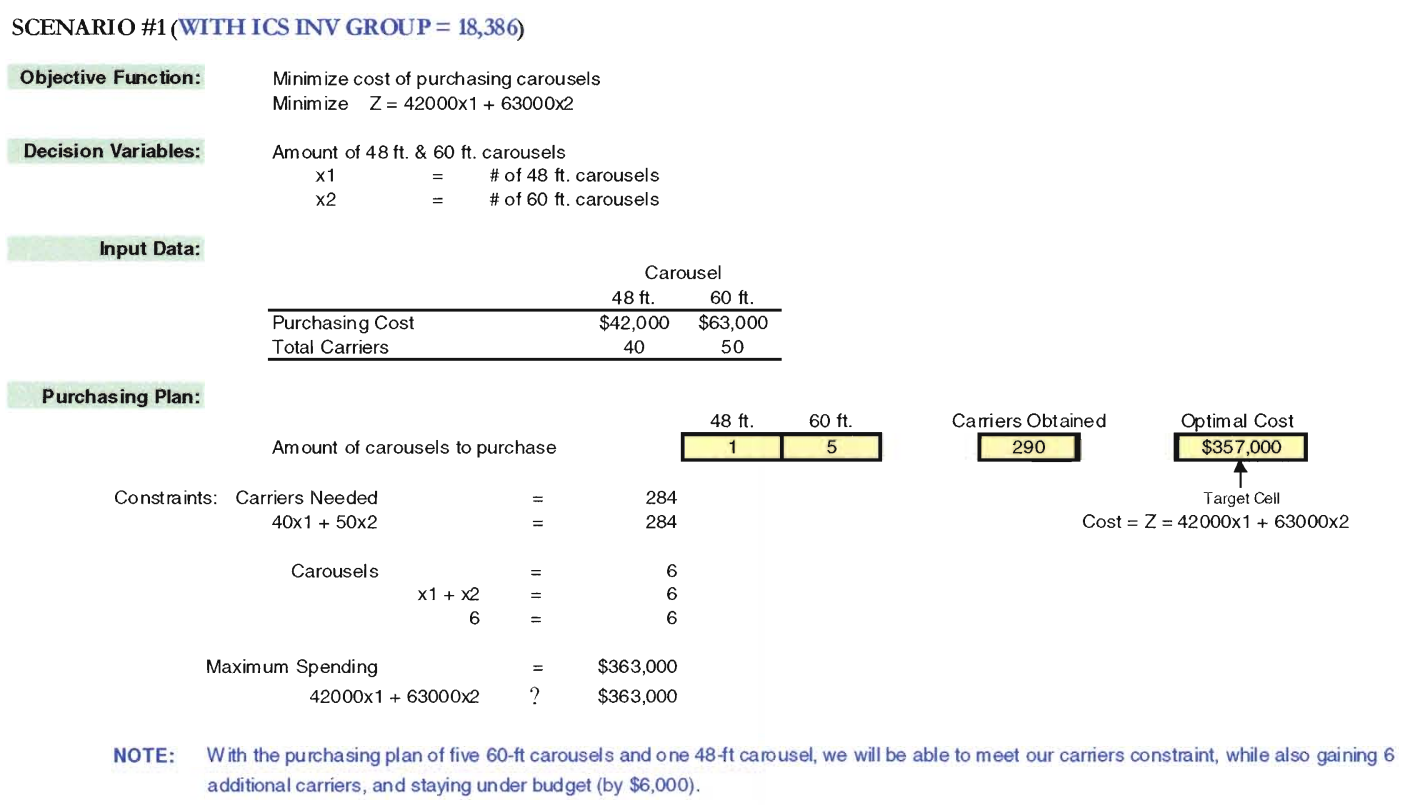




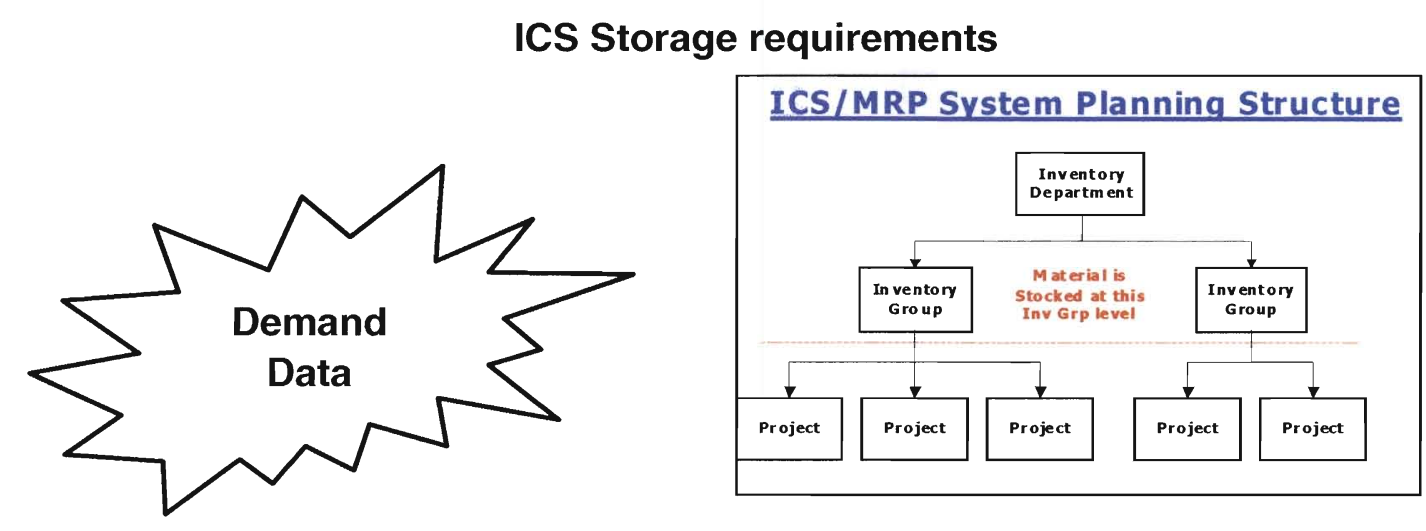

\begin{tabular}{|c|c|c|c|c|c|c|}
\hline ICS Data: & & \multicolumn{4}{|c|}{ \# of Part Numbers } & \\
\hline Inv Dept & $\begin{array}{c}\text { Program } \\
\text { Name }\end{array}$ & PRJ level & $\begin{array}{c}\text { INV GRP } \\
\text { level }\end{array}$ & $\begin{array}{l}\text { INV GRP } \\
\text { level with } \\
\text { stock } \\
\end{array}$ & $\begin{array}{l}\text { INV GRP } \\
\text { level with } \\
\text { stock or } \\
\text { orders }\end{array}$ & $\begin{array}{l}\text { INV GRP } \\
\text { level with } \\
\text { stock or } \\
\text { orders or } \\
\text { MRP }\end{array}$ \\
\hline 62 & Warehouse 1 & 25277 & 18655 & 13256 & 14678 & 18386 \\
\hline 73 & Warehouse 2 & 27661 & 15212 & 9434 & 9528 & 13213 \\
\hline 74 & Warehouse 3 & 9233 & 8266 & 5255 & 5374 & 7372 \\
\hline 75 & Warehouse 4 & 9549 & 7211 & 4872 & 4923 & 6389 \\
\hline TOTAL & Total & 71,720 & 49,344 & 32,817 & 34,503 & 45,360 \\
\hline
\end{tabular}

Horizontal Carousel storage locations (also called bin boxes or line items) required:
\begin{tabular}{|l|c|r|}
\hline Unique Part Numbers (PN, Inv Dept, Inv Grp) with stock or orders & 34,503 & 45,360 \\
\hline$\%$ that is bulk & $3 \%$ & $3 \%$ \\
\hline Unique carousel Part Numbers & 33468 & 43999 \\
\hline$\%$ or number that requires vertical carousel controlled storage (nitrogen, etc.) & $20 \%$ & $20 \%$ \\
\hline Unique horizontal carousel Part Numbers & 26774 & 35199 \\
\hline Growth factor (remember, this is hopefully offset by obsolescence) & $20 \%$ & $20 \%$ \\
\hline Horizontal carousel Part Numbers with growth & 32129 & 42239 \\
\hline Storage locations per Part Number (due to random stocking) & 1.4 & 1.4 \\
\hline Horizontal carousel storage unique locations needed & 44981 & 59135 \\
\hline Utilization factor (for efficient location of empty bin boxes when stocking) & $90 \%$ & $90 \%$ \\
\hline Total horizontal carousel storage loc ations needed & $\mathbf{4 9 , 4 7 9}$ & $\mathbf{6 5 , 0 4 8}$ \\
\hline
\end{tabular}




\section{ECS STORE SUMMARY \\ Excludes F, G, and S stores \\ For Records with Positive Stock Balances \\ Data as of February 26, 2004}

\begin{tabular}{|c|c|c|c|c|c|c|c|}
\hline & & & & & & & \\
\hline & & & & & & & \\
\hline & LINE & TOTAL & & & & & \\
\hline STORE & ITEM & STOCK & & & & & \\
\hline CODE & COUNT & VALUE & Lot & Clerks & Supervisors & & \\
\hline & & & & & & gen Purd & Bulk \\
\hline A & 147 & & & & & 1 & 0 \\
\hline$B$ & 6,440 & & & & & 112 & 235 \\
\hline$J$ & 5,776 & & & & & 45 & 27 \\
\hline Total & 12,363 & & & & & 158 & 262 \\
\hline
\end{tabular}

Horizontal Carousel storage locations (also called bin boxes or line items) required:

\begin{tabular}{|l|r|}
\hline Unique Part Numbers (PN, Inv Dept, Inv Grp) with stock or orders & 12,363 \\
\hline Number of bulk line item & 262 \\
\hline Unique carousel Part Numbers & 12101 \\
\hline Number needed vertical carousel controlled storage (nitrogen, etc.) & 158 \\
\hline Unique horizontal carousel Part Numbers & 11943 \\
\hline Growth factor (remember, this is hopefully offset by obsolescence) & $20 \%$ \\
\hline Horizontal carousel Part Numbers with growth & 14332 \\
\hline Storage locations per Part Number (due to random stocking) & 1.4 \\
\hline Horizontal carousel storage locations needed & 20064 \\
\hline Utilization factor (for efficient location of empty bin boxes when stocking) & $90 \%$ \\
\hline Total horizontal carousel storage locations needed & $\mathbf{2 2 , 0 7 1}$ \\
\hline
\end{tabular}

\section{J ST ORES}

\begin{tabular}{|c|c|c|c|c|c|}
\hline J stores & line item & value & lot numbers & clerks & supervisor \\
\hline \hline Cabinets & 13,415 & & & & \\
\hline Bulk & 3,446 & & & & \\
\hline GN2 & 2226 & & & & \\
\hline
\end{tabular}

Horizontal Carousel storage locations (also called bin boxes or line items) required:

\begin{tabular}{|l|r|}
\hline Unique Part Numbers (PN, Inv Dept, Inv Grp) with stock or orders & 13,415 \\
\hline Number that is bulk & 3446 \\
\hline Unique carousel Part Numbers & 9969 \\
\hline Number that requires vertical carousel controlled storage (nitrogen, etc.) & 2226 \\
\hline Unique horizontal carousel Part Numbers & 7743 \\
\hline Growth factor (remember, this is hopefully offset by obsolescence) & $20 \%$ \\
\hline Horizontal carousel Part Numbers with growth & 9292 \\
\hline Storage locations per Part Number (due to random stocking) & 1.4 \\
\hline Horizontal carousel storage locations needed & 13008 \\
\hline Utilization factor (for efficient location of empty bin boxes when stocking) & $90 \%$ \\
\hline Total horizontal carousel stora ge locations needed & $\mathbf{1 4 , 3 0 9}$ \\
\hline
\end{tabular}




\section{F STORES}

\begin{tabular}{|c|c|c|c|c|c|}
\hline F stores & line item & value & lot numbers & clerks & supervisor \\
\hline \hline Cabinets & 12,998 & & & & \\
\hline Bulk & 2,132 & & & & \\
\hline GN2 & 1667 & & & & \\
\hline
\end{tabular}

Horizontal Carousel storage locations (also called bin boxes or line items) required:

\begin{tabular}{|l|r|}
\hline Unique Part Numbers (PN, Inv Dept, Inv Grp) with stock or orders & 12,998 \\
\hline
\end{tabular}

\begin{tabular}{|r|r}
\hline$\%$ that is bulk & 2132 \\
\hline
\end{tabular}

\begin{tabular}{|r|r}
\hline Unique carousel Part Numbers & 10866 \\
\hline
\end{tabular}

\begin{tabular}{|r|r}
\hline Number that requires vertical carousel controlled storage (nitrogen, etc.) & 1667 \\
\hline
\end{tabular}

\begin{tabular}{|l|r|}
\hline Unique horizontal carouse I Part Numbers & 9199 \\
\hline
\end{tabular}

\begin{tabular}{|l|r|}
\hline Growth factor (remember, this is hopefully offset by obsolescence) & $20 \%$ \\
\hline
\end{tabular}

\begin{tabular}{|r|r}
\hline Horizontal carousel Part Numbers with growth & 11039 \\
\hline
\end{tabular}

\begin{tabular}{|r|r}
\hline Storage locations per Part Number (due to random stocking) & 1.4 \\
\hline
\end{tabular}

\begin{tabular}{|r|r|}
\hline Horizontal carousel storage locations needed & 15454 \\
\hline
\end{tabular}

\begin{tabular}{|l|r}
\hline Utilization factor (for efficient location of empty bin boxes when stocking) & $90 \%$ \\
\hline
\end{tabular}

\begin{tabular}{|lr|}
\hline Total horizonta l carousel stora ge locations needed & 17,000 \\
\hline
\end{tabular} 


\section{ICS Storage requirements}

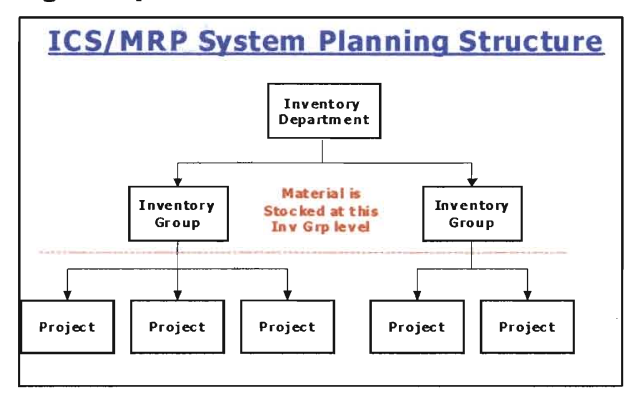

\begin{tabular}{|c|c|c|c|c|c|c|}
\hline ICS Data: & & \multicolumn{4}{|c|}{$\#$ of Part Numbers } & \\
\hline Inv Dept & $\begin{array}{c}\text { Program } \\
\text { Name }\end{array}$ & PRJ level & $\begin{array}{c}\text { INV GRP } \\
\text { level }\end{array}$ & $\begin{array}{l}\text { INV GRP } \\
\text { level with } \\
\text { stock }\end{array}$ & $\begin{array}{l}\text { INV GRP } \\
\text { level with } \\
\text { stock or } \\
\text { orders }\end{array}$ & $\begin{array}{l}\text { INV GRP } \\
\text { level with } \\
\text { stock or } \\
\text { orders or } \\
\text { MRP }\end{array}$ \\
\hline 85 & R24 Centr: & 25277 & 18655 & 13256 & 14678 & 18386 \\
\hline 88 & ATFLIR & 27661 & 15212 & 9434 & 9528 & 13213 \\
\hline 98 & EPPS & 9233 & 8266 & 5255 & 5374 & 7372 \\
\hline 99 & R23 Fabs & 9549 & 7211 & 4872 & 4923 & 6389 \\
\hline TOTAL & & 71,720 & 49,344 & 32,817 & 34,503 & 45,360 \\
\hline
\end{tabular}

\begin{tabular}{|l|c|}
\hline Horizontal Carousel storage locations (also called bin boxes or line items) required: \\
\hline Unique part numbers & 34,503 \\
\hline Percentage that is bulk & $3 \%$ \\
\hline Unique carousel part numbers without bulk & 33468 \\
\hline Percentage that requires special storage (environmental, sensitive, etc.) & $20 \%$ \\
\hline Unique carousel part numbers w/o bulk and environmental need & 26774 \\
\hline Potential growth factor & $20 \%$ \\
\hline Horizontal carousel part numbers with growth & 32129 \\
\hline Storage locations per part number through time factor & 1.4 \\
\hline Horizontal carousel storage unique locations needed & 44981 \\
\hline Utilization factor (for efficient location of empty bin boxes when stocking) & $90 \%$ \\
\hline Total horizontal carousel storage locations needed & 49.479 \\
\hline
\end{tabular}

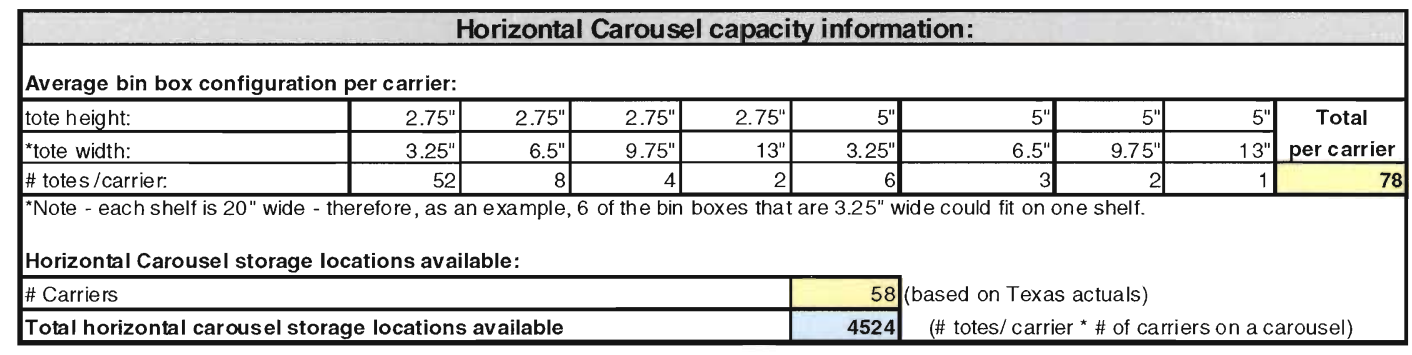

\# of carousels needed:

Total horizontal carousel storage locations needed

Total horizontal carousel storage locations available

Total carouse Is needed 


\section{ECS STORE SUMMARY}

Excludes F, G, and $S$ stores

For Records with Positive Stock Balances

Data as of February 26, 2004

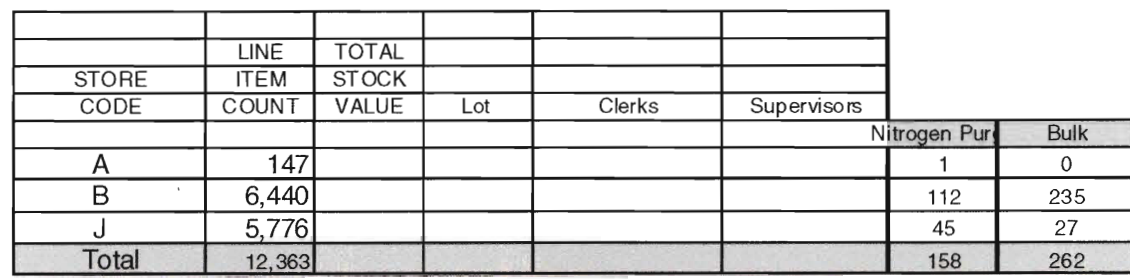

Horizontal Carousel storage locations (also called bin boxes or line items) required:

\begin{tabular}{|l|r|}
\hline Unique Part Numbers (PN, Inv Dept, Inv Grp) with stock or orders & 12,363 \\
\hline Number of bulk line item & 262 \\
\hline Unique carousel Part Numbers & 12101 \\
\hline$\%$ needed vertical carou sel controlled storage (nitrogen, etc.) & 158 \\
\hline Unique horizontal carousel Part Numbers & 11943 \\
\hline Growth factor (remember, this is hopefully offset by obsolescence) & $20 \%$ \\
\hline Horizontal carousel Part Numbers with growth & 14332 \\
\hline Storage locations per Part Number (due to random stocking) & 1.4 \\
\hline Horizontal carousel storage locations needed & 20064 \\
\hline Utilization factor (for efficient location of empty bin boxes when stocking) & $90 \%$ \\
\hline Total horizontal carousel storage locations needed & 22,071 \\
\hline
\end{tabular}

Horizontal Carousel capacity information:

Dimensions/specifications (based on McKinney carousels):

\begin{tabular}{|l|l|}
\hline Total length & $60 \mathrm{ft}$. \\
\hline Total width & $5 \mathrm{ft} .4 \mathrm{in}$. \\
\hline Total height & $8 \mathrm{ft} .8 \mathrm{in}$. \\
\hline Total height (top of track) & $9 \mathrm{ft} .8 \mathrm{in}$. \\
\hline Total height (including motor, mechanical, etc.) & $12 \mathrm{ft} .8 \mathrm{in}$. \\
\hline
\end{tabular}

Average bin box configuration per rack/carrier:

\begin{tabular}{|c|c|c|c|c|c|c|c|c|c|}
\hline bin box height: & $2.75^{4}$ & $2.75^{\prime \prime}$ & $2.75^{\mathrm{N}}$ & $2.75^{\prime \prime}$ & $5^{n}$ & $5^{\prime \prime}$ & $5^{\prime \prime}$ & $5^{\prime \prime}$ & Total \\
\hline "bin box width: & $3.25^{\prime \prime}$ & $6.5^{n}$ & $9.75^{\prime \prime}$ & $13^{\prime \prime}$ & $3.25^{\prime \prime}$ & $6.5^{\prime \prime}$ & $9.75^{\prime \prime}$ & $13^{\prime \prime}$ & per rack \\
\hline \# bin boxes/carrier: & 52 & 8 & 4 & 2 & 6 & 3 & 2 & 1 & 78 \\
\hline
\end{tabular}

\# bin boxes/carrier

"Note - each shelf is 20 " wide - therefore, as an example, 6 of the bin boxes that are $3.25^{\prime \prime}$ wide could fit on one shelf.

Also, the widths of all bin boxes are multiples of $3.25^{\prime \prime}$, so one $6.5^{\prime \prime}$ wide bin box can be removed and replaced with

two $3.25^{\prime \prime}$ wide bin boxes.

Horizontal Carousel storage locations available:

\begin{tabular}{|l|r|}
\hline \# Carriers & 58 (based on McKinney actuals) \\
\hline Shelves per carrier & 19 \\
\hline Avg locations (bin boxes) per shelf & 4.1 \\
\hline Total bin boxes per carousel & 4524 \\
\hline \# of divided compartments per bin box & 1 \\
\hline Total horizontal carousel storage locations available & 4524 \\
\hline
\end{tabular}

\# of carousels needed:

\begin{tabular}{|l|r|}
\hline Total horizontal carousel storage locations needed & 22,071 \\
\hline Total horizontal carousel storage locations available & 4524 \\
\hline
\end{tabular}

\begin{tabular}{|l|r|}
\hline Total carousels needed & 5 \\
\hline
\end{tabular} 


\begin{tabular}{|c|c|c|c|c|c|}
\hline F stores & line item & value & lot numbers & clerks & supervisor \\
\hline \hline Cabinets & 12,998 & $\$ 10,779,497.00$ & & & \\
\hline Bulk & 950 & $\$ 6,542,293.00$ & & & \\
\hline GN2 & 133 & $\$ 19,283.00$ & & & \\
\hline
\end{tabular}

Horizontal Carousel storage locations (also called bin boxes or line items) required:

\begin{tabular}{|l|r|}
\hline Unique Part Numbers (PN, Inv Dept, Inv Grp) with stock or orders & 12,998 \\
\hline$\%$ that is bulk & 2132 \\
\hline Unique carousel Part Numbers & 10866 \\
\hline Number that requires vertical carousel controlled storage (nitrogen, etc.) & 1667 \\
\hline Unique horizontal ca rousel Part Numbers & 9199 \\
\hline Growth factor (remember, this is hopefully offset by obsolescence) & $20 \%$ \\
\hline Horizontal carousel Part Numbers with growth & 11039 \\
\hline Storage locations per Part Number (due to random stocking) & 1.4 \\
\hline Horizontal carousel storage locations needed & 15454 \\
\hline Utilization factor (for efficient location of empty bin boxes when stocking) & $90 \%$ \\
\hline Total horizontal carousel storage locations needed & 17,000 \\
\hline
\end{tabular}

Horizontal Carousel capacity information:

Dimensions/specifications (based on McKinney carousels):

\begin{tabular}{|l|l|}
\hline Total length & $60 \mathrm{ft}$. \\
\hline Total width & $5 \mathrm{ft} .4 \mathrm{in}$. \\
\hline Total height & $8 \mathrm{ft} .8 \mathrm{in}$. \\
\hline Total height (top of track) & $9 \mathrm{ft} .8 \mathrm{in}$. \\
\hline Total height (including motor, mechanical, etc.) & $12 \mathrm{ft} .8 \mathrm{in}$. \\
\hline
\end{tabular}

Average bin box configuration per rack/carrier:

\begin{tabular}{|l|r|r|r|r|r|r|r|r|r|}
\hline bin box height: & $2.75^{\prime \prime}$ & $2.75^{\prime \prime}$ & $2.75^{\prime \prime}$ & $2.75^{\prime \prime}$ & $5^{\prime \prime}$ & $5^{\prime \prime}$ & $5^{\prime \prime}$ & $5^{\prime \prime}$ & Total \\
"bin box width: & $3.25^{\prime \prime}$ & $6.5^{\prime \prime}$ & $9.75^{\prime \prime}$ & $13^{\prime \prime}$ & $3.25^{\prime \prime}$ & $6.5^{\prime \prime}$ & $9.75^{\prime \prime}$ & $13^{\prime \prime}$ & perk \\
\hline \# bin boxes/carrier: & 52 & 8 & 4 & 2 & 6 & 3 & 2 & 1 & 78 \\
\hline
\end{tabular}

*Note - each shelf is $20 "$ wide - therefore, as an example, 6 of the bin boxes that are $3.25^{\prime \prime}$ wide could fit on one shelf.

Also, the widths of all bin boxes are multiples of $3.25^{\prime \prime}$, so one $6.5^{\prime \prime}$ wide bin box can be removed and replaced with

two 3.25 " wide bin boxes.

Horizontal Carousel storage locations available:

\begin{tabular}{|l|r|}
\hline \# Carriers & 58 (based on McKinney actuals) \\
\hline Shelves per carrier & 19 \\
\hline Avg locations (bin boxes) per shelf & 4.1 \\
\hline Total bin boxes per carousel & 4524 \\
\hline \# of divided compartments per bin box & 1 \\
\hline Total horizontal carousel storage locations available & $\mathbf{4 5 2 4}$ \\
\hline
\end{tabular}

\# of carousels needed:

\begin{tabular}{|l|r|}
\hline Total horizontal carousel storage locations needed & 17,000 \\
\hline Total horizontal carousel storage locations available & 4524 \\
\hline Total carousels needed & 4 \\
\hline
\end{tabular}




\begin{tabular}{|c|c|c|c|c|c|}
\hline J stores & line item & value & lot numbers & clerks & supervisor \\
\hline \hline Cabinets & 13,415 & $\$ 2,551,378.00$ & & & \\
\hline Bulk & 1,641 & $\$ 2,024,329.00$ & & & \\
\hline GN2 & 29 & $\$ 33,144.00$ & & & \\
\hline
\end{tabular}

Horizontal Carousel storage locations (also called bin boxes or line items) required:

\begin{tabular}{|l|r|}
\hline Unique Part Numbers (PN, Inv Dept, Inv Grp) with stock or orders & 13,415 \\
\hline$\%$ that is bulk & 3446 \\
\hline Unique carousel Part Numbers & 9969 \\
\hline Number that requires vertical carousel controlled storage (nitrogen, etc.) & 2226 \\
\hline Unique horizontal carousel Part Numbers & 7743 \\
\hline Growh factor (remember, this is hopefully offset by obsolescence) & $20 \%$ \\
\hline Horizontal carousel Part Numbers with growth & 9292 \\
\hline Storage locations per Part Number (due to random stocking) & 1.4 \\
\hline Horizontal carousel storage locations needed & 13008 \\
\hline Utilization factor (for efficient location of empty bin boxes when stocking) & $90 \%$ \\
\hline Total horizontal carousel storage locations needed & $\mathbf{1 4 , 3 0 9}$ \\
\hline
\end{tabular}

Horizontal Carousel capacity information:

Dimensions/specifications (based on McKinney carousels):

\begin{tabular}{|l|l|}
\hline Total length & $60 \mathrm{ft}$. \\
\hline Total width & $5 \mathrm{ft} .4 \mathrm{in}$. \\
\hline Total height & $8 \mathrm{ft} .8 \mathrm{in}$. \\
\hline Total height (top of track) & $9 \mathrm{ft} .8 \mathrm{in}$. \\
\hline Total height (including motor, mechanical, etc.) & $12 \mathrm{ft} .8 \mathrm{in}$. \\
\hline
\end{tabular}

Average bin box configuration per rack/carrier:

\begin{tabular}{|c|c|c|c|c|c|c|c|c|c|}
\hline bin box height: & $2.75^{m}$ & $2.75^{\prime \prime}$ & $2.75^{\prime \prime}$ & $2.75^{\prime \prime}$ & $5^{\prime \prime}$ & $5^{\prime \prime}$ & $5^{\prime \prime}$ & $5^{\prime \prime}$ & Total \\
\hline${ }^{*}$ bin box width: & $3.25^{\prime \prime}$ & $6.5 "$ & $9.75^{\prime \prime}$ & $13^{\prime \prime}$ & $3.25^{n}$ & $6.5^{11}$ & $9.75^{\prime \prime}$ & $13^{\prime \prime}$ & per rack \\
\hline \# bin boxes/carrierl: & 52 & 8 & 4 & 2 & 6 & 3 & 2 & 1 & 78 \\
\hline
\end{tabular}

"Note - each shelf is 20" wide - therefore, as an example, 6 of the bin boxes that are $3.25^{\prime \prime}$ wide could fit on one shelf.

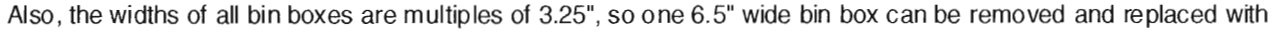

two 3.25 " wide bin boxes.

Horizontal Carousel storage locations available:

\begin{tabular}{|l|r|}
\hline \# Carriers & 58 (based on McKinney actuals) \\
\hline Shelves per carrier & 19 \\
\hline Avg locations (bin boxes) per shelf & 4.1 \\
\hline Total bin boxes per carousel & 4524 \\
\hline \# of divided compartments per bin box & 1 \\
\hline Total horizontal carousel storage locations available & 4524 \\
\hline
\end{tabular}

Total horizontal carousel storage locations needed

Total horizontal carousel storage locations available

Total carousels needed 
F Stores

\begin{tabular}{|l|c|c|c|}
\hline \multicolumn{1}{|c|}{ Part Sizes } & Percent & Cum \% & Count \\
\hline $5.0 \times 4.0 \times 0.75$ to $6.75 \times 5.75 \times 0.5$ & 25.9 & 25.9 & 42 \\
$9.0 \times 8.5 \times 0.5$ to $10.75 \times 7.0 \times 1.0$ & 22.2 & 48.1 & 36 \\
$7.0 \times 4.0 \times 0.75$ to $8.75 \times 6.25 \times 0.25$ & 19.8 & 67.9 & 32 \\
$3.25 \times 3.0 \times 3.0$ to $4.75 \times 4.5 \times 0.25$ & 16 & 84 & 26 \\
$15.0 \times 5.5 \times 2.0$ to $16.5 \times 4.5 \times 0.75$ & 6.2 & 90.1 & 10 \\
$11.0 \times 3.75 \times 0.25$ to $12.5 \times 9.5 \times 2.0$ & 5.6 & 95.7 & 9 \\
$25.0 \times 7.0 \times 1.25$ to $27.5 \times 4.75 \times 0.50$ & & 100 & 7 \\
$0.75 \times 6.75 \times 1.0$ to $2.0 \times 3.0 \times 3.0$ & 4.3 & & 2 \\
$13.0 \times 8.0 \times 0.75$ to $14.0 \times 13.0 \times 3.0$ & & & 3 \\
$22.0 \times 5.0 \times 2.5$ to $25.0 \times 4.0 \times 1.5$ & & & 2 \\
\hline
\end{tabular}

J Stores

\begin{tabular}{|l|c|c|c|}
\hline \multicolumn{1}{|c|}{ Part Sizes } & Percent & Cum \% & Count \\
\hline $5.0 \times 4.0 \times 0.75$ to $6.75 \times 5.75 \times 0.5$ & 31.3 & 31.3 & 55 \\
$9.0 \times 8.5 \times 0.5$ to $10.75 \times 7.0 \times 1.0$ & 23.9 & 55.1 & 42 \\
$7.0 \times 4.0 \times 0.75$ to $8.75 \times 6.25 \times 0.25$ & 16.5 & 71.6 & 29 \\
$3.25 \times 3.0 \times 3.0$ to $4.75 \times 4.5 \times 0.25$ & 9.7 & 81.3 & 17 \\
$15.0 \times 5.5 \times 2.0$ to $16.5 \times 4.5 \times 0.75$ & 6.8 & 88.1 & 12 \\
$11.0 \times 3.75 \times 0.25$ to $12.5 \times 9.5 \times 2.0$ & 5.1 & 93.2 & 9 \\
$25.0 \times 7.0 \times 1.25$ to $27.5 \times 4.75 \times 0.50$ & 3.4 & 96.6 & 6 \\
$0.75 \times 6.75 \times 1.0$ to $2.0 \times 3.0 \times 3.0$ & 3.4 & 100 & 6 \\
\hline
\end{tabular}

R24 Stores \& ATFLIR combined

\begin{tabular}{|l|c|c|c|}
\hline \multicolumn{1}{|c|}{ Part Sizes } & Percent & Cum \% & Count \\
\hline $11.0 \times 6.25 \times 0.25$ to $12.75 \times 10.75 \times 0.5$ & 25.5 & 25.5 & 78 \\
$9.0 \times 4.0 \times 0.75$ to $10.75 \times 10.75 \times 1.5$ & 23.5 & 49 & 72 \\
$7.0 \times 4.0 \times 1.5$ to $8.75 \times 8.0 \times 0.5$ & 18 & 67 & 55 \\
$13.0 \times 4.5 \times 2.25$ to $14.75 \times 10.75 \times 0.5$ & 12.4 & 79.4 & 38 \\
$5.0 \times 3.5 \times 0.25$ to $6.88 \times 5.63 \times 0.13$ & 5.9 & 85.3 & 18 \\
$15.0 \times 10.5 \times 2.5$ to $16.0 \times 8.5 \times 0.5$ & 3.6 & 88.9 & 11 \\
$3.5 \times 2.63 \times 2.0$ to $4.75 \times 4.75 \times 2.13$ & 3.6 & 92.5 & 11 \\
$25.0 \times 7.0 \times 1.25$ to $27.5 \times 4.75 \times 0.5$ & 2.6 & 95.1 & 8 \\
$17.0 \times 11.5 \times 1.25$ to $18.5 \times 15.25 \times 2.5$ & & 100 & 15 \\
$19.0 \times 16.0 \times 0.5$ to $20.0 \times 16.0 \times 5.0$ & 4.9 & & \\
$21.5 \times 4.25 \times 0.50$ to $22.0 \times 4.0 \times 1.0$ & & & \\
$23.0 \times 9.0 \times 3.5$ to $24.5 \times 4.5 \times 0.25$ & & & \\
\hline
\end{tabular}

F Stores Sorted

\begin{tabular}{|l|c|c|c|}
\hline \multicolumn{1}{|c|}{ Part Sizes } & Percent & Cum \% & Count \\
\hline $0.75 \times 6.75 \times 1.0$ to $2.0 \times 3.0 \times 3.0$ & 1.075 & & 2 \\
$3.25 \times 3.0 \times 3.0$ to $4.75 \times 4.5 \times 0.25$ & 16 & 84 & 26 \\
$5.0 \times 4.0 \times 0.75$ to $6.75 \times 5.75 \times 0.5$ & 25.9 & 25.9 & 42 \\
$7.0 \times 4.0 \times 0.75$ to $8.75 \times 6.25 \times 0.25$ & 19.8 & 67.9 & 32 \\
$9.0 \times 8.5 \times 0.5$ to $10.75 \times 7.0 \times 1.0$ & 22.2 & 48.1 & 36 \\
$11.0 \times 3.75 \times 0.25$ to $12.5 \times 9.5 \times 2.0$ & 5.6 & 95.7 & 9 \\
$13.0 \times 8.0 \times 0.75$ to $14.0 \times 13.0 \times 3.0$ & 1.075 & & 3 \\
$15.0 \times 5.5 \times 2.0$ to $16.5 \times 4.5 \times 0.75$ & 6.2 & 90.1 & 10 \\
$22.0 \times 5.0 \times 2.5$ to $25.0 \times 4.0 \times 1.5$ & 1.075 & & 2 \\
$25.0 \times 7.0 \times 1.25$ to $27.5 \times 4.75 \times 0.50$ & 1.075 & 100 & 7 \\
\hline
\end{tabular}

J Stores Sorted

\begin{tabular}{|l|c|c|c|}
\hline \multicolumn{1}{|c|}{ Part Sizes } & Percent & Cum \% & Count \\
\hline $0.75 \times 6.75 \times 1.0$ to $2.0 \times 3.0 \times 3.0$ & 3.4 & 100 & 6 \\
$3.25 \times 3.0 \times 3.0$ to $4.75 \times 4.5 \times 0.25$ & 9.7 & 81.3 & 17 \\
$5.0 \times 4.0 \times 0.75$ to $6.75 \times 5.75 \times 0.5$ & 31.3 & 31.3 & 55 \\
$7.0 \times 4.0 \times 0.75$ to $8.75 \times 6.25 \times 0.25$ & 16.5 & 71.6 & 29 \\
$9.0 \times 8.5 \times 0.5$ to $10.75 \times 7.0 \times 1.0$ & 23.9 & 55.1 & 42 \\
$11.0 \times 3.75 \times 0.25$ to $12.5 \times 9.5 \times 2.0$ & 5.1 & 93.2 & 9 \\
$15.0 \times 5.5 \times 2.0$ to $16.5 \times 4.5 \times 0.75$ & 6.8 & 88.1 & 12 \\
$25.0 \times 7.0 \times 1.25$ to $27.5 \times 4.75 \times 0.50$ & 3.4 & 96.6 & 6 \\
\hline
\end{tabular}

R24 Stores \& ATFLIR Sorted

\begin{tabular}{|l|r|c|c|}
\hline \multicolumn{1}{|c|}{ Part Sizes } & Percent & Cum \% & Count \\
\hline $3.5 \times 2.63 \times 2.0$ to $4.75 \times 4.75 \times 2.13$ & 3.6 & 92.5 & 11 \\
$5.0 \times 3.5 \times 0.25$ to $6.88 \times 5.63 \times 0.13$ & 5.9 & 85.3 & 18 \\
$7.0 \times 4.0 \times 1.5$ to $8.75 \times 8.0 \times 0.5$ & 18 & 67 & 55 \\
$9.0 \times 4.0 \times 0.75$ to $10.75 \times 10.75 \times 1.5$ & 23.5 & 49 & 72 \\
$11.0 \times 6.25 \times 0.25$ to $12.75 \times 10.75 \times 0.5$ & 25.5 & 25.5 & 78 \\
$13.0 \times 4.5 \times 2.25$ to $14.75 \times 10.75 \times 0.5$ & 12.4 & 79.4 & 38 \\
$15.0 \times 10.5 \times 2.5$ to $16.0 \times 8.5 \times 0.5$ & 3.6 & 88.9 & 11 \\
$17.0 \times 11.5 \times 1.25$ to $18.5 \times 15.25 \times 2.5$ & 1.225 & 100 & 15 \\
$19.0 \times 16.0 \times 0.5$ to $20.0 \times 16.0 \times 5.0$ & 1.225 & & \\
$21.5 \times 4.25 \times 0.50$ to $22.0 \times 4.0 \times 1.0$ & 1.225 & & \\
$23.0 \times 9.0 \times 3.5$ to $24.5 \times 4.5 \times 0.25$ & 1.225 & & \\
$25.0 \times 7.0 \times 1.25$ to $27.5 \times 4.75 \times 0.5$ & 2.6 & 95.1 & 8 \\
\hline
\end{tabular}




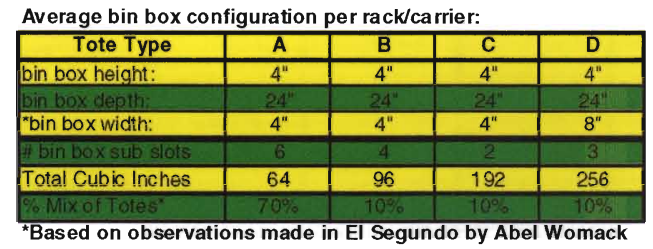

Ave rage bin box configuration per rack/carrier:
\begin{tabular}{|l|c|c|c|c|c|}
\hline \multicolumn{1}{|c|}{ Tote Type } & A & B & C & D & Extra \\
\hline bin box height: & $4^{\prime \prime}$ & $4^{\prime \prime}$ & $4^{\prime \prime}$ & $4^{\prime \prime}$ & bin size greater \\
\hline bin box depth: & $24^{\prime \prime}$ & $24^{\prime \prime}$ & $24^{\prime \prime}$ & $24^{\prime \prime}$ & than Tote Type D \\
\hline "bin box width: & $4^{\prime \prime}$ & $4^{\prime \prime}$ & $4^{\prime \prime}$ & $8^{\prime \prime}$ & \\
\hline \# bin box sub slots & 6 & 4 & 2 & 3 & \\
\hline Total Cubic Inches & 64 & 96 & 192 & 256 & \\
\hline$\%$ Mix of Totes & $54.35 \%$ & $13.51 \%$ & $16.61 \%$ & $6.21 \%$ & $9.32 \%$ \\
\hline$\%$ Mix of Totes ${ }^{* *}$ & $2.80 \%$ & $5.12 \%$ & $1.71 \%$ & $24.07 \%$ & $66.30 \%$ \\
\hline
\end{tabular}
"Based on cubic in. of random sample of parts

\begin{tabular}{l|c|c|c}
$\%$ Mix of Totes & $2.80 \%$ & $5.12 \%$ & 1.7 \\
\hline *Based on cubic in. of random sample of parts
\end{tabular}

**Based on actual dimensions of random sample of parts

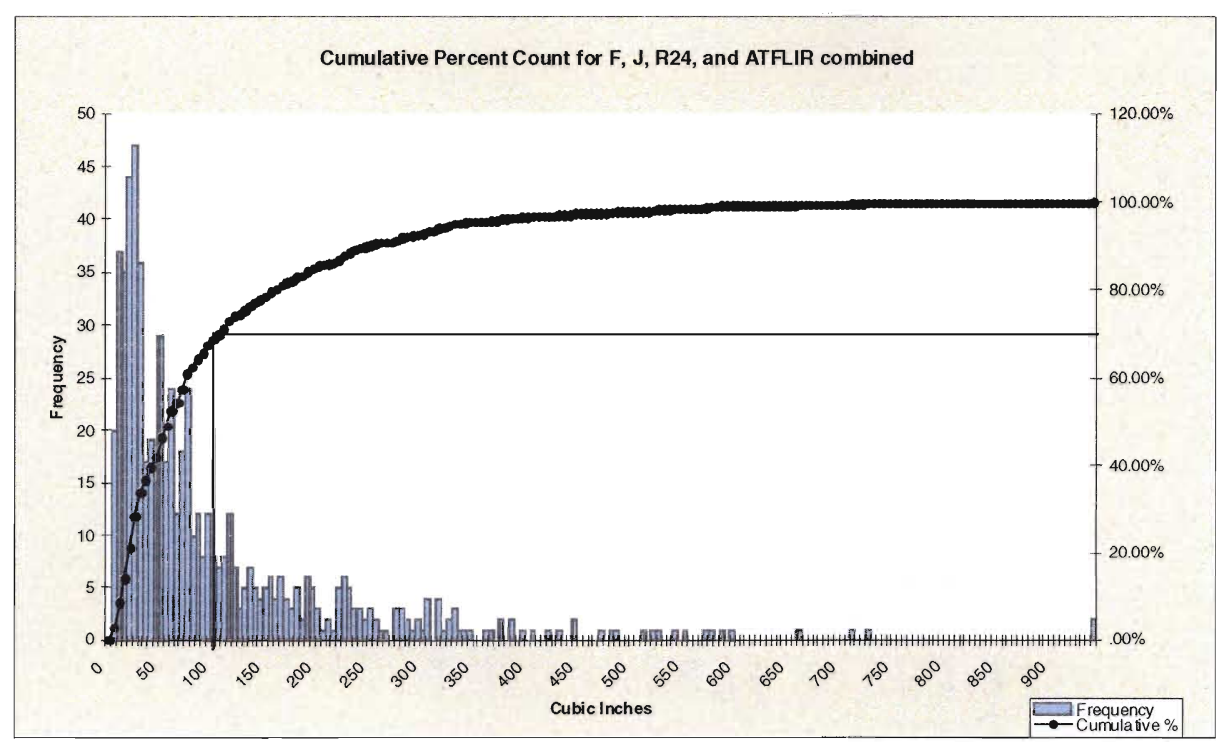

RESULTS:

\begin{tabular}{|l|c|}
\hline $70 \%$ of the data & 105 cubic inches or less \\
\hline Population size & 56,929 \\
\hline Sample size (@95\% confidence) & 644 \\
\hline Confidence Interval $(+/-)$ & $3.80 \%$ \\
\hline
\end{tabular}

ASSUMPTIONS:

${ }^{*}$ Results mentioned above are based on the combination of individual random sampling of each store 


\begin{tabular}{|c|c|c|c|c|}
\hline Length & Width & Depth & Cubic In. & Tote Size (based on dimensions) \\
\hline 5.50 & 4.00 & 0.07 & 1.54 & $\mathrm{~B}$ \\
\hline 0.50 & 8.00 & 0.50 & 2.00 & $\mathrm{C}$ \\
\hline 5.00 & 4.00 & 0.13 & 2.50 & $\mathrm{~B}$ \\
\hline 4.75 & 4.25 & 0.13 & 2.62 & $\bar{D}$ \\
\hline 4.75 & 4.75 & 0.13 & 2.93 & $\mathrm{D}$ \\
\hline 3.5 & 3.5 & 0.25 & 3.06 & A \\
\hline 3.5 & 3.5 & 0.25 & 3.06 & A \\
\hline 5.50 & $4 . \overline{75}$ & 0.13 & 3.27 & $\bar{D}$ \\
\hline 3.75 & 3.5 & 0.25 & 3.28 & $\mathrm{~A}$ \\
\hline 4 & 3.5 & 0.25 & 3.50 & $\bar{A}$ \\
\hline 4 & 3.5 & 0.25 & 3.50 & A \\
\hline 4 & 3.5 & 0.25 & 3.50 & $\mathrm{~A}$ \\
\hline 6.50 & 4.75 & 0.13 & 3.86 & D \\
\hline 6.00 & 5.00 & 0.13 & 3.90 & D \\
\hline 4 & 4 & 0.25 & 4.00 & $\mathrm{~A}$ \\
\hline 4.75 & 3.5 & 0.25 & 4.16 & $B$ \\
\hline 4.75 & 3.5 & 0.25 & 4.16 & $B$ \\
\hline 6.00 & 5.75 & 0.13 & 4.31 & $D$ \\
\hline 5.00 & 3.50 & 0.25 & 4.38 & $B$ \\
\hline 6.88 & 5.63 & 0.13 & 4.83 & D \\
\hline 0.75 & 6.75 & 1 & 5.06 & $\mathrm{C}$ \\
\hline 6 & 3.5 & 0.25 & 5.25 & $B$ \\
\hline 4.75 & 4.5 & 0.25 & 5.34 & $\bar{D}$ \\
\hline 4.75 & 4.5 & 0.25 & 5.34 & $\mathrm{D}$ \\
\hline 4.75 & 4.5 & 0.25 & 5.34 & D \\
\hline 4.75 & 4.5 & 0.25 & 5.34 & $\mathrm{D}$ \\
\hline 4.75 & 4.5 & 0.25 & 5.34 & $\mathrm{D}$ \\
\hline 4.75 & 4.5 & 0.25 & 5.34 & D \\
\hline 4.75 & 4.5 & 0.25 & 5.34 & D \\
\hline 7.50 & 5.75 & 0.13 & 5.39 & $\bar{D}$ \\
\hline 4.75 & 4.75 & 0.25 & 5.64 & D \\
\hline 4.75 & 4.75 & 0.25 & 5.64 & $\bar{D}$ \\
\hline 5 & 4.75 & 0.25 & 5.94 & $\mathrm{D}$ \\
\hline 6 & 4 & 0.25 & 6.00 & $B$ \\
\hline 6 & 4 & 0.25 & 6.00 & $B$ \\
\hline 6 & 4 & 0.25 & 6.00 & $B$ \\
\hline 6 & 4 & 0.25 & 6.00 & $B$ \\
\hline 6 & 4 & 0.25 & 6.00 & B \\
\hline 6 & 4 & 0.25 & 6.00 & $B$ \\
\hline 3.5 & 3.5 & 0.5 & 6.13 & A \\
\hline 9.00 & 5.75 & 0.13 & 6.73 & Extra \\
\hline 6 & 0.75 & 1.5 & 6.75 & B \\
\hline 5.75 & 4.75 & 0.25 & 6.83 & D \\
\hline 8.50 & 3.25 & 0.25 & 6.91 & C \\
\hline 5.75 & 5 & 0.25 & 7.19 & D \\
\hline 6.5 & 4.5 & 0.25 & 7.31 & D \\
\hline 4 & 3.75 & 0.5 & 7.50 & A \\
\hline 4 & 3.75 & 0.5 & 7.50 & A \\
\hline 6.5 & 4.75 & 0.25 & 7.72 & $\bar{D}$ \\
\hline 7.00 & 4.50 & 0.25 & 7.88 & $\bar{D}$ \\
\hline 5.75 & 5.5 & 0.25 & 7.91 & $\mathrm{D}$ \\
\hline 6 & 5.5 & 0.25 & 8.25 & $\mathrm{D}$ \\
\hline 5.5 & 3.25 & 0.5 & 8.94 & C \\
\hline 6.75 & 5.5 & 0.25 & 9.28 & D \\
\hline 5 & 3.75 & 0.5 & 9.38 & $B$ \\
\hline 6.5 & 6 & 0.25 & 9.75 & $D$ \\
\hline 6.5 & 6 & 0.25 & 9.75 & D \\
\hline 4.75 & 4.25 & 0.50 & 10.09 & D \\
\hline 4.5 & 4.5 & 0.5 & 10.13 & $\mathrm{D}$ \\
\hline 4.5 & 4.5 & 0.5 & 10.13 & D \\
\hline 11 & 3.75 & 0.25 & 10.31 & C \\
\hline 6.75 & 6.25 & 0.25 & 10.55 & $\mathrm{D}$ \\
\hline 10.00 & 8.50 & 0.13 & 10.63 & Extra \\
\hline 4.75 & 4.50 & 0.50 & 10.69 & $\mathrm{D}$ \\
\hline 4.75 & 4.5 & 0.5 & 10.69 & D \\
\hline 8.5 & 5.25 & 0.25 & 11.16 & Extra (?) \\
\hline 5.00 & 4.50 & 0.50 & 11.25 & D \\
\hline 6 & 3.75 & 0.5 & 11.25 & $B$ \\
\hline 6 & 3.75 & 0.5 & 11.25 & $B$ \\
\hline 7 & 6.5 & 0.25 & 11.38 & D \\
\hline 8.75 & 5.25 & 0.25 & 11.48 & Extra (?) \\
\hline 8 & 5.75 & 0.25 & 11.50 & $\mathrm{D}$ \\
\hline 4.75 & 3.25 & 0.75 & 11.58 & $B$ \\
\hline
\end{tabular}

\begin{tabular}{|c|}
\hline Key \\
\hline R24 \\
\hline F Stores \\
\hline J Stores \\
\hline ATFLIR \\
\hline
\end{tabular}

\begin{tabular}{|c|c|}
\hline Tote Size & Frequency \\
\hline A & 18 \\
\hline B & 33 \\
\hline C & 11 \\
\hline D & 155 \\
\hline Extra & 427 \\
\hline \multicolumn{2}{|c}{} \\
\hline
\end{tabular}


\begin{tabular}{|c|c|c|c|}
\hline Cubic In. & Frequency & Cum & Cumulative \% \\
\hline
\end{tabular}

\begin{tabular}{|c|c|c|c|}
\hline 0 & 0 & 0 & $.00 \%$ \\
\hline 5 & 20 & 20 & $3.11 \%$ \\
\hline 10 & 37 & 57 & $8.85 \%$ \\
\hline 15 & 35 & 92 & $14.29 \%$ \\
\hline 20 & 44 & 136 & $21.12 \%$ \\
\hline 25 & 47 & 183 & $28.42 \%$ \\
\hline 30 & 36 & 219 & $34.01 \%$ \\
\hline 35 & 17 & 236 & $36.65 \%$ \\
\hline 40 & 19 & 255 & $39.60 \%$ \\
\hline 45 & 15 & 270 & $41.93 \%$ \\
\hline 50 & 29 & 299 & $46.43 \%$ \\
\hline 55 & 17 & 316 & $49.07 \%$ \\
\hline 60 & 24 & 340 & $52.80 \%$ \\
\hline 65 & 12 & 352 & $54.66 \%$ \\
\hline 70 & 18 & 370 & $57.45 \%$ \\
\hline 75 & 24 & 394 & $61.18 \%$ \\
\hline 80 & 10 & 404 & $62.73 \%$ \\
\hline 85 & 12 & 416 & $64.60 \%$ \\
\hline 90 & 8 & 424 & $65.84 \%$ \\
\hline 95 & 12 & 436 & $67.70 \%$ \\
\hline 100 & 8 & 444 & $68.94 \%$ \\
\hline 105 & 7 & 451 & $70.03 \%$ \\
\hline 110 & 8 & 459 & $71.27 \%$ \\
\hline 115 & 12 & 471 & $73.14 \%$ \\
\hline 120 & 7 & 478 & $74.22 \%$ \\
\hline 125 & 3 & 481 & $74.69 \%$ \\
\hline 130 & 5 & 486 & $75.47 \%$ \\
\hline 135 & 7 & 493 & $76.55 \%$ \\
\hline 140 & 5 & 498 & $77.33 \%$ \\
\hline 145 & 4 & 502 & $77.95 \%$ \\
\hline 150 & 5 & 507 & $78.73 \%$ \\
\hline 155 & 6 & 513 & $79.66 \%$ \\
\hline 160 & 4 & 517 & $80.28 \%$ \\
\hline 165 & 6 & 523 & $81.21 \%$ \\
\hline 170 & 4 & 527 & $81.83 \%$ \\
\hline 175 & 3 & 530 & $82.30 \%$ \\
\hline 180 & 5 & 535 & $83.07 \%$ \\
\hline 185 & 2 & 537 & $83.39 \%$ \\
\hline 190 & 6 & 543 & $84.32 \%$ \\
\hline 195 & 5 & 548 & $85.09 \%$ \\
\hline 200 & 3 & 551 & $85.56 \%$ \\
\hline 205 & 1 & 552 & $85.71 \%$ \\
\hline 210 & 2 & 554 & $86.02 \%$ \\
\hline 215 & 1 & 555 & $86.18 \%$ \\
\hline 220 & 5 & 560 & $86.96 \%$ \\
\hline 225 & 6 & 566 & $87.89 \%$ \\
\hline 230 & 5 & 571 & $88.66 \%$ \\
\hline 235 & 3 & 574 & $89.13 \%$ \\
\hline 240 & 3 & 577 & $89.60 \%$ \\
\hline 245 & 2 & 579 & $89.91 \%$ \\
\hline 250 & 3 & 582 & $90.37 \%$ \\
\hline 255 & 2 & 584 & $90.68 \%$ \\
\hline 260 & 1 & 585 & $90.84 \%$ \\
\hline 265 & 1 & 586 & $90.99 \%$ \\
\hline 270 & 0 & 586 & $90.99 \%$ \\
\hline 275 & 3 & 589 & $91.46 \%$ \\
\hline 280 & 3 & 592 & $91.93 \%$ \\
\hline 285 & 2 & 594 & $92.24 \%$ \\
\hline 290 & 1 & 595 & $92.39 \%$ \\
\hline 295 & 2 & 597 & $92.70 \%$ \\
\hline 300 & 1 & 598 & $92.86 \%$ \\
\hline 305 & 4 & 602 & $93.48 \%$ \\
\hline 310 & 0 & 602 & $93.48 \%$ \\
\hline 315 & 4 & 606 & $94.10 \%$ \\
\hline 320 & 1 & 607 & $94.25 \%$ \\
\hline 325 & 2 & 609 & $94.57 \%$ \\
\hline 330 & 3 & 612 & $95.03 \%$ \\
\hline 335 & 1 & 613 & $95.19 \%$ \\
\hline 340 & 1 & 614 & $95.34 \%$ \\
\hline 345 & 1 & 615 & $95.50 \%$ \\
\hline 350 & 0 & 615 & $95.50 \%$ \\
\hline 355 & 0 & 615 & $95.50 \%$ \\
\hline 360 & 1 & 616 & $95.65 \%$ \\
\hline
\end{tabular}



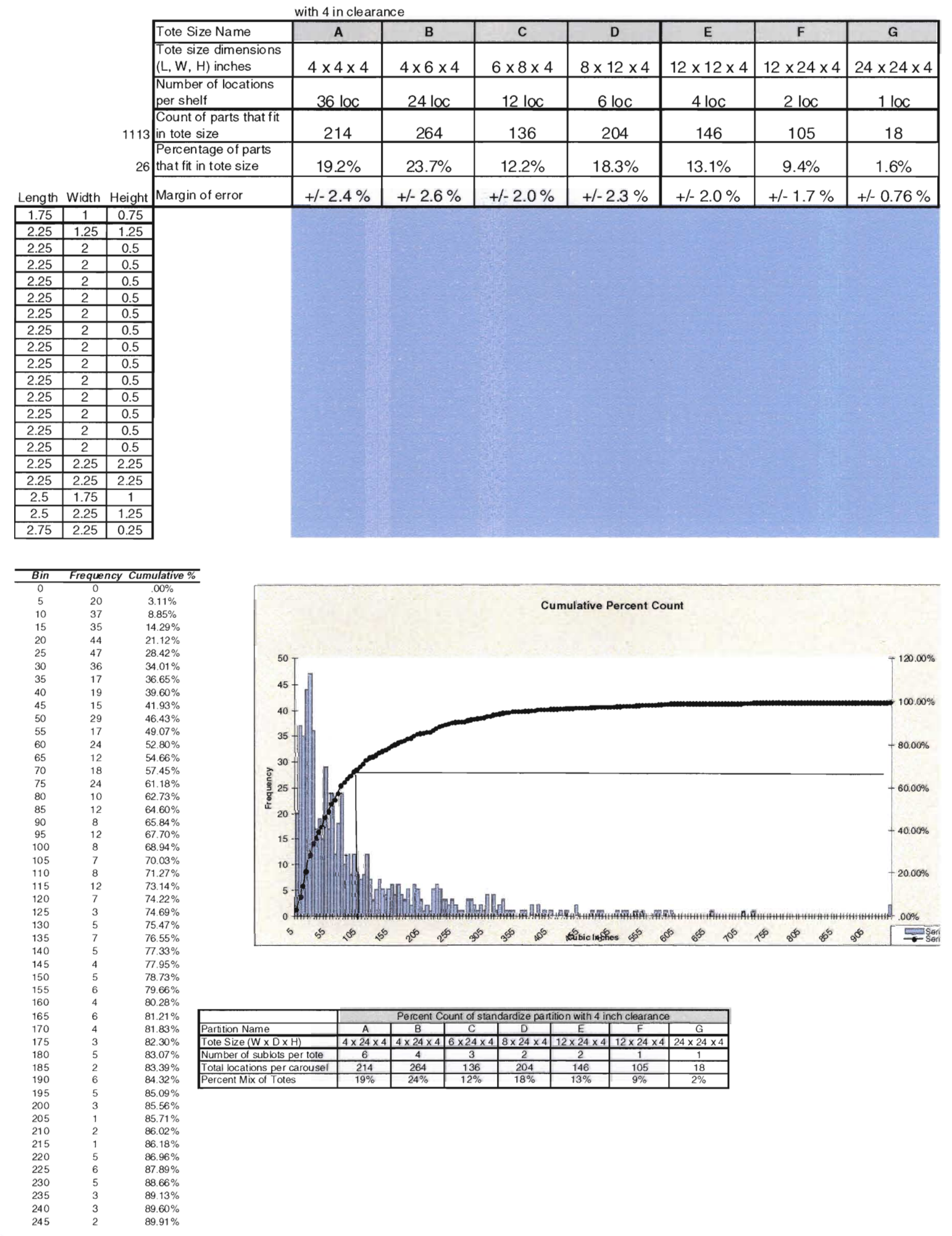
Cubing Optimization Report

Tuesday, December 05, 2006 06:51

Warehoust ES01

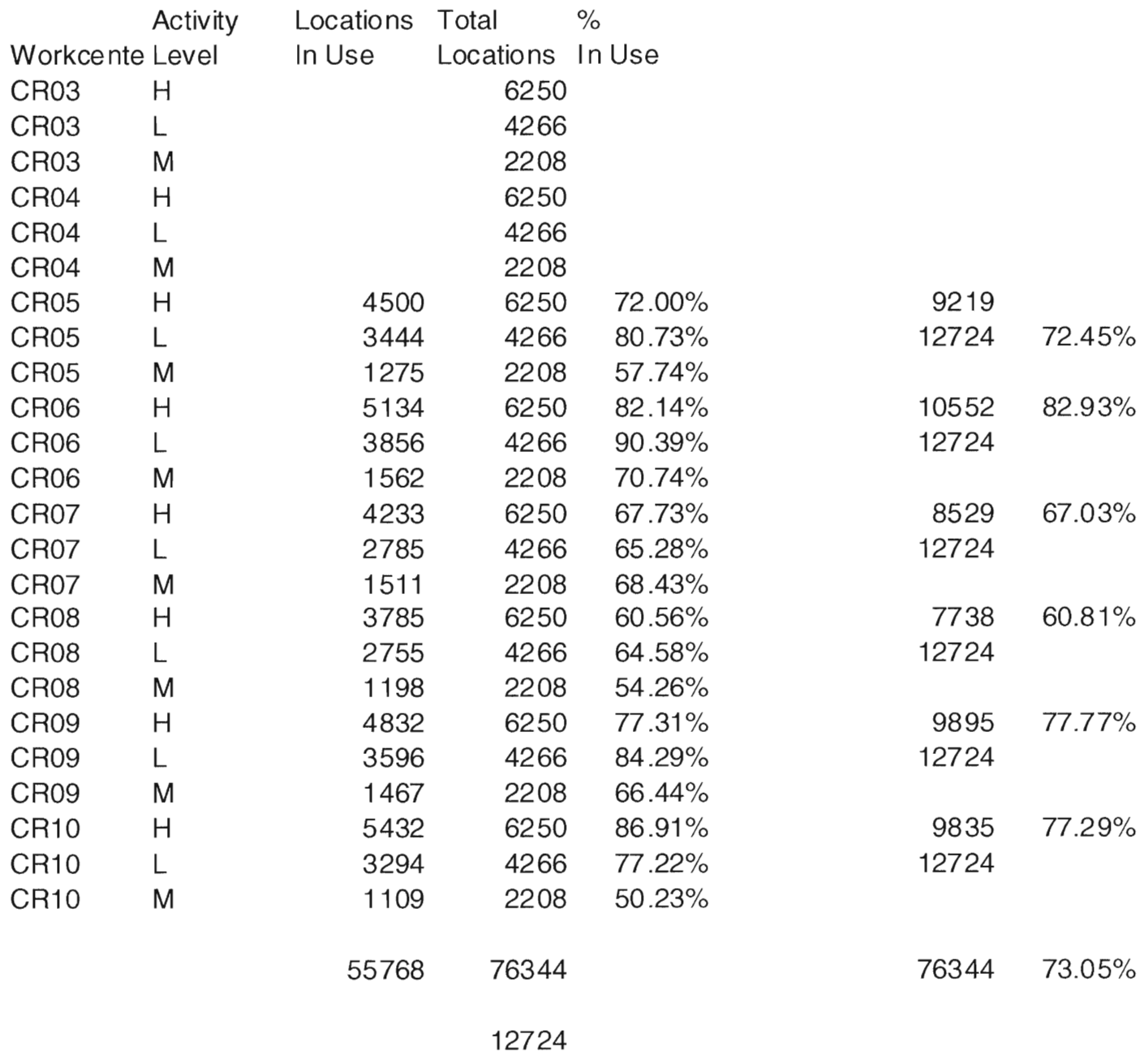


SCENARIO \#1 (WITH ICS INV GROUP $=35,500$ )

\begin{tabular}{lc|}
\hline 50 -Carrier Carousel & \\
\hline Total Carrier/Carousel & 50 \\
Camier Height & 97 \\
Camier Width & 24.5 \\
Camier Depth & 24 \\
Tote Height & 4 \\
Shelf Height w/Clearance & 6.0625 (actual is 5.51) \\
Total Shelf/Carrier & 16
\end{tabular}

\begin{tabular}{|c|c|c|c|c|c|c|}
\hline Tote Trpe & $\mathbf{A}$ & B & $\mathrm{C}$ & D & $\mathbf{E}$ & $\mathrm{F}$ \\
\hline Tote Size $(W \times D \times H)$ & $4 \times 24 \times 4$ & $4 \times 24 \times 4$ & $6 \times 24 \times 4$ & $8 \times 24 \times 4$ & $12 \times 24 \times 4$ & $12 \times 24 \times 4$ \\
\hline Subslots & 6 & 4 & 3 & 2 & 2 & 1 \\
\hline Count & 214 & 264 & 136 & 204 & 146 & 105 \\
\hline Percent Mix of Totes & $20.0 \%$ & $24.7 \%$ & $12.7 \%$ & $19.1 \%$ & $13.7 \%$ & $9.8 \%$ \\
\hline Locations/Shelf & 36 & 24 & 12 & 6 & 4 & 2 \\
\hline Locations/Carrier & 115 & 94 & 24 & 18 & 8 & 3 \\
\hline Total Storage Locations/Carrier & \multicolumn{6}{|c|}{262} \\
\hline Locations/Carousel & 5765 & 4741 & 1221 & 915 & 437 & 157 \\
\hline Total Storage Locations/Carousel & \multicolumn{6}{|c|}{13236} \\
\hline \# of Carriers & 10.0 & 12.3 & 6.4 & 9.5 & 6.8 & 4.9 \\
\hline \# of Locations & 5765.4 & 4741.6 & 1221.3 & 916.0 & 437.0 & 157.2 \\
\hline \# of Bins & 961 & 1186 & 408 & 458 & 219 & 158 \\
\hline
\end{tabular}

\# of Carriers Needed:

\begin{tabular}{|l|c|}
\hline$*$ Total carrier storage locations needed & 94,269 \\
\hline Total carrier storage locations available & 262 \\
\hline Total carriers needed & 359.8 \\
\hline
\end{tabular}

\# of Carousels Needed:

\begin{tabular}{|l|c|}
\hline *Total horizontal carousel storage locations needed & 94,269 \\
\hline Total horizontal carousel storage locations available & 13,236 \\
\hline Total carousels needed & 7.1 \\
\hline
\end{tabular}

** Total of ICS $(70,540)$ and ECS $(23,729)$ inventory

NOTE: Data is based on $96 \%$ of parts. The $4 \%$, which yields 2,020 parts, will need to be located elsewhere. 